
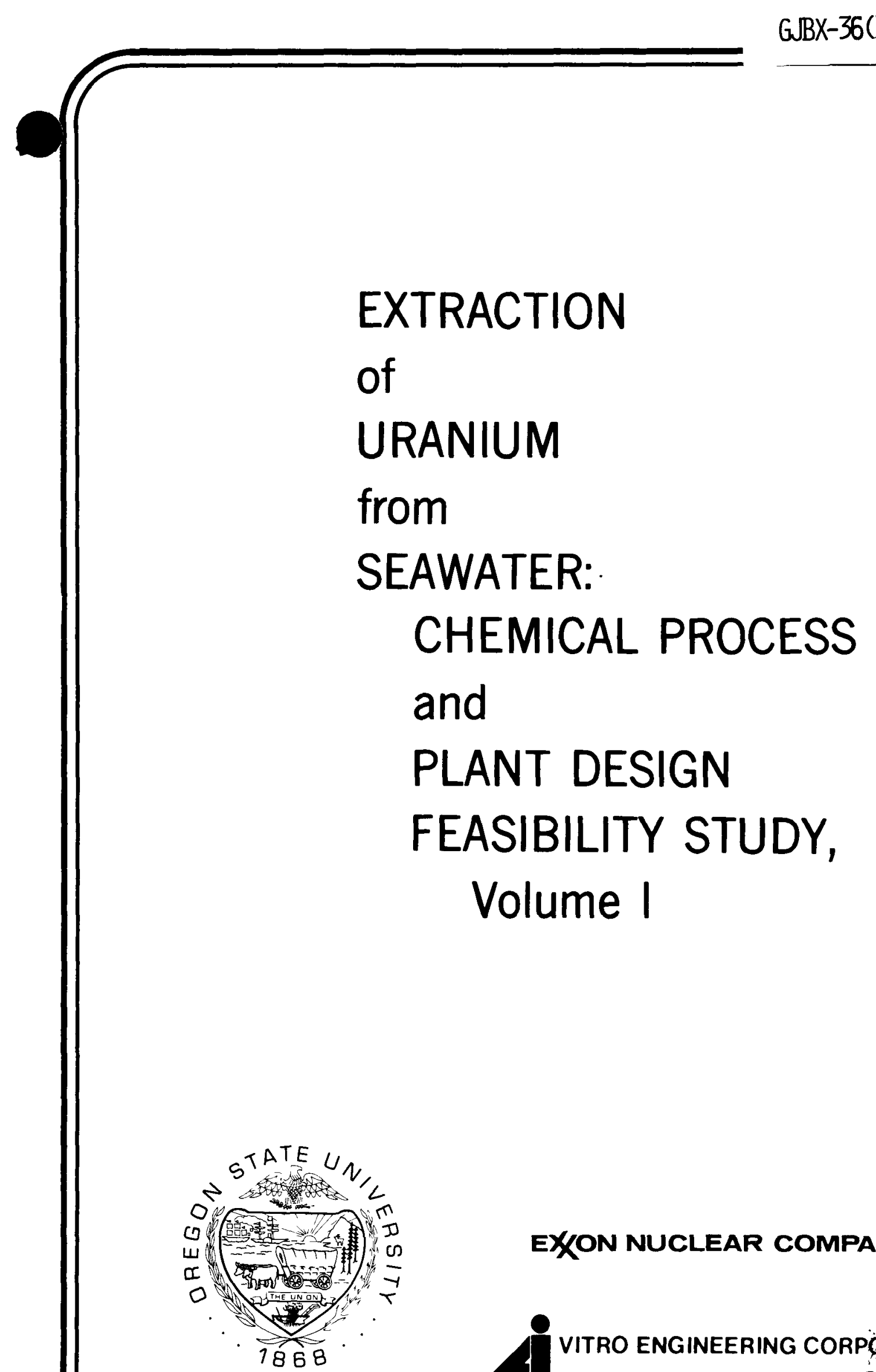

EXXN NUCLEAR COMPANY, InC. VITRO ENGINEERING CORPQQRATION

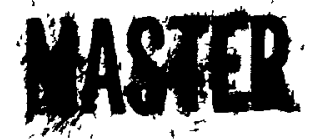




\section{DISCLAIMER}

This report was prepared as an account of work sponsored by an agency of the United States Government. Neither the United States Government nor any agency Thereof, nor any of their employees, makes any warranty, express or implied, or assumes any legal liability or responsibility for the accuracy, completeness, or usefulness of any information, apparatus, product, or process disclosed, or represents that its use would not infringe privately owned rights. Reference herein to any specific commercial product, process, or service by trade name, trademark, manufacturer, or otherwise does not necessarily constitute or imply its endorsement, recommendation, or favoring by the United States Government or any agency thereof. The views and opinions of authors expressed herein do not necessarily state or reflect those of the United States Government or any agency thereof. 


\section{DISCLAIMER}

Portions of this document may be illegible in electronic image products. Images are produced from the best available original document. 


\section{NOTICE}

This report was prepared as an account of work sponsored by the United States Government. Neither the United States nor the Department of Energy, nor any of their employees, nor any of their contractors, subcontractors, or their employees, makes any warranty, express or implied, or assumes any legal liability or responsibility for the accuracy, completeness or usefulness of any information, apparatus, product or process disclosed, or represents that its use would not infringe privately owned rights.

The views, opinions and conclusions contained in this report are those of the contractor and do not necessarily represent those of the United States Government or the United States Department of Energy.

Work on this program is performed for the UNITED STATES DEPARTMENT OF ENERGY

$$
\text { by }
$$

BENDIX FIELD ENGINEERING CORP.

and

EXXON NUCLEAR COMPANY, INC.

Under Contract 78-232-L

and by

OREGON STATE UNIVERSITY

Under Contract

and

VITRO ENGINEERING CORP.

Under Contract 


\title{
EXTRACTION OF URANIUM FROM SEAWATER: \\ CHEMICAL PROCESS AND PLANT DESIGN FEASIBILITY SIUDY
}

\author{
Prepared by \\ M. H. Campbell \\ J. M. Frame \\ N. D. Dudey \\ G. R. Kiel \\ V. Mesec \\ F. W. Woodfield \\ Exxon Nuclear Company \\ S. E. Binney \\ M. R. Jante \\ Oregon State University \\ R. C. Anderson \\ G. T. Clark \\ Vitro Engineering Corporation
}

This report was prepared as an account of work sponsored by the United States Government Netther the United States nor the Unuted States Department of Energy, nor any of therr employees, nor any of ther contractors, subcontractors, or their employees, makes any warranty, express or impled, or assumes any lega liablity or responsibulity for the accuracy completes or usefulness of any information apparatus, product process disclosed, or represents that its use provid or infrnge pnvately owned nghts
4

February, 1979

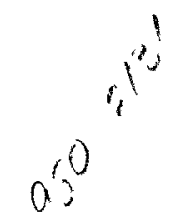

Oregon State University

Department of Nuclear Engineering Corvallis, Oregon 97331

Stephen E. Binney

Principal Investigator

Work performed under Bendix Field Engineering Corporation Subcontract No. 78-232-L and Bendix Contract No. EY-76-C-13-1664.

Prepared for the U.S. Department of Energy, Grand Junction, Colorado 81501. 


\author{
EXTRACTION OF URANIUM FROM SEAWATER: \\ CHEMICAL PROCESS AND PLANT DESIGN FEASIBILITY STUDY \\ VOLUME I
}

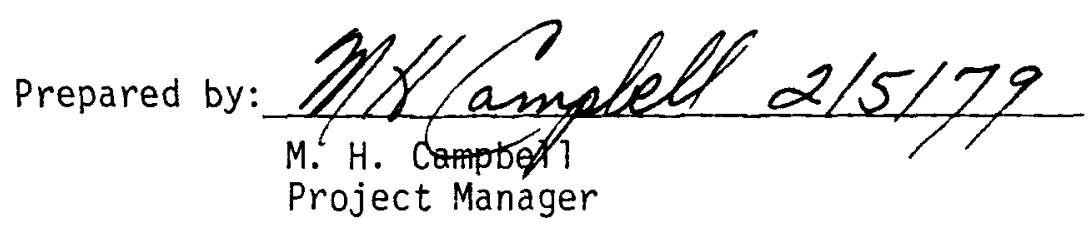

Approved by: R. Y licald $2 / 5 / 79$

R. C. Voge 1

Manager, Chemical Processes

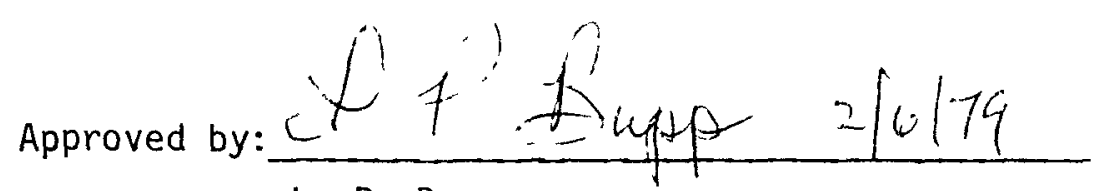

L. P. Bupp

Vice President and Executive-in-Charge

Technology and Overseas Nuclear Fuel Supply 
•

• 
CHAPTER 1

ABSTRACT

As part of an assessment of low-level uranium resources, the U. S. Department of Energy has funded a study of the feasibility of extracting uranium from seawater. This project was jointly conducted by Exxon Nuclear Company and Oregon State University, with Vitro Engineering Corporation serving as a subcontractor.

A major assessment was made of the uranium resources in seawater. All U. S. coastal waters were considered to determine a typical potential site for location of a uranium extraction plant. Several concepts for moving seawater to recover the uranium were investigated, including pumping the seawater and using natural ocean currents or tides directly. Severe limitations exist on current and tidal based plants due to siting and engineering considerations. Consequently only the pumped seawater scheme was investigated in detail. The optimal site chosen was on the southeastern Puerto Rico coast, with the south U. S. Atlantic coast as an alternate. The Puerto Rico site possessed the favorable conditions of warm, clean seawater with a strong current flowing past the site, as well as favorable terrestrial properties for iocating a site.

The various processes for extracting uranium from seawater were reviewed, with the adsorption process being the most promising at the present time. Of the possible adsorbents, hydrous titanium oxide was found to have the best properties, specifically a reasonably high loading capacity coupled with other properties such as low solubility in seawater and ammonium carbonate, the likely eluant for removing the uranium from the adsorbent.

A uranium extraction plant was conceptually designed. Of the possible methods for contacting the seawater with the adsorbent, a continuous fluidized bed concept was chosen as most practical for a pumped system. A plant recovering 500 tonnes of $\mathrm{U}_{3} \mathrm{O}_{8}$ per year requires 5900 cubic meters per second of seawater to be pumped through the adsorbent beds for a $70 \%$ overall recovery efficiency. Total cost of the plant was estimated to be about $\$ 6.2$ billion. 
A computer model for the process was used for parametric sensitivity studies and economic projections. Several design case variations were developed to more nearly optimize the design and reduce the production costs.

Other topics addressed were the impact of co-product recovery, environmental considerations, and necessary topics for further research and development. In addition, two bibliographies of over 800 different references related to the extraction of uranium from seawater were compiled. 
CHAPTER 2

TABLE OF CONTENIS

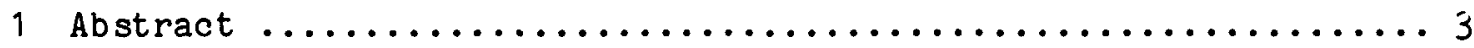

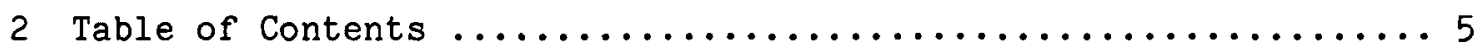

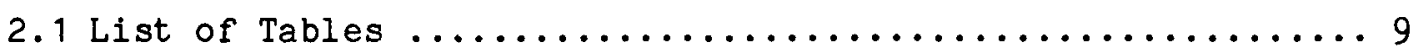

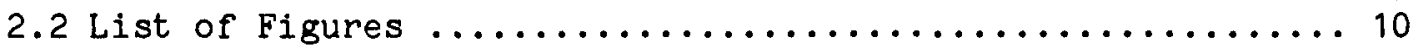

2.3 Acknowledgements $\ldots \ldots \ldots \ldots \ldots \ldots \ldots \ldots \ldots \ldots \ldots \ldots \ldots \ldots \ldots$

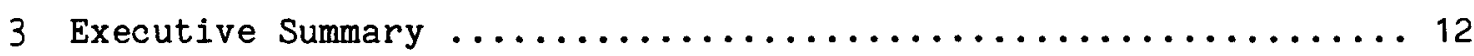

4 Introduction $\ldots \ldots \ldots \ldots \ldots \ldots \ldots \ldots \ldots \ldots \ldots \ldots \ldots \ldots \ldots \ldots$

5 Chemical Process and Site Selection $\ldots \ldots \ldots \ldots \ldots \ldots \ldots \ldots$

5.1 Overview of Bibliography on Uranium Resource

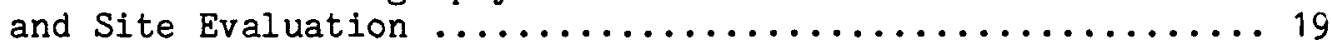

5.2 Overview of Bibliography on Chemical Process

and Plant Design Feasibility Study ................... 19

5.3 Synopsis of Uranium Resource and Site Evaluation Document .. 19

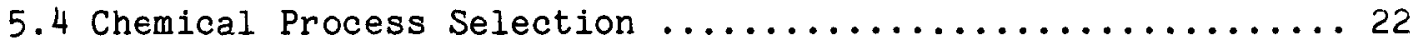

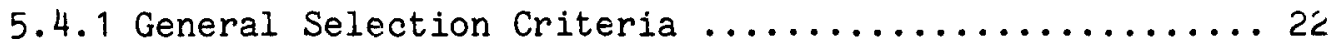

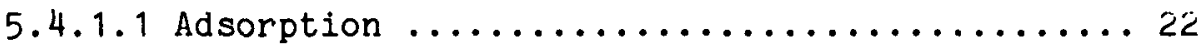

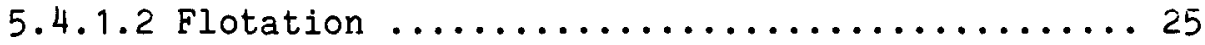

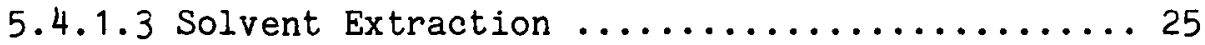

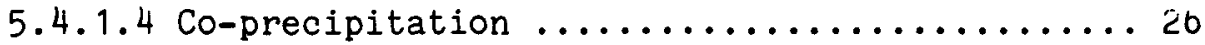

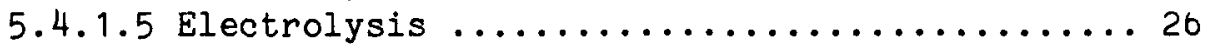

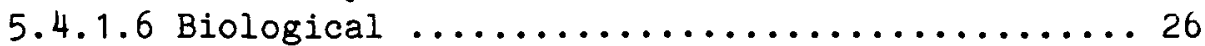

5.4.2 Specific Selection Criteria (Adsorption Process) ..... 26

5.5 Interrelationships Between Siting and Chemical Processing .. 28

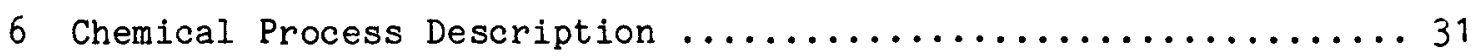

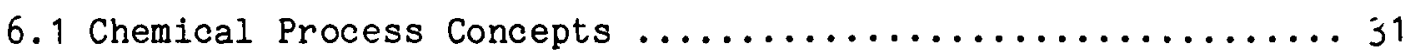

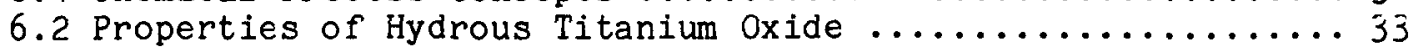

6.2.1 Preparation and Physical Properties ............ 33

6.2 .2 Capacity and Kinetics ......................... 35

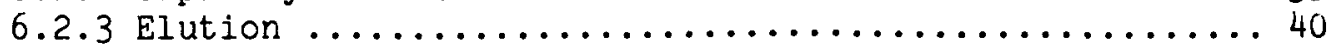


6.2 .4 Other Properties ........................ 41

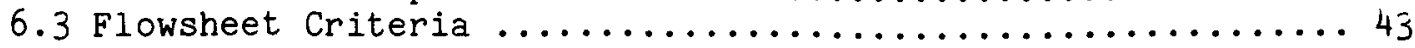

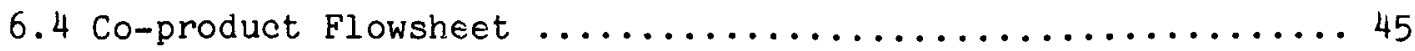

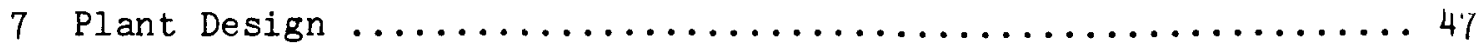

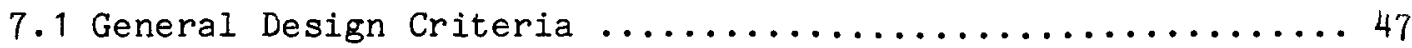

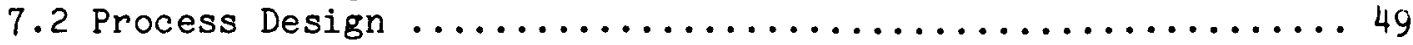

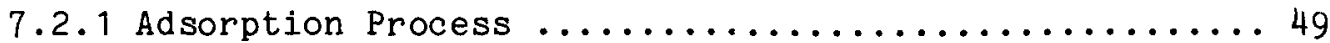

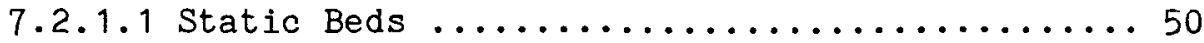

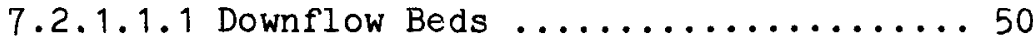

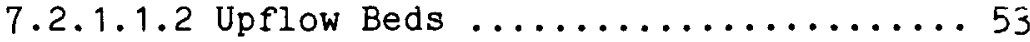

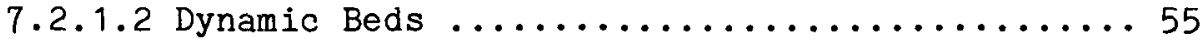

7.2.1.2.1 Continuous Slurry Bed Concept ..... 55

7.2.1.2.2 Continuous Fluidized Bed Concept ... 50

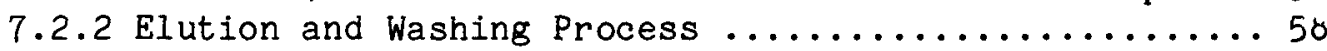

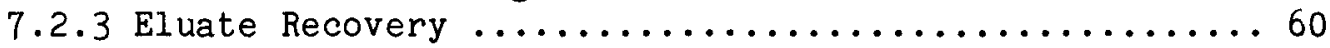

7.2.4 Clean-up and Concentration of Uranium Product ....... 02

7.2.5 Material and Energy Balance of the Chemical Process .. 05

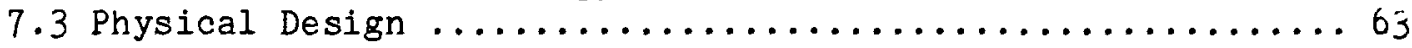

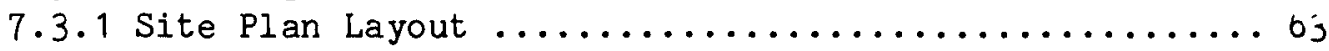

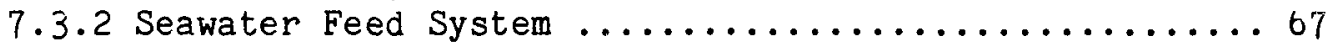

7.3.2.1 Seawater Pump Description ............667

7.3 .2 .2 Seawater Pump Installation ............667

7.3.2.3 Seawater Pretreatment ................69

7.3.2.4 Seawater Transport ..................69

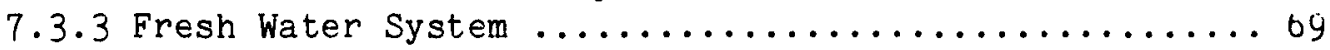

7.3.3.1 Source and Availability ............... by

7.3.3.2 Plant Fresh Water Requirements .......... 71

7.3.3.3 Fresh Water Pumping System ............. 71

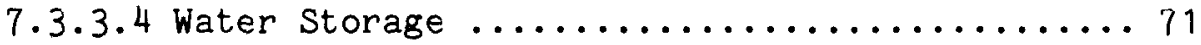

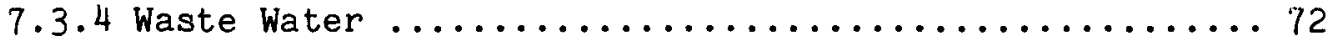

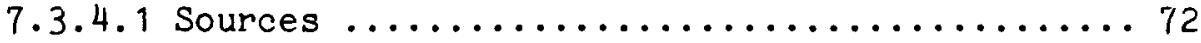

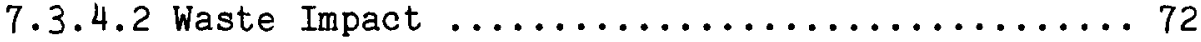

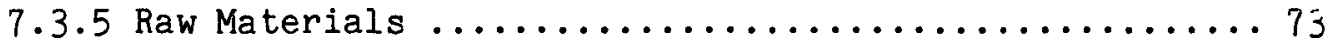

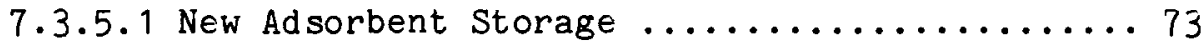

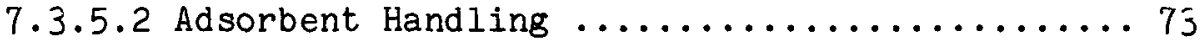

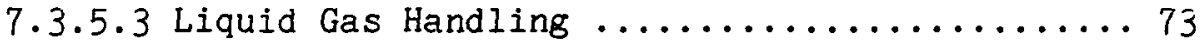

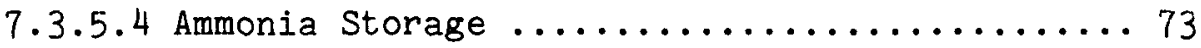

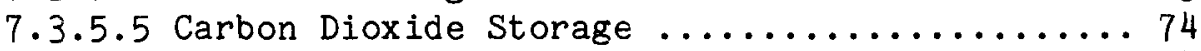

7.3.5.6 Eluant and Eluate Pumping and Storage ...... 74

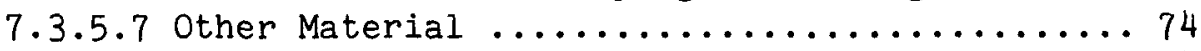

7.3 .6 Support Facilities ........................... 74

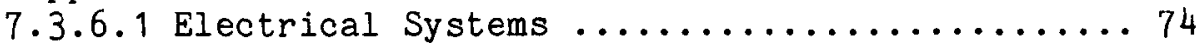

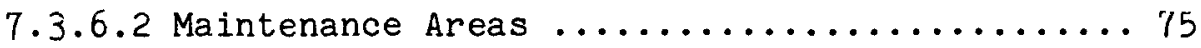

7.3 .6 .3 Port Facilities ........................ 75

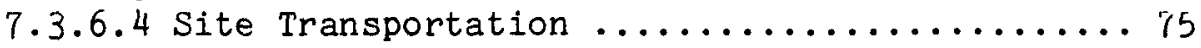

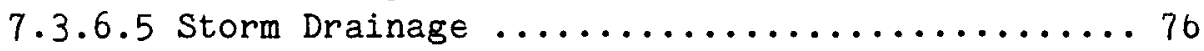

7.3 .6 .6 offices ........................

7.3.6.7 Geographical Area Requirement

and Site Development ................. 76

7.3 .6 .8 Mobile Equipment ...................... 77

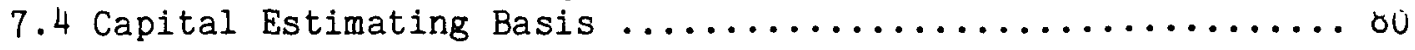


7.5 Operating Costs - Estimating Basis ...............

8 Capital Cost Estimate - Continuous Fluidized Bed System .......

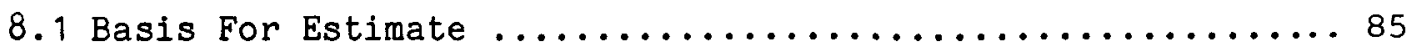

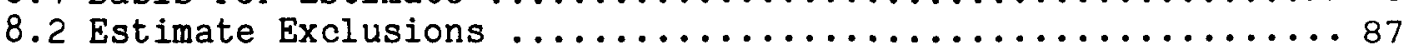

8.3 Cost Estimate Assuming $2100 \mathrm{mg} \mathrm{U} / \mathrm{kg} \mathrm{Ti}$ Adsorbent Loading Capacity ...................... ol

8.4 Cost Estimate for a Static Bed Design Assuming

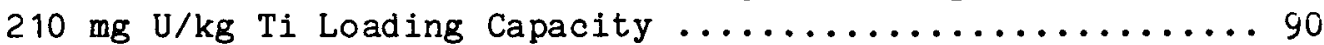

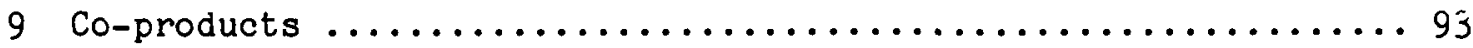

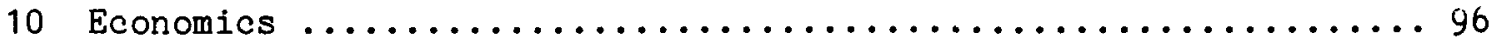

10.1 Introduction and Summary $\ldots \ldots \ldots \ldots \ldots \ldots \ldots \ldots$

10.2 Methodology for Projecting Unit Production

Costs and for Performing Sensitivity Studies ........... 97

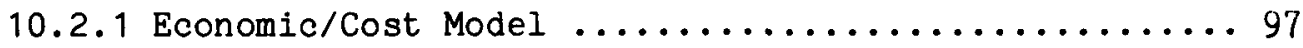

10.2.1.1 Capacity Adjustment ............... 101

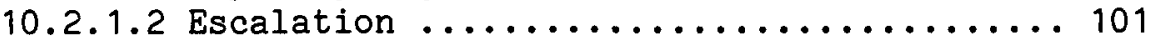

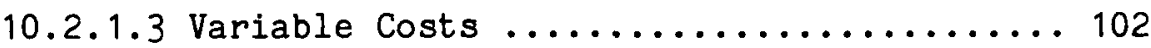

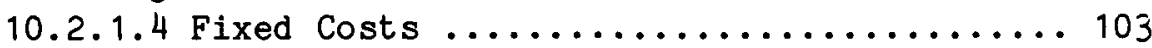

10.2.1.5 Uranium Production Cost ................. 103

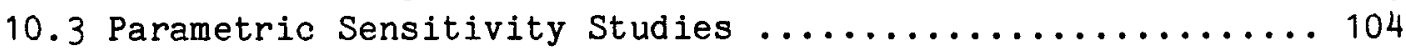

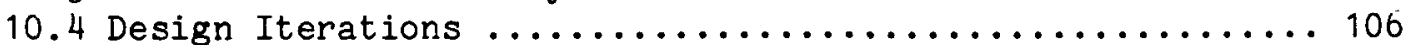

10.4.1 Design Based Upon Increased Flow Rate: Case 2 ... 106

10.4.2 Design Based Upon Increased Flow Rate and

Increased Loading Capacity: Case $3 \ldots \ldots \ldots . \ldots 109$

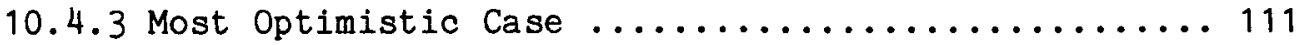

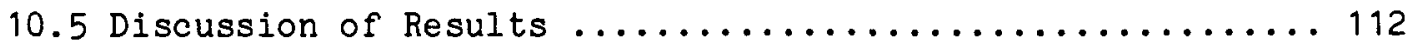

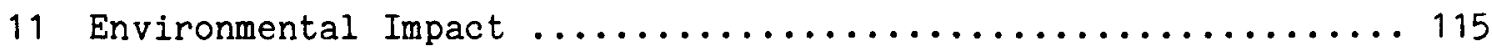

11.1 Effects of Site Preparation and Facility Operation ...... 115

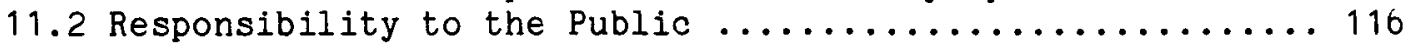

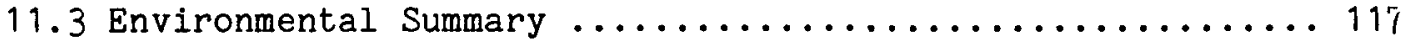

12 Research and Development Required $\ldots \ldots \ldots \ldots \ldots \ldots \ldots \ldots \ldots \ldots$

13 Feasibility of Uranium Recovery from Seawater ............ 123

13.1 Technical Feasibility .......................... 123

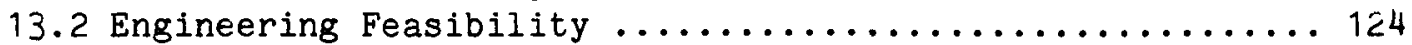

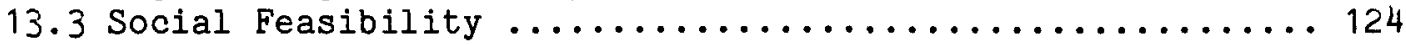

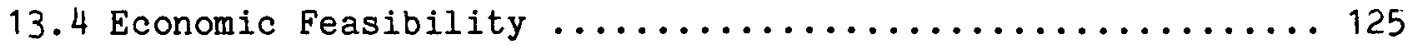

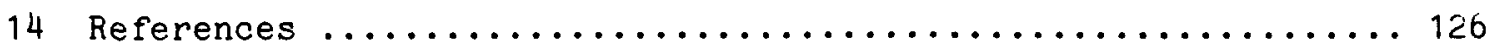

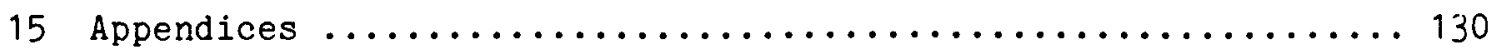

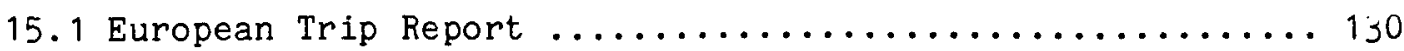

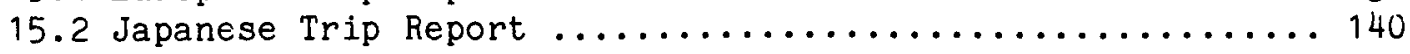


15.3 Chemical Process Selection Criteria ................. 160

15.4 Adsorbents Tested for Extraction of Uranium

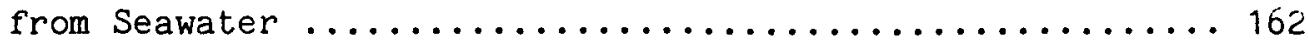

15.5 Glossary of Chemical Process Terminology ............. 16́y 


\subsection{LIST OF TABLES}

5.4-1 Chemical process selection criteria ............... 23

5.4-2 Selected list of high capacity adsorbents ........... 28

6.2-1 Summary of hydrous titanium oxide experiments ........ 37

6.2-2 Partition coefficients for elution

of hydrous titanium oxide ................... 41

6.2-3 Solubility of hydrous titanium oxide in eluants ...... 42

6.2-4 Concentration factors in hydrous titanium oxide

( 30 days contact with seawater) $\ldots \ldots \ldots \ldots \ldots \ldots \ldots \ldots$

6.4-1 Trace elements adsorbed on and eluted

from hydrous titanium oxide ................... 45

7.2-1 Flow line designations for Figures $7.2-1 \mathrm{~A}$,

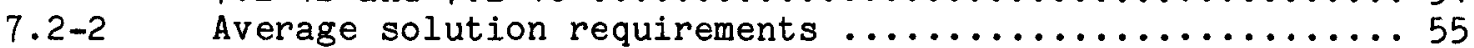

7.2-3 Average daily solution requirements for a

7.2-4 Uranium concentration in the stripper bottoms ........62

7.2-5 Continuous fluidized bed material balance ........... 64

$7 \cdot 3-1$

$7 \cdot 5-1$

$7 \cdot 5-2$

$7 \cdot 5-3$

$8.0-1$

$8.0-2$

$8 \cdot 3-1$

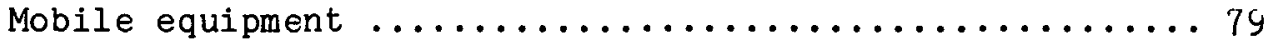

Chemical and energy unit cost summary ............. 80

Labor cost summary ...................... 1

Plant staffing requirements ................. 82

Cost estimate (Puerto Rico Site)

(Continuous fluidized bed with

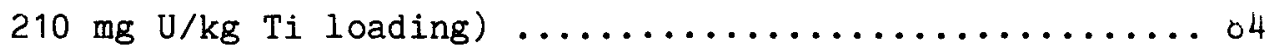

$8 \cdot 3-1$

Summary of estimated quantities ................ o5

$8 \cdot 3-2$

Cost estimate (Puerto Rico Site)

(Continuous fluidized bed with

$2100 \mathrm{mg} \mathrm{U} / \mathrm{kg} \mathrm{Ti}$ loading) .................. 8

$8.4-1$

Summary of estimated quantities (increased loading) .... ช9

Cost estimate (Puerto Rico Site)

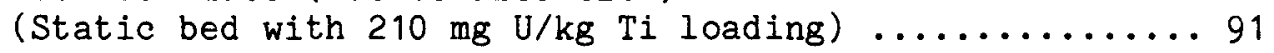

8.4-2 Summary of estimated quantities (static bed) .........92

9.0-1 Nuclear power facilities using seawater from

open coastal points or reasonably open bays ......... 95

$10.2-1$

$10.2-2$

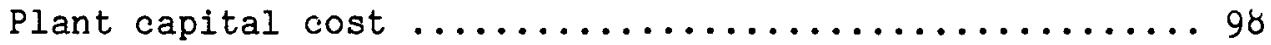

$10.2-3$

$10.2-4$

$10.3-1$

$10.4-1$

Reference design process parameters ................ 99

Reference design case - economic data summary ........ 100

Uranium production costs for reference design case .... 104

Uranium production cost sensitivity .............. 105

Cost estimates for increased particle size of

10.4-2 Production cost improvements due to increasing

adsorbent particle size and adsorbent

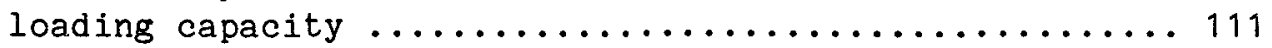

10.4-3 Most optimistic case (hypothetical) $\ldots \ldots \ldots \ldots \ldots \ldots \ldots 112$

10.5-1 Summary and comparison of uranium costs in

1978 and 1995 dollars ............................ 113

15.2-1 Extraction of uranium from seawater:

$15.4-1$

Recommended plant conditions ................ 141

Adsorbents tested for extraction of

uranium from seawater ..................... 162 


\subsection{LIST OF FIGURES}

6.2-1 Uptake of uranium from seawater by titanium hydroxide ... 36

$7.2-1 \mathrm{~A}$

$7 \cdot 2-1 \mathrm{~B}$

$7.2-1 \mathrm{C}$

$7 \cdot 2-2$

$7.2-3$

$7 \cdot 2-4$

$7 \cdot 2-5$

$7 \cdot 3-1$

$7 \cdot 3-2$

$7 \cdot 3-3$

$7 \cdot 3-4$

$7 \cdot 3-5$

10. $4-1$

15.2-1

$15 \cdot 2-2$

$15.2-3$

$15.2-4$

$15.2-5$

$15.2-6$

15.2-7

15.2-8

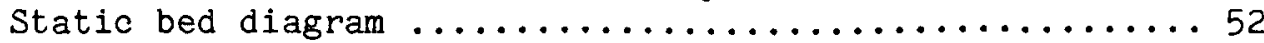

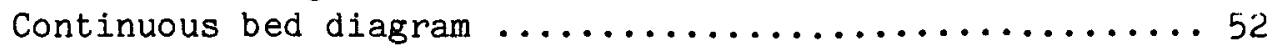

Continuous fluidized bed diagram ............... 52

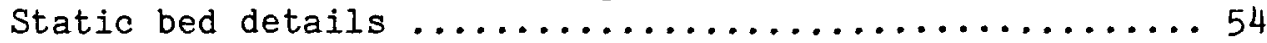

Continuous slurry bed details ................. 57

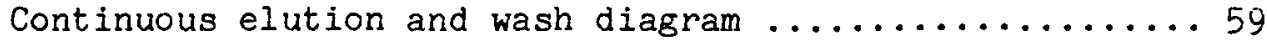

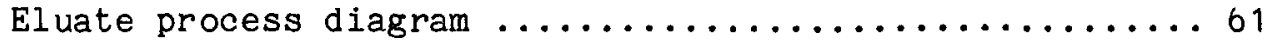

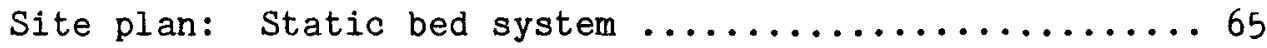

Site plan: Continuous bed system ...............66

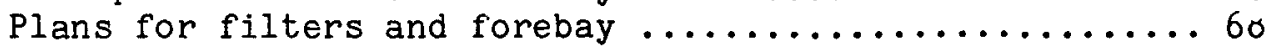

Influent and effluent canals ................. 70

Port facilities .............................. 74

Impact of increased particle size of adsorbent ....... 108

Uranium loading on metal hydroxides ............. 145

Uranium extraction schematic, Takamatsu, Japan ....... 146

Uranium extraction schematic at Sakaide City, Japan .... 140

Continuous and tidal flow contactors

at Sakaide City, Japan ..................... 149

Continuous contactor at Sakaide City, Japan .......... 150

Tidal flow unit (upper) and packed contactors (lower)

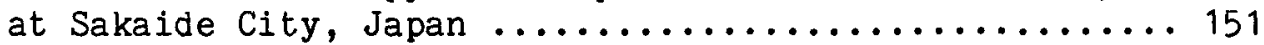

Temperature dependence of uranium adsorption on $\mathrm{C}-\mathrm{Ti}-\mathrm{OH}$ 15s

Artist's concept of an ocean current

uranium extraction plant ......................... 158

15.2-9 Artist's concept of a pumped seawater

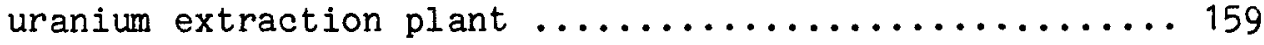




\subsection{ACKNOWLEDGEMENTS}

This work was performed for the U. S. Department of Energy (DOE) and Bendix Field Engineering Corporation (BFEC), with $\mathrm{Mir}$. Owen Kingman of $B F E C$ serving as Contract Manager and providing many helpful suggestions during the course of this work.

The Technical Review Committee for this project consisted of Dr. John V. Byrne (Chairman), Dr. Chih H. Wang, Dr. Richard C. Vogel, $\mathrm{Dr}$. O. H. Greager, and $\mathrm{Mr}$. Roy E. Tomlinson. Many valuable comments wère received from this Committee and incorporated into the findings of this study.

A great amount of appreciation is due to the oceanographers who served as co-principal investigators on this project, Dr. Louis I. Gordon, Dr. Arthur C-T. Chen, and Dr. Michael R. Rodman. Their unique insight was very important in maintaining the proper perspective throughout the project. Much of the essence of this document was based on several key conclusions drawn from the companion report of which they are the principal authors [26]. In addition, Dr. Wendell H. Slabaugh and Dr. Charles E. Wicks contributed significant comments during the early stages of the study.

of special value to the progress of this study were the personai contacts with many foreign scientists who have considerable knowledge about the process of extracting uranium from seawater. In particular, discussions with the following individuals were extremely helpful in defining and confirming the direction of this project: Dr. Norman J. Keen and Mr. E. W. Hooper of Great Britain; Dr. M. Shinagawa, Dr. Y. Shigetomi, Mr. Y. Kojima, Mr. Kazuhiko Hida, Dr. Masayoshi Kanno, Dr. Noboru Ogata, Mr. Ken Saito, Mr. Takashi Mayama, Mr. Hiroshi Iwasaki, Mr. Kyoichi Koyama, and Mr. Takahisa Yamamoto of Japan; Mr. Hans G. Bals, Dr. Erwin Oser, Dr. Klaus Schwochau, Dr. Ludwig Astheimer, Dr. Hans J. Schenk, and Dr. E. O. Witte of West Germany; and Mr. F. Pantanetti of Italy. The assistance of Mr. Y. Murozono and Dr. P. Kruys was also invaluable.

Several others spent a considerable amount of time on this project, including Mr. Steven Polkinghorne, who worked extensively on the bibliography associated with this document; Ms. Mary Knower, who provided a considerable amount of the clerical support; and Ms. Joan Oylear, who both entered text into the computer and served as a proofreader.

It was the overall cooperation between the organizations involved, namely Bendix Field Engineering Corporation, Exxon Nuclear Company, Oregon State University, and Vitro Engineering Corporation, which facilitated the entire study to be completed in less than six months. 
CHAPTER 3

EXECUTIVE SUMMARY

The overall objective for this study is to determine the resource base and the technical, economic, and environmental feasibility of large scale recovery of uranium, as a co-product and a single product, from seawater of $f$ the coasts of the United States.

A multidisciplinary work group were assembled under the project management of Exxon Nuclear Company, Inc. (ENC) to fulfill this broad objective. Oregon State University (OSU) provided technical expertise from its Department of Nuclear Engineering and School of Oceanography, as well as the Departments of Chemistry and Chemical Engineering. Vitro Engineering Corporation (VEC) developed engineering flowsheets and provided architectural engineering design. Exxon Nuclear Company utilized its demonstrated ability to transfer technology from development activities to operating systems in coordinating all activities; cost estimating, operating experience, environmental impact and economic modeling were specifically provided by Exxon Nuclear Company.

In an endeavor to assure the technical reliability of this report, a Technical Review Committee composed of experts from the above mentioned fields who were not involved in this study was asked to review and comment on the technical aspects of this study three times during the course of the project. Technical Review Committee comments were taken very seriously and were incorporated into the study.

In that much of the prior work on recovering uranium from seawater was reported by European and Japanese scientists and engineers, trips were taken to these locations to learn of the state of the art (Chapter 15). These visits were most helpful in providing a more substantial basis for the many decisions needed in arriving at acceptable data and facility designs.

The general approach to this work was to consider a number of interrelated parametric studies, details of which have been recorded in two documents each comprised of two volumes. The first document (Report XN-RT-14) was devoted to uranium resource evaluation and site selection. The scope was limited to the oceans adjacent to the continental united 
States and its possessions, trust territories, etc., and considered such parameters as uranium concentration, current flow, temperature, turbidity, among others, as they may effect availability, recoverability, and deliverability to an extraction plant. Delivery schemes utilizing (1) current flow, (2) tidal flow, and (3) pumped flow were considered in the site selection as they would apply to the chemical extraction process for the reference design effort.

As far as the United States is concerned, the only possibie location for a tidal flow plant is along the Alaskan coastline, bordering the Gulf of Alaska. High tides, generally greater than $5 \mathrm{~m}$ and sometimes as high as $10 \mathrm{~m}$ are found in Cook inlet. However, the year-round temperature range of the water is from 0 to $\gamma \mathrm{C}$ which offers poor adsorption kinetics while the biological productivity is high which creates an adsorbent fouling problem. Limited flushing within Cook Inlet and lack of fresh water were also found. For the above reasons, tidal flow was not considered for a delivery scheme.

Current flow delivery was discussed with Japanese and German investigators (Sections 15.1 and 15.2). Within current documentation, the configuration of adsorbent beds or films are still in the developmental stages and not yet sufficiently well defined for conceptual design and cost estimation; hence this delivery scheme was not considered further.

Pumped flow delivery permits siting at a location with optimum uranium recovery conditions. Briefly, these include: high salinity (which also indicates a higher uranium concentration); assurance of seawater feed undepleted in uranium by having an optimum ocean current regime; seawater temperature in the 26-30 C range to assure a high extraction efficiency; low water clarification requirements; near sea level elevation for the plant with a minimum offshore-onshore slope; and a large volume supply of fresh water.

A location in southeastern Puerto Rico, Puerto Yubucoa and the Guayanes River valley, was selected as the reference design plant site. This site is very suitable for a pumped flow delivery system because it has the following features:

- The location is less than two kilometers from the continental shelf where strong, warm $(28 \mathrm{C})$ Caribbean currents bring a constant resupply of relatively fresh seawater.

- Over six square kilometers of the river flood plain adjacent to the shoreline is less than three meters above mean sea level.

- An estimated 115,000 cubic meters of fresh water is available per day for process use, and storage reservoirs could double this supply.

- Population density is low. 
This document, which includes an extensive bibliography in volume II, is devoted to chemical process selection, conceptual design and cost estimates, economic analysis, environmental impact considerations, research and development requirements, and feasibility assessment.

The various known methods of extracting uranium from seawater were compared to a set of criteria; the adsorption process appeared to be the most reasonable chemical process. Of the many adsorbent materiais which have been investigated, hydrous titanium oxide was chosen as the most promising adsorbent at the present time (Section 5.4).

The chemical process selected (Section 5.4) for separating uranium from seawater requires four operational steps:

- Loading the hydrous titanium oxide adsorbent with uranium by direct contact with seawater

- Eluting the uranium from the hydrous titanium oxide with ammonium carbonate

- Steam stripping the eluate to remove and recover the ammonium carbonate

- Preparing a solid uranium product

The following flowsheet criteria (Section 6.j) were used for process design purposes:

- Uranium concentration in seawater is 3.35 parts per bilition

- Plant capacity is 500 tonnes $\mathrm{U}_{3} \mathrm{O}_{8}$ per year

- On-stream load factor is $90 \%$ for a continuous fluidized bed

- Adsorbent is hydrous titanium oxide

- Adsorbent bed adsorption efficiency is $80 \%$

- Adsorbent capacity is $210 \mathrm{mg} \mathrm{U} / \mathrm{kg} \mathrm{Ti}$

- Elution efficiency is $97 \%$

- Product concentration and recovery efficiency is $91 \%$

- Mean flow through the adsorbent bed is $0.4 \mathrm{~cm} / \mathrm{s}$

- Ammonium carbonate is used to elute uranyl ions from the hydrous titanium oxide 
- Pumped flow is used to pass seawater through the hydrous titanium oxide

In the process design, four possible configurations for the adsorption beds were considered (Section 7.2.1):

- Static downflow bed

- Static upfiow bed

- Continuous slurry bed

- Continuous fluidized bed

The continuous fluidized bed was selected for design and cost estimating because it had several advantages over the static beds (Section 7.2). These include: nearly continuous operation; washing and elution in a separate continuous operation; reduced sizes for pumps, piping and storage; elimination of three piping systems and reduction in water requirements.

One hundred sixty vertical turbine pumps are needed for meeting peak flow and spare equipment requirements for a 500 tonne per year plant. The seawater pumps are used to maintain a constant head differential between the forebay and adsorbent bed influent canal system. A $4 \mathrm{~m}$ head above sea level is required. Since the seawater of the Caribbean Sea is nearly void of nutrients, and the fluidized bed can pass up to 50 micron sand particles, the seawater can be pretreated by drawing it through a 278 mesh fabric screen (Section 7.3.2).

The fresh water pumping system was planned to meet a peak flow of 200,000 cubic meters per day with one pump out of service. The system was designed to pump from a stream-fed, wet well to a pressure balancing and storage reservoir. The system includes major water pipes, mechanical filtration equipment, chlorination equipment for potable fraction, and pressure regulation equipment (Section 7.3 .3 ).

The total geographical area requirements are: 8,000 hectares for the basic plant area; 200 hectares for pipelines and roadway rights-of-way; 200 hectares for port and storage facilities; 900 hectares for a fresh water reservoir; and 1,000 hectares of sea floor for the forebay and miscellaneous area (Section 7.3.6.7).

A labor force of 700 was projected for this facility with an annual labor cost of $\$ 12.5$ million (Section 7.5 ).

Extensive material takeoff sheets for the reference design were prepared by process and plant designers for pricing and extension to a complete construction estimate by personnel having many years of experience with major industries on large international projects (Section 7.4). 
The approximate capital cost for the reference design of the continuous fluidized bed uranium recovery facility, utilizing adsorbent beds with a loading capacity of $210 \mathrm{mg} \mathrm{U} / \mathrm{kg} \mathrm{Ti}$, is estimated to be $\$ 6.2$ billion in 1978 dollars (Chapter 8).

Using capital and operating cost breakdowns, sensitivity studies were made using a computer model to vary a number of process, construction, and financing parameters. These sensitivity studies indicated that increasing the flow rate of seawater through the adsorbent beds would reduce the overall cost of product uranium. Practically, this can be accomplished by increasing the particle size. At this point, adjusted takeoffs were made and a new lower capital cost estimate of $\$ 4.9$ billion ( 1978 dollars) was projected (Chapter 10).

It was concluded that if a plant were built by 1995 the cost of extracting uranium from seawater would range from $\$ 2100$ to $\$ 2000$ per pound of $\mathrm{U}_{3} \mathrm{O}_{8}$. The production cost is extremely capital intensive and as such, the projected costs are sensitive to the method of financing the project. A private venture, without government support, could not produce uranium for under $\$ 2700 / 1 b$ and the most probable commercial cost would be about $\$ 3600 / 1$ b (Chapter 10 ).

Uranium can be removed from seawater by a process that can be made to be compatible with the environment within which it is located (Chapter 11). The environment of the site would have to be evaluated prior to the start of detailed design so that the environmental inputs could be used in the final design. Although there would be a major environmental impact due to the removal of uranium from seawater, these impacts appeared to be amenable to mitigation by current technology.

During the course of this project, several key assumptions had to be made in the absence of concrete experimental evidence ( $\epsilon . g .$, loading capacity, kinetics, loss due to mechanical attrition and solubility, etc.). Thus, many factors need further investigation to provide information needed for a more detailed conceptual design. Chapter 12 discusses some of the key factors that need further study to either improve the present understanding about the process or to reduce the cost of uranium recovery.

Feasibility of uranium recovery has four readily definable sub-divisions: (1) technical feasibility; (2) engineering feasibility; (3) economic feasibility; and (4) social feasibility (Chapter 13). It was found in this study that it would be technically feasible to recover uranium from seawater, although there are a number of site-specific studies that should be conducted prior to site selection. It is not feasible from an engineering viewpoint to go beyond the preliminary conceptual design for a pumped flow system without conducting further studies. It would be socially feasible to recover uranium from the seawater as long as the plant site were in a low population area. Without several major technical breakthroughs leading to significantly lower production costs and/or federal subsidy, a pumped seawater plant to extract uranium from seawater is not economically feasible. 


\title{
CHAPTER 4
}

\author{
INTRODUCTION
}

The overall objective for this study is to determine the resource base and the technical, economic, and environmental feasibility of large scale recovery of uranium, as a co-product and a single product, from seawater of $f$ the coasts of the United States.

A multidisciplinary work group was assembled under the project management of Exxon Nuclear Company, Inc. (ENC) to fulfill this broad objective. Oregon State University (OSU) provided technical expertise from its Department of Nuclear Engineering and School of Oceanography, as well as the Departments of Chemistry and Chemical Engineering. Vitro Engineering Corporation (VEC) developed engineering flowsheets and provided architectural engineering design. Exxon Nuclear Company utilized its demonstrated ability to transfer technology from development activities to operating systems in coordinating all activities; cost estimating, operating experience, environmental impact considerations, and economic modeling were specifically provided by Exxon Nuclear Company. Oregon State University provided the evaluation of the chemicai process for uranium extraction, the uranium resource evaluation, and plant site study.

In an endeavor to assure the technical reliability of this report, a Technical Review Committee composed of experts from the above mentioned fields who were not involved in this study was asked to review and comment on the technical aspects of this study three times during the course of the project. Technical Review Committee comments were taken very seriously and were incorporated into the conclusions of the study.

In that much of the prior work on recovering uranium from seawater was reported by European and Japanese scientists and engineers, trips were taken to these locations to learn of the state of the art. These visits were most helpful in providing a more substantial basis for the many decisions needed in arriving at effective data and facility design as a basis for the conclusions and recommendations presented in the Executive Summary and in the body of the report. 
The general approach to this work was to consider a number of interrelated parametric studies, details of which have been recorded in two documents each comprised of two volumes. The first document (Report XN-RT-14) [26] was devoted to uranium resource evaluation and site selection. The scope was limited to the oceans adjacent to the continental United States and its possessions, trust territories, etc., and considered such parameters as uranium concentration, current flow, temperature, turbidity, among others, as they may effect availability, recoverability, and deliverability to an extraction plant. Delivery schemes utilizing (1) current flow, (2) tidal flow, and (3) pumped flow were considered in the site selection for the reference design effort. A location in southeastern Puerto Rico was selected as a basis for the reference design. This site was suitable only for a pumped flow delivery system.

This document (Report XN-RT-15) was devoted to chemical process selection, conceptual designs and estimates, economic analysis, and environmental impact considerations. Based on published information, a chemical process flowsheet was developed to establish the basic process steps required together with flow relationships and stream compositions. Hydrous titanium oxide was selected as the adsorbent and ammonium carbonate as the eluant. Plant design parameters were then considered, which resulted in a decision to carry forward conceptual designs and estimates for two plant configurations to a point where rough economic information was available which could be used, in conjunction with experienced judgment, as a basis for selection of a single concept upon which to complete the work. The concept finally selected employed a continuous fluidized bed for seawater/adsorbent contact with washing and elution being carried out in separate continuous equipment.

A mathematical model was developed which incorporated both fixed and variable quantities and costs which entered into the determination of the overall economics of the system. First order scaling factors were incorporated to adjust fixed costs in relation to variable quantity input, as appropriate. This economic model was programmed for computer analysis and used for various parametric studies and sensitivity analyses on several process and cost factors. 
CHAPTER 5

CHEMICAL PROCESS AND SITE SELECTION

\subsection{OVERVIEW OF BIBLIOGRAPHY ON URANIUM RESOURCE AND SITE EVALUATION}

This bibliography, Report XN-RT-14, Volume II [1], contains 471 references pertaining to the evaluation of $U$. S. territorial ocean waters as a potential uranium resource and to the selection of a site for a plant designed for large-scale extraction of uranium from seawater. It was prepared using machine literature retrieval, bibliographic, and word processing systems at Oregon State University. The literature cited was listed by author with indices to the author's countries, geographic areas of study, and to a set of keywords to the subject matter.

\subsection{OVERVIEW OF BIBLIOGRAPHY ON CHEMICAL PRGCESS AND PLANT DESIGN FEASIBILITY STUDY}

A selected annotated bibliography of $5<1$ references was prepared as a part of a feasibility study of the extraction of uranium from seawater (Report XN-RT-15, Volume II) [36]. For the most part, these references were related to the chemical processes whereby the uranium is removed from the seawater. The bibliography was prepared by computer retrieval from Chemical Abstracts, Nuclear Science Abstracts, Energy Data Base, NTIS, and Oceanic Abstracts. References were listed by author, country of author, and selected keywords.

\subsection{SYNOPSIS OF URANIUM RESOURCE AND SITE EVALUATION DOCUMENT}

As mentioned previously, the companion document to this study, Report XN-RT-14, Volume I, addressed the issues of uranium resources in 
seawater and siting considerations for a uranium extraction plant. Major findings of this report are included here, as extracted from the Executive Summary of XN-RT-14, Volume I.

Examination of the chemical and physical marine literature revealed nothing to weaken the conception currently held by marine chemists that approximately $98 \%$ of the uranium in seawater occurs in the dissolved state as negatively charged uranyl tricarbonate complex ions. Somewhat less than $2 \%$ occurs as negatively charged uranyl hydroxide complex ions. Other forms such as overall neutrally charged chemical forms may exist but probably in relative amounts much less than one percent. Uranium behaves as what the oceanographer calls a conservative constituent of the oceans, i.e., it remains dissolved in the oceans, on the average, for periods of time which are very long compared to the circulation and mixing times of the deep waters of the oceans. This results from the annual supply and removal rates of uranium to and from the sea being very small fractions of the total amount contained therein. As a resuit, uranium is distributed much like sea salt in the oceans and, to maximize the local resource, a location should be sought where the salinity is high. Although the concentration of uranium is quite low, 3.35 parts per billion (ppb) in seawater of average oceanic salinity, the amount present in the total volume of the oceans is very great, some 4.5 billion tonnes. of this, perhaps only that uranium contained in the upper $100 \mathrm{~m}$ or so of the surface well-mixed layer should be considered accessible for recovery, some 500 million tonnes. Practically speaking, the amount contained in the ocean surface layers is unlimited with respect to large-scale extraction in the foreseeable future. This results from the replenishment by continental weathering and river runoff being much larger than likely extraction rates. This study indicated that open ocean seawater acquired for the purpose of uranium extraction would be a more favorable resource than would rivers entering the sea, the cooling water of present or planned power plants, or the feed or effluent streams of existing plants producing other products such as magnesium, bromine, or potable and/or agricultural water from seawater. In the case of rivers and streams, production on the scale of a thousand tonnes of uranium per year would require total extraction of the uranium from a major fraction of even the largest U. S. river, the Mississippi. Furthermore, the sediment load carried by any large river would incapacitate any known process for the extraction. In the case of existing power or material production plants utilizing seawater as coolant or feed, the scales are simply too small. It was concluded relative to marine resources that only seawater pumped or otherwise accessed for the purpose of uranium extraction would constitute a viable resource.

To select suitable extraction plant sites, it was necessary to consult both colleagues in this project and the scattered literature on coastal oceanography, geography, geology, and geophysics of coastai regions. Colleagues were able to provide process and plant specific criteria for site selection. Literature information allowed for the evaluation of various regions and local areas against these and resource 
considerations. Process and plant specific criteria included relatively high temperature of the local seawater, topography, geological and geophysical suitability of the potential site, availability of sufficient fresh water and other process needs, accessibility to logistical and labor bases for plant construction and operation, etc. Resource specific considerations included ready access to a steady supply of relatively saline seawater with minimal biological or other fouling potential, and assurance that the uranium-stripped plant outflow stream would not mix back into the plant intake.

Process selection and plant design were intimately connected with certain aspects of resource evaluation concerning regional oceanographic conditions. Three basic plant configurations were considered: (1) an open ocean platform, either bottom supported, free floating with dynamic position control, or more or less loosely moored to the bottom; (2) a tidal-driven seawater feed stream; and (3) a coastal plant with a pumped seawater feed stream. It was found that the only U. S. site with a favorable tidal range to permit tidal energy as the seawater motive power was Cook Inlet, Alaska. Unfortunately the temperatures and salinities in that region are too low. Relatively high seawater temperatures are required because of the high temperature coefficients involved in the extraction processes considered. Low temperatures adversely affect the amount of uranium which can be extracted by an adsorbent. Low salinity of the seawater feed stream may be equated with dilution of the uranium contained in it. This is an effect of about 10\%. Finally, the regional circulation patterns of the waters in and around Cook Inlet are such that the uranium-stripped outflow of the plant would mix back into the feed stream, drastically reducing plant efficiency.

Offshore plants, either bottom mounted or floating, would offer several advantages in principle. These include accessibility to more steady surface currents than available closer inshore and typically Iower sediment loads and biological fouling, as well as potentially better separation of feed and outflow streams. However, it was found that a poor data base was accessible upon which to develop a technical, economic, and environmental feasibility study for such a design.

Such considerations led to the selection of a site for a pumped seawater plant at a coastal location. Puerto Yabuoca, Puerto Rico was selected. This coastal site has a narrow continental shelf which allows the Antilles Current to bring a relatively constant supply of warm, saline seawater relatively close to the potential plant site and to assist in carrying away the plant outflow. More than six square kilometers of nearly level terrain less than three meters above sea level are suitable for a plant site near the shoreline. An ample fresh water supply is available or could be economically developed. The present land use is of relatively low intensity, as is human habitation. 


\subsection{CHEMICAL PROCESS SELECTION}

As $\in$ videnced by the bibliography mentioned in Section 5.2 , considerable work has been done on the extraction of uranium from seawater. In particular, a wide variety of methods and chemical materials have been used. In order to systematically evaluate the different processes of uranium extraction, some criteria were necessary to compare these methods.

\subsubsection{General Selection Criteria}

The major chemical processes used for uranium extraction from seawater are shown in Table 5.4-1. Six general criteria were used in this table as an initial screening to eliminate the more unlikely processes from further consideration in this study. Although other criteria could have been used (see Section 15.3), these criteria tenaed to show major differences between the different chemical processes and clearly demonstrated the disadvantages of several of these processes. Specifically, the six criteria used were:

- Does the process have the capability of utilizing large volume flow rates of seawater?

- Is the specific uranium yield attractive?

- Can the process use untreated seawater?

- Is the process compatible with the local ecosystem?

- Can the raw materials be efficiently recycled?

- Are large scale engineering techniques for the process well understood?

A brief discussion of each of the major chemical processes is given below.

\subsubsection{Adsorption}

Many chemical compounds have been used to extract uranium from seawater. A list of materials used to adsorb uranium from seawater is contained in Section 15.4 as an appendix. The more promising of these are treated in some detail in section 5.4.2. The adsorption, absorption, and ion exchange (inorganic and organic) processes are all considered 
Table 5.4-1 Chemical process selection criteria

\begin{tabular}{|c|c|c|c|c|c|c|c|}
\hline \multirow[b]{2}{*}{ Criterion } & Technique & Adsorption & Flotation & $\begin{array}{l}\text { Solvent } \\
\text { Extraction }\end{array}$ & $\begin{array}{c}\text { Co-precipi- } \\
\text { tation }\end{array}$ & Electrolys is & \multirow{2}{*}{$\frac{\text { Biological }}{5.4 .1 .6}$} \\
\hline & Section & 5.4 .7 .1 & 5.4 .1 .2 & 5.4 .1 .3 & 5.4 .7 .4 & 5.4 .7 .5 & \\
\hline $\begin{array}{l}\text { Capability } \\
\text { to utilize } \\
\text { volume flon } \\
\text { seawater }\end{array}$ & $\begin{array}{l}f \text { process } \\
\text { arge } \\
\text { rates of }\end{array}$ & $\begin{array}{l}\text { Very poor } \\
\text { to adequate }\end{array}$ & Poor & Poor & Poor & & Adequate \\
\hline \multicolumn{2}{|c|}{$\begin{array}{l}\text { Specific uranium } \\
\text { yield }\end{array}$} & $\begin{array}{l}\text { Low to } \\
\text { moderate }\end{array}$ & & Moderate & $\begin{array}{l}\text { Low to } \\
\text { moderate }\end{array}$ & Very low & $\begin{array}{l}\text { Low, al though } \\
\text { data sparse }\end{array}$ \\
\hline \multicolumn{2}{|c|}{$\begin{array}{l}\text { Required seawater } \\
\text { treatment }\end{array}$} & None & $\begin{array}{l}\text { Consider- } \\
\text { able }\end{array}$ & $\begin{array}{l}\text { Consider- } \\
\text { able }\end{array}$ & & & None \\
\hline \multicolumn{2}{|c|}{$\begin{array}{l}\text { Compatibility with } \\
\text { local ecosystems }\end{array}$} & $\begin{array}{l}\text { slightly to } \\
\text { moderately } \\
\text { adverse }\end{array}$ & Adverse & Adverse & Adverse & Adverse & $\begin{array}{l}\text { Slightly to } \\
\text { moderately } \\
\text { adverse }\end{array}$ \\
\hline \multicolumn{2}{|c|}{$\begin{array}{l}\text { Recyclability of raw } \\
\text { materials }\end{array}$} & $\begin{array}{l}\text { Poor } \\
\text { to } \\
\text { good }\end{array}$ & $\begin{array}{l}\text { Large } \\
\text { losses }\end{array}$ & $\begin{array}{l}\text { Large } \\
\text { losses }\end{array}$ & $\begin{array}{l}\text { Large } \\
\text { losses }\end{array}$ & $N / A$ & $N / A$ \\
\hline \multicolumn{2}{|c|}{$\begin{array}{l}\text { Large scale engineer- } \\
\text { ing techniques for } \\
\text { process }\end{array}$} & Known & Uncertain & $\begin{array}{l}\text { Known, but } \\
\text { scale up } \\
\text { not } \\
\text { feasible }\end{array}$ & $\begin{array}{l}\text { Known, but } \\
\text { intricate }\end{array}$ & N/A & Unknawn \\
\hline
\end{tabular}


together for this initial evaluation. In fact it is often not clear whether adsorption or absorption is the correct term for a particular process.

The evaluation of the six criteria for the adsorption process varied considerably depending upon the particular adsorbent material being considered. In general the adsorption process is very responsive to using large volume flow rates of seawater during the contacting time. However, certain experiments involving the adsorption of uranium from seawater have bes done using flowthrough column, in which case the flow rates involved are quite slow. Nonetheless, for the more promising adsorbent materials, it appears that the process is compatible with the large volume flow rates of seawater required for large-scale uranium extraction from seawater.

Reported uranium loadings for adsorbents vary from a few micrograms of uranium per gram of material up to 1500 micrograms of uranium per gram of adsorbent material [2,3], although not all of the values reported in the literature involved experiments with unspiked natural seawater (see Section 5.4.2). A distinct advantage of most adsorption processes is the fact that the seawater does not need to be chemically treated. Although all extraction processes would have some environmental effect, the more promising adsorption processes tend to minimize this effect.

The opportunity for recycling the raw materials involved in the adsorption process is fairly good (see Chapter 7). Many adsorption processes are designed to include elution materials which can be easily reconstituted as well as adsorbent materials that can be used for a large number of loading and elution cycles. The adsorption process would most likely require large beds of adsorbent material or other structures which could expose large amounts of adsorbent materials to the seawater. Nonetheless, techniques are available for designing and building large-scale structures in a seawater environment.

There are a myriad of properties that ideally would be possessed by an adsorbent for efficient extraction of uranium from a seawater enviromment. Some of the more important of these criteria are:

- Operable at low concentrations of uranium that is in a highly complexed form

- Competitive with high concentrations of other ions

- Operable at ambient $\mathrm{pH}$, temperature, and salinity of seawater

- Insoluble in seawater, resistant to chemical and biological degradation, structurally stable

- Inexpensive and available in large quantities

- Physically in a form to facilitate contact with large volumes of seawater

- High rate of adsorption from seawater and easy elution from adsorbent 


\subsubsection{Flotation}

The flotation technique has been investigated primarily in the laboratory. Ferric hydroxide has been used in seawater adjusted to ph 6.7 to adsorb uranium [4]. A surfactant, sodium dodecyl sulfate, was added to form a colloid of ferric hyroxide. The colloid particulates floated to the surface and were removed when air was bubbled through the seawater. Another colloid flotation method used thorium hydroxide as the adsorbent, sodium dodecanoate as the surfactant, and air [5].

In order to utilize extremely large volumes of seawater, the disadvantage of containing the large amounts of acid that must be useo readily becomes apparent. Without some sort of containment, the acids become very dilute and success of the process becomes quite unlikely outside the laboratory environment. Reasonably high uranium recoveries have been performed in short time periods on the laboratory scale [4], but no evidence is available for the success of in situ uranium extraction by the flotation method. A major disadvantage to the flotation method is that the $\mathrm{pH}$ of the seawater must be adjusted to an acidic condition in order for the process to work efficiently. Obviously, for the large amounts of seawater involved, this criterion alone would rule out this process from further consideration. Furthermore, the large amounts of acid that must be added to the seawater as a neutralizing agent would tend to have an adverse environmental effect on marine organisms in the sea. Another deficiency of this method is the large losses of the chemicals used in the process and the impossibility for recycle of these materials.

\subsubsection{Solvent extraction}

The solvent extraction process has been widely used in the uranium fuel cycle for uranium extraction [6]; however, the technique is most useful in a confined volume as opposed to the open ocean. Although its specific uranium yield is attractive, as is the fact that there is a commercially developed process, nonetheless there are several

disadvantages for large scale extraction of uranium from seawater. Most solvents function only at $\mathrm{pH}$ lower than 7 , which would necessitate adjusting the $\mathrm{pH}$ of natural seawater [7]. Furthermore, very large volumes of acid would be required in this process which would pose both an economic and environmental disadvantage. Solubility and entrainment of the solvent in the seawater would likewise be undesirable economically and environmentally. 


\subsubsection{Co-precipitation}

The long precipitation times involved in this process are not compatible with the large volume flow rates necessary to expose the material to a sufficient amount of uranium. Concentration factors of only several hundreds have been reported in natural lake waters $[8 \mathrm{~J}$. For ferric and aluminum hydroxides, the $\mathrm{pH}$ of natural seawater gave optimal results which would tend to indicate that very little pre-treatment of the seawater might be necessary for this method. However, the large amounts of precipitate produced would have an adverse effect on marine sediment organisms, as would the large hydroxide concentration. Economically the large amounts of hydroxides required as raw materials would be difficult to recover. The intricate filtration and precipitation also detract from the utility of this process for industrial application.

\subsubsection{Electrolysis}

The major work investigating the possibility of using electrolysis for recovery of uranium from seawater was done by Westinghouse for the Electric Power Research Institute [9]. The concentration of uranium in seawater is about $10^{-8} \mathrm{M}$. Successful electrodeposition could on $1 \mathrm{y}$ be accomplished in acid or neutral solutions with the lowest initial concentration being $10^{-2} \mathrm{M}$. Thus this process is clearly orders of magnitude away from efficiently recovering uranium from natural seawater. Another major disadvantage of the electrolysis process is that the electrolysis itself would have an adverse effect on various marine organisms.

\subsubsection{Biological}

Several forms of biota have been observed to concentrate uranium from seawater [10]. The attractiveness of this technique lies in the fact that it is a naturally occurring technique and obviously takes place in the natural seawater environment. Although the seawater itself is not treated in this process, nonetheless there could be some environmental effect due to the recovery of the biological material. Uranium concentration factors have been noted up to about 10,000 to 100,000, although some of these experiments were performed in artificial seawater (see Section 15.1.3). Typically uranium concentration factors have been reported as less than 1000 in natural seawater.

\subsubsection{Specific Selection Criteria (Adsorption Process)}

On the basis of the above discussion, the flotation, solvent 
extraction, co-precipitation, electrolysis, and biological methods are not at all feasible for the large-scale recovery of uranium from seawater at the present time. Hence only the adsorption process was considered for further evaluation in this study.

Before the capacities of various adsorbent materials could be evaluated, it was necessary to establish some criteria to evaluate the conditions under which the data had been obtained. Three criteria were chosen as necessary conditions for further consideration of published or unpublished data:

Chemical species of the uranium in seawater

Experiments performed with uranyl nitrate or other chemical forms of uranium other than the uranyl tricarbonate ion were not considered, since the adsorption of uranium on the adsorbent depends upon the chemical form of the uranium compound.

Type of seawater

Only experiments conducted in natural seawater were considered. Most artificial seawater samples that are produced do not have the same major and trace element concentrations as found in natural seawater. This factor also has a significant effect on uranium uptake by the adsorbent. For example, Shigetomi [11] reported about $20 \%$ more adsorption of uranium in artificial seawater than in natural seawater.

Concentration of uranium in seawater

Experiments performed in spiked seawater (elevated concentration of uranium above $3.35 \mathrm{ppb}$ ) have resulted in atypically higher uranium loadings than in natural seawater. Shigetomi [11] reported recovery of about twice the percentage of uranium from a spiked seawater sample that was two orders of magnitude less concentrated than another spiked seawater sample. Hence, for a given volume, about 50 times as much uranium was recovered from the more highly spiked seawater sample.

Table 5.4-2 contains a list of the adsorbent materials for which the highest uranium loading capacities have been reported. Although other materials have been investigated with other properties more favorable than some of the adsorbents in Table 5.4-2, their lower uranium loading capacities make them less attractive as a best choice for the adsorbent. However, the materials listed in Table 5.4-2 are not without some severe deficiencies either, as noted in that table. In fact, the high solubility of all but the hydrous titanium oxide eliminates these materials from further consideration. 
Table 5.4-2 Selected list of high capacity adsorbents

\begin{tabular}{|c|c|c|c|c|}
\hline Adsorbent & $\begin{array}{l}\text { Range of } \\
\text { capacities, } \\
\mathrm{mg} \mathrm{U/kg} \text { ads }\end{array}$ & $\begin{array}{l}\text { Rate of } \\
\text { loading, } \\
\mathrm{mg} \mathrm{U/kg-day}\end{array}$ & Note & Reference \\
\hline $\begin{array}{l}\text { Resorcinol arsonic } \\
\text { acid }\end{array}$ & 1100 & $15-29$ & $\begin{array}{l}\text { High rate of } \\
\text { loss of arsenic in } \\
\text { natural seawater } \\
\text { lowers capacity }\end{array}$ & $\lfloor 7\rfloor$ \\
\hline $\begin{array}{l}\text { Various lead } \\
\text { compounds }\end{array}$ & $9-1893$ & $1.6-45$ & $\begin{array}{l}\text { Good capacity; } \\
\text { loss in loading } \\
\text { after first cycle; } \\
\text { high solubility in } \\
\text { natural seawater }\end{array}$ & $\lfloor 7 \mathrm{~J}$ \\
\hline $\begin{array}{l}\text { Hydrous titanium } \\
\text { oxide }\end{array}$ & $24-1500$ & $11-150$ & $\begin{array}{l}\text { Good capacity; } \\
\text { relatively } \\
\text { insoluble }\end{array}$ & $\begin{array}{c}\lfloor 7,12 \\
2,3\rfloor\end{array}$ \\
\hline $\begin{array}{l}\text { Basic zinc } \\
\text { carbonate }\end{array}$ & $442-625$ & $21-84$ & $\begin{array}{l}\text { Good capacity; } \\
\text { high solubility in } \\
\text { natural seawater }\end{array}$ & $17 j$ \\
\hline
\end{tabular}

The combination of relatively high uranium capacity and low solubility in seawater makes hydrous titanium oxide the best choice of adsorbent at the present time. This decision has been confirmed by conversations with the leading experts in the subject of the extraction of uranium from seawater (see Sections 15.1 and 15.2). Detailed information on hydrous titanium oxide is found in Section 6.2.

\subsection{INTERRELATIONSHIPS BETWEEN SITING AND CHEMICAL PROCESSING}

The first document (Report XN-RT-14) was devoted to uranium resource evaluation and site selection as they would apply to the chemical extraction process. The scope was limited to the oceans adjacent to the continental United States and its, trust territories, etc., and considered such parameters as uranium concentration, current flow, temperature, turbidity, among others, as they may effect availability, recoverability, and deliverability to an extraction plant. Delivery schemes utilizing (1) current flow, (2) tidal flow, and (j) pumped flow 
were considered in the site selection as they would apply to the chemical extraction process for the reference design effort.

As far as the United States is concerned, the only possible location for a tidal flow plant is along the Alaskan coastline, bordering the Gulf of Alaska. High tides, generally greater than $5 \mathrm{~m}$ and sometimes as high as $10 \mathrm{~m}$ are found in Cook iniet. However, the year-round temperature range of the water is from 0 to $8 \mathrm{C}$ which offers poor adsorption kinetics while the biological productivity is high which creates an adsorbent fouling problem. Limited flushing within Cook Inlet and lack of fresh water were also found. For the above reasons, tidai flow was not considered for a delivery scheme.

Current flow delivery was discussed with Japanese and German investigators (Sections 15.1 and 15.2). Within current documentation, the configuration of adsorbent beds or films are still in the developmental stages and not yet sufficiently well defined for conceptual design and cost estimation; hence this delivery scheme was not considered further.

Pumped flow delivery permits siting at a location with optimum uranium recovery conditions. Briefly, these include: high salinity (which also indicates a higher uranium concentration); assurance of seawater feed undepleted in uranium by having an optimum ocean current regime; seawater temperature in the 26-30 C range to assure a high extraction efficiency; low water clarification requirements; near sea level elevation for the plant with a minimum offshore-onshore slope; and a large volume supply of fresh water.

The location in southeastern Puerto Rico, Puerto Yubucoa and the Guayanes River valley, was selected as the reference design plant site. This site is very suitable for a pumped flow delivery system because it has the following features:

- The location is less than two kilometers from the continental shelf where strong, warm $(28 \mathrm{C})$ Caribbean currents bring a constant resupply of relatively clean fresh seawater

- Over six square kilometers of the river flood plain adjacent to the shoreline is less than three meters above mean sea level

- An estimated 115,000 cubic meters of fresh water is available per day for process use, and storage reservoirs could double this supply

- Population density is low

- The low tide difference of less than $0.2 \mathrm{~m}$ would result in a more constant pump suction head with less flow surging and less planned pump overcapacity 
- The water reaches a depth of 6 to $10 \mathrm{~m}$ at $0.5 \mathrm{~km}$ from shore. This depth is required for the large vertical turbine pumps

- A port docking facility can be located at the site 
CHAPTER 6

CHEMICAL PROCESS DESCRIPTION

This chapter deals with application of the chemical process selected (Chapter 5). The flowsheet criteria (Section 6.3) were designed using the bases described in Section 6.1, Chemical Process Concepts, and Section 6.2, Properties of Hydrous Titanium Oxide. The relationship of co-products to the flowsheet is discussed in Section 0.4 .

\subsection{CHEMICAL PROCESS CONCEPTS}

The chemical process and adsorbent selected (Sections 5.4.1 and 5.4.2) for separating uranium from seawater require four operational steps:

- Loading the hydrous titanium oxide adsorbent with uranium by direct contact with seawater

- Eluting the uranium from the hydrous titanium oxide with ammonium carbonate

- Steam stripping the eluant to remove and recover the ammonium carbonate

- Preparing a solid uranium product

Uranium is present in seawater as the anionic uranyl tricarbonate complex, $\left[\mathrm{UO}_{2}\left(\mathrm{CO}_{3}\right)_{3}\right]^{-4}$. The adsorption mechanism for extracting uranium from seawater onto hydrous titanium oxide is:

$\mathrm{Ti} x(\mathrm{OH})_{y}+\mathrm{UO}_{2}\left(\mathrm{CO}_{3}\right)_{3}^{-4} \rightarrow \mathrm{Ti}_{x}(\mathrm{OH})_{y-2} \mathrm{O}_{2} \cdot \mathrm{UO}_{2}+\mathrm{CO}_{3}^{-2}+2 \mathrm{HCO}_{3}^{-1}$ 
When the hydrous titanium oxide capacity of uranium has been reached, the flow of seawater feed solution is stopped. The loaded adsorbent is washed with fresh water to remove residual seawater containing calcium and magnesium ions that would otherwise precipitate during elution with the ammonium carbonate solution. Such precipitation fouls the adsorbent causing elution problems and producing an adsorbent with reduced capacity for reuse.

Elution is a reversal of the adsorption mechanism due to the excess carbonate and bicarbonate concentrations in the eluant. (The commercial grade ammonium carbonate has the formula $\mathrm{NH}_{3} \mathrm{NH}_{2} \mathrm{CO}_{2} \cdot \mathrm{NH}_{4} \mathrm{HCO}_{3}$ which decomposes in water to give variable amounts of ammonium carbonate and ammonium bicarbonate). Thus:

$$
\begin{aligned}
& \left(\mathrm{NH}_{4}\right)_{2} \mathrm{CO}_{3}+\mathrm{NH}_{4} \mathrm{HCO}_{3}+\mathrm{Ti}_{\mathrm{x}}{ }_{\mathrm{y}-2}^{(\mathrm{OH})_{2}} \mathrm{O}_{2} \cdot \mathrm{UO}_{2} \rightarrow \mathrm{Ti}{ }_{\mathrm{x}}(\mathrm{OH})_{\mathrm{y}} \\
& \text { excess excess } \\
& +\left(\mathrm{NH}_{4}\right)_{4} \mathrm{UO}_{2}\left(\mathrm{CO}_{3}\right)_{3}+\left(\mathrm{NH}_{4}\right)_{2} \mathrm{CO}_{3}+\mathrm{NH}_{4} \mathrm{HCO}_{3} \\
& \text { excess }
\end{aligned}
$$

Steam stripping the eluant to remove and recover the ammonium carbonate accomplishes two purposes. First, this convenient method for producing a solution with a minimum eluant salt content provides an optimum condition for secondary purification and recovery of uranium. More important still is the fact that as the $\mathrm{pH}$ approaches $7\lfloor L-1\rfloor$ the uranium precipitates. The second purpose accomplished by steam stripping is the recovery of the expensive eluting salt, ammonium carbonate, in a purified form suitable for reuse. The following equations express the above described chemical reactions:

$$
\begin{aligned}
& \left(\mathrm{NH}_{4}\right)_{2} \mathrm{CO}_{3}(\mathrm{aq})+\text { heat } \rightarrow 2 \mathrm{NH}_{3}(\mathrm{~g})+\mathrm{CO}_{2}(\mathrm{~g})+\mathrm{H}_{2} \mathrm{O}(1) \\
& \mathrm{NH}_{4} \mathrm{HCO}_{3}(\mathrm{aq})+\text { heat } \rightarrow \mathrm{NH}_{3}(\mathrm{~g})+\mathrm{CO}_{2}(\mathrm{~g})+\mathrm{H}_{2} \mathrm{O}(1) \\
& 2 \mathrm{NH}_{3}(\mathrm{~g})+\mathrm{CO}_{2}(\mathrm{~g})+\mathrm{H}_{2} \mathrm{O}(1) \rightarrow\left(\mathrm{NH}_{4}\right)_{2} \mathrm{CO}_{3} \\
& \left(\mathrm{NH}_{4}\right)_{4} \mathrm{UO}_{2}\left(\mathrm{CO}_{3}\right)_{3}(\mathrm{aq})+\text { heat } \rightarrow 4 \mathrm{NH}_{3}(\mathrm{~g})+3 \mathrm{CO}_{2}(\mathrm{~g})+\mathrm{UO}_{3} \cdot 2 \mathrm{H}_{2} \mathrm{O}(\mathrm{s})
\end{aligned}
$$

The solid uranium trioxide product is recovered by filtration; however, the filtrate still contains $0.006 \mathrm{~g} / 1$ of uranium that may be recovered by anion exchange according to the following reaction:

$$
4 \mathrm{RCl}+\left[\mathrm{UO}_{2}\left(\mathrm{CO}_{3}\right)_{3}\right]^{-4} \rightarrow \mathrm{R}_{4} \mathrm{UO}_{2}\left(\mathrm{CO}_{3}\right)_{3}+4 \mathrm{Cl}^{-}
$$


Elution of the uranyl ion from the anion exchanger ( $R$ ) is accomplished by reaction (2) above.

For the reader who has not had occasion to work with adsorbent separations, the following description of an adsorbent bed operation may be helpful.

As the feed solution passes through the adsorbent bed, the uranium will adsorb first near the feed inlet until all the adsorption sites are taken. Thus the concentration gradient for uranium in the feed solution will be in the form of an "S" curve, the highest uranium concentration being at the feed inlet and the lowest uranium concentration being at the column discharge. The gradient proceeds gradually through the entirety of the bed if loading to breakthrough is the objective. Likewise, the concentration gradient of the adsorbent bed is an "S" curve with the highest uranium inventory at the feed inlet and the lowest at the column discharge. This effect is graphically described by caddell and Moison [14].

During the course of this study, it became apparent that a definition of terms unique to this chemical process would be helpful in promoting understanding, due to the interdisciplinary nature of this subject. Hence a glossary of selected terms is included as an appendix (see Section 15.5).

\subsection{PROPERTIES OF HYDROUS TITANIUM OXIDE}

\subsubsection{Preparation and Physical Properties}

Work has been done to investigate the structure of hydrous titanium oxide by such techniques as $x$-ray and electron diffraction, infrared spectroscopy, density measurements and observation of the behavior of the material upon heating. Evidence points to the fact that the material is actually titanium oxide with water molecules filling the sites among the titanium oxide crystals [15]. The size of the spaces in the matrix probably controls the ability of large ions, such as uranyl tricarbonate ions, to diffuse into the gel granule. The water can be removed by heating, but too much heating causes the removal of enough water for the matrix to collapse. This produces a higher density adsorbent with a corresponding lower uranium uptake.

Hydrous titanium oxide functions as an anion exchanger in acidic and neutral solutions and as a cation exchanger in alkaline solutions $\mathrm{L} 16 \mathrm{~J}$. The granular oxides are physically very stable in water and in aqueous 
salt solutions. The "basic" hydrous titanium oxide dissolves in mildly acidic solutions (greater than $0.1 \mathrm{~N}$ ) unless dried at elevated temperatures, but is stable in alkaline solutions.

Various methods are known for the production of hydrous titanium oxide. The two principal methods involve starting with either titanic sulfate or titanic chloride. Hydrous titanium oxide can be prepared by the rapid addition of either ammonium hydroxide or sodium hydroxide (although higher uranium uptakes have been observed when the hydrous titanium oxide is treated with the former) to a well stirred solution containing titanyl sulfate or titanium sulfate in $1 \mathrm{~N}$ sulfuric acid (prepared by fusing titanium oxide with potassium hydrogen sulfate and extracting them out with a hot $1 \mathrm{~N}$ acid). The dense flocculent precipitate of hydrous titanium oxide is then washed several times with water by decantation, filtered under suction, and washed until free from salt and alkali. It is then dried at 50 to $100 \mathrm{C}$. Upon subsequent immersion in water, the granular material breaks down to a smaller particle size, after which it is stable to further treatment with water. A range of sizes is obtained including coarse material of about 20 mesh. This method has been used by both the British $[16,7]$ and the Japanese [2].

Another method has been used by the British [7], the Japanese [17], and the Russians [18] to produce hydrous titanium oxide. Titanium chloride is added to either sodium or ammonium hydroxide and vigorously stirred in a cooled vessel. A white precipitate forms which becomes increasingly viscous until the solution forms a coagulated gel. After standing for several hours the precipitate is filtered and then dispersed into distilled water. At this point the material is aged at room temperature for a period of time. After subsequent filtering the material is air dried at room temperature until it shrinks. The $g \in l$ is then again immersed in distilled water to break it down into smaller particle sizes followed by drying at room temperature. Larger particles can be ground to any desired size, if necessary, and sieved.

The Germans also prepare hydrous titanium oxide by precipitation in ammonium hydroxide with crushing taking place immediately after precipitation (see Section 15.1).

The hydrous titanium oxide produced varies in the amount of water it contains. Inoue [Inoue 76] reported obtaining $\mathrm{TiO}_{2} \cdot(22.0-2.2) \mathrm{H}_{2} \mathrm{O}$ independent of the conditions of synthesis. Ryabinin [74] reported a titanium oxide content of $51 \%$, while the British have reported a compound composed of $60 \%$ titanium oxide, $35 \%$ water, and $5 \%$ sodium by weight [15].

Typical hydrous titanium oxide densities in the wet bulk form are about $1.5 \mathrm{~g} / \mathrm{cc}$ although densities as low as 1.1 to $1.2 \mathrm{~g} / \mathrm{cc}$ have been achieved (see Section 15.1).

The preparation technique for hyorous titanium oxide can produce a product that will achieve reproducible uranium loading; however, it is 
important at several key steps to watch the process quite closely. Specific surface areas of about 400 to 500 square meters per gram have been reported for hydrous titanium oxide after drying out, i.e., in its collapsed form (see Section 15.1). Presumably even higher specific surface areas would exist for the hydrous titanium oxide in its wetted form.

\subsubsection{Capacity and Kinetics}

In reviewing the literature it was found that several chemical terms were used to describe the various titanium compounds that are used as adsorbents in extracting uranium from seawater. These include hydrous titanium oxide, $\mathrm{TiO}_{2} \cdot 2 \mathrm{H}_{2} \mathrm{O}$; titanium hydroxide, $\mathrm{Ti}(\mathrm{OH})_{4} ;$ and titanic acid, $\mathrm{H}_{4} \mathrm{TiO}_{4}$. In this report the term hydrous titanium oxide is used to describe all of these forms. Table 6.2-1 contains a compilation of some of the more significant experiments performed with hydrous titanium oxide. A problem arose in evaluating the data due to incomplete loading data as a function of contact time, variations in the experimental method of contacting the seawater, and other variations which were not always reported, such as the temperature of the seawater. Furthermore, some investigators reported loadings in micrograms of uranium per gram of titanium metal, while other investigators reported their data on a microgram of uranium per gram of adsorbent basis. Since the amount of water in the adsorbent varies from sample to sample, there is no simple way to convert the published data to a consistent set of units. As seen in Figure 6.2-1 from Davies [19], the adsorbent reaches a saturated value in approximately 3 weeks for particles in a flowthrough column and in as short a time as two days to about a week for particles embedded on a muslin net or glass wool.

There exists a large amount of data on hydrous titanium oxide which has not yet been published; consequently some of the earlier experiments may have lower capacities than some of the later experiments which were performed, although not indicated as such in Table 6.2-1 or in the published literature (see Section 15.1). Some of the data listed were based purely on laboratory results and are not necessarily indicative of the loading values that would be obtained in an actual in situ seawater environment. 


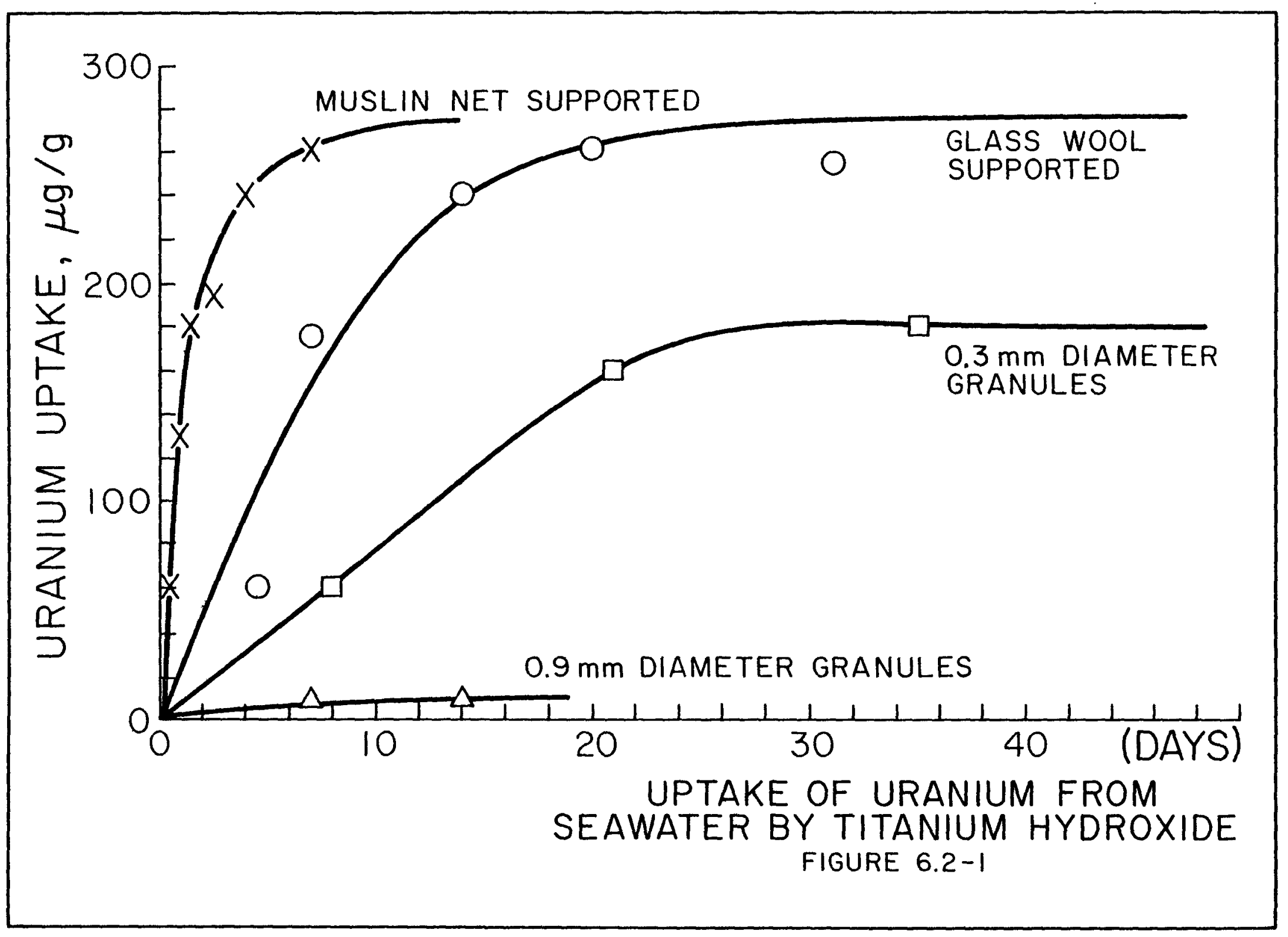


Table 6.2-1 Summary of hydrous titanium oxide experiments

\begin{tabular}{|c|c|c|c|c|c|}
\hline $\begin{array}{l}\text { (if } \\
\text { is }\end{array}$ & $\begin{array}{l}\text { Flow } \\
\text { Rate } \\
\text { column } \\
\text { used) }\end{array}$ & $\begin{array}{l}\text { Capacity } \\
\text { (mg } \mathrm{U} / \mathrm{kg} \mathrm{T}\end{array}$ & $\begin{array}{l}\text { Particle } \\
\text { size }\end{array}$ & Method of extraction & Reference \\
\hline \multirow[t]{2}{*}{0.04} & $\mathrm{~cm} / \mathrm{s}$ & $\begin{array}{l}268 \text { in } \\
21 \text { days }\end{array}$ & NR & $\begin{array}{l}\text { precipitated by caustic } \\
\text { soda method on glass } \\
\text { wool and packed into a } \\
\text { glass column ( } 40 \mathrm{~cm} \mathrm{x} \\
5 \mathrm{~cm} \text { ) f filtered seawater } \\
\text { flowed upward through } \\
\text { the bed }\end{array}$ & $\lfloor 19\rfloor$ \\
\hline & $R$ & $\begin{array}{l}60 \text { in } \\
1 \text { day }\end{array}$ & $\begin{array}{l}14-24 \text { mesh } \\
(0.9 \mathrm{~mm} \text { dia.) }\end{array}$ & $\begin{array}{l}\text { granules were produced } \\
\text { by ammonia route; } \\
\text { exposed to flowing } \\
\text { seawater }\end{array}$ & [19] \\
\hline 101 & $/ \mathrm{hr}$ & $\begin{array}{l}320 \text { in } \\
30 \text { days }\end{array}$ & NR & $\begin{array}{l}\text { seawater was pumped into } \\
\text { a head tank, flowed } \\
\text { through a sand filter } \\
\text { into the apparatus } \\
\text { where samples were } \\
\text { contained in } 2.5 \mathrm{~cm} \\
\text { diameter glass columns } \\
\text { between sintered glass } \\
\text { plates in a } 2.5 \mathrm{~cm} \text { deep } \\
\text { bed; water flowed upward, } \\
\text { keeping the particles } \\
\text { gently mixed by } \\
\text { fluidization; samples } \\
\text { were removed periodically } \\
\text { for analysis }\end{array}$ & $\lfloor 15,20 j$ \\
\hline 0.42 & $\mathrm{~cm} / \mathrm{s}$ & $\begin{array}{l}550 \text { in } \\
28 \text { days }\end{array}$ & $\begin{array}{l}100-150 \text { mesh } \\
\text { (saturation } \\
\text { value) }\end{array}$ & same as above & $\lfloor 12,15\rfloor$ \\
\hline 0.3 & $\mathrm{~cm} / \mathrm{s}$ & $\begin{array}{l}93 \text { in } \\
1 \text { day }\end{array}$ & NR & $\begin{array}{l}\text { muslin support in bed } \\
\text { of } 7.6 \mathrm{~cm} \text { diameter and } \\
33 \mathrm{~cm} \text { height }\end{array}$ & [19] \\
\hline 0.04 & $\mathrm{~cm} / \mathrm{s}$ & $\begin{array}{l}26 \text { in } \\
1.4 \text { days }\end{array}$ & NR & $\begin{array}{l}\text { glass wool support in } \\
\text { bed of } 5.1 \mathrm{~cm} \text { diameter } \\
\text { and } 61 \mathrm{~cm} \text { height }\end{array}$ & $\lfloor 19\rfloor$ \\
\hline
\end{tabular}


Table 6.2-1 (continued)

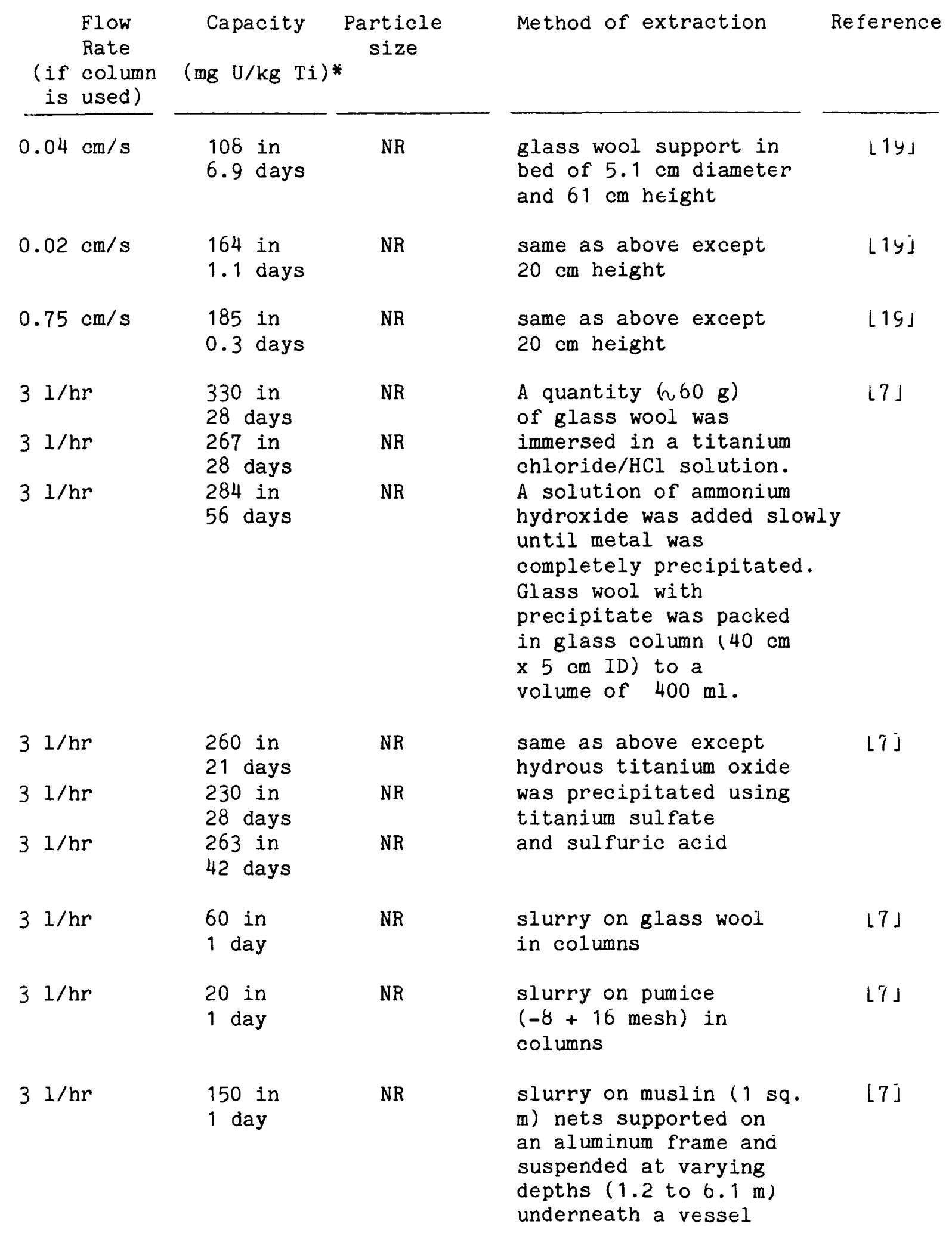




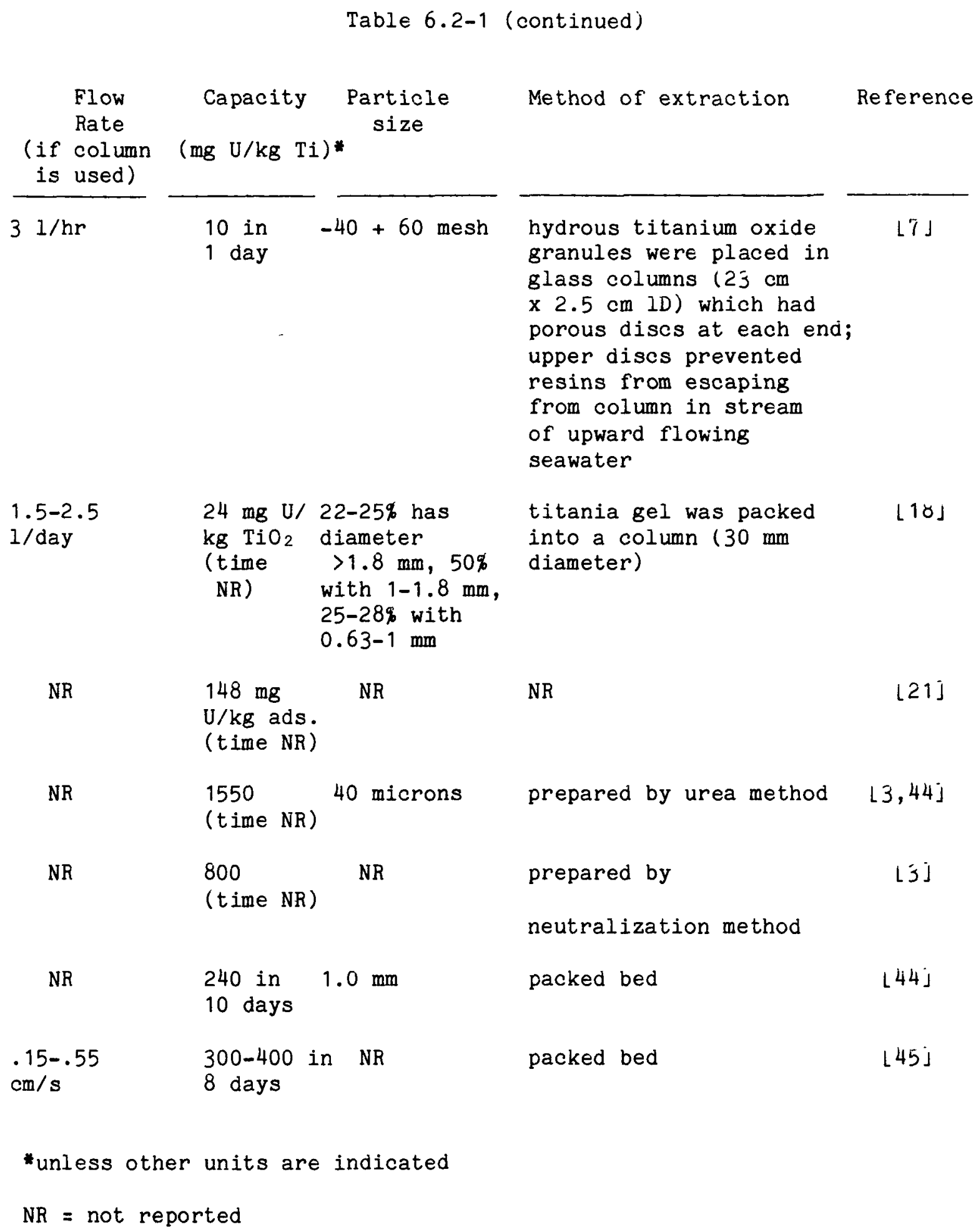


Experiments have been performed to determine the sensitivity of uranium loading to the temperature of the seawater. Unfortunately not much of this data has been published. Bals has observed an increase of a factor of about two in uranium loading from $20 \mathrm{C}$ to $30 \mathrm{C}$, with the loading at $15 \mathrm{C}$ being "very bad" (see Section 15.1.3). It was thought that the increased loading with increasing seawater temperature is due to an increase in the uranyl ion diffusion coefficient at higher temperatures. Kanno [22] observed a 40\% increase in 10 days from $15 \mathrm{C}$ to $25 \mathrm{C}$ (see Section 15.2.1). Sugasaka [23] reported a factor of two increase from $17 \mathrm{C}$ to $45 \mathrm{C}$ at 100 minutes and greater than two at 10 minutes (see Section 15.2.3.2).

Ogata [2] reported a uranium loading temperature dependence proportional to the exponential of the seawater temperature squared, although this experiment was performed in spiked seawater.

Keen and Hooper have performed a complete, but unpublishd series of uranium loading experiments with flow rate, seawater temperature, particle size, and time as parameters. They reported an increase of a factor of 10 from $10 \mathrm{C}$ to $30 \mathrm{C}$ (see Section 15.1.4). In addition, the British have observed seasonal variations in their uranium loading values in in situ seawater experiments.

\subsubsection{Elution}

After the uranium is adsorbed during exposure to seawater, it must then be removed from the adsorbent material in an elution process. Several eluants have been investigated, the more common among them being sodium carbonate, ammonium carbonate, and sodium bicarbonate, although the latter has not been tested as extensively as the others $124 j$. Davies [19] reported that a mixture of two volumes of sodium bicarbonate and one volume of sodium carbonate gave a 75\% elution using 8 bed volumes of eluant. Also $1 \mathrm{M}$ ammonium carbonate gave $65 \%$ elution in 2 bed volumes and 93\% in 8 bed volumes. This information was reconfirmed in recent discussions with the British (see Section 15.1). It appears that ammonium carbonate will give the best elution results for hydrous titanium oxide $[19,25]$. Ammonium carbonate has the further advantage of being more easily recovered by steam distillation for reuse. Partition coefficients (the ratio of the amount of uranium per gram of titanium to the amount of uranium per milliliter of eluant) have been measured for

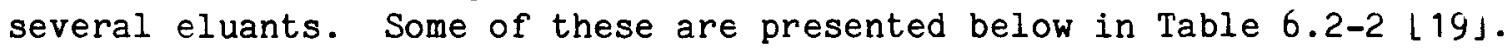


Table 6.2-2 Partition coefficients for elution of hydrous titanium oxide

Reagent

$0.25 \mathrm{M}$ sodium carbonate

$0.5 \mathrm{M}$ sodium carbonate

$1.0 \mathrm{M}$ sodium carbonate

$0.25 \mathrm{M}$ ammonium carbonate

$0.5 \mathrm{M}$ ammonium carbonate
U per $\mathrm{g} T i / U$ per ml eluant

1511

602

200

45

Generally speaking the elution process is slow $119 j$. Actually a maximum elution is obtained when acids are used. However, this results in too much of the hydrous titanium oxide being dissolved.

The elution process removes only small amounts of other materials that have been adsorbed on the hydrous titanium oxide $\lfloor 15\rfloor$.

\subsubsection{Other Properties}

An important consideration in the selection of both an adsorbent and an eluant is the solubility of the adsorbent in seawater and in the eluant. Inoue [17] reported that hydrous titanium oxide is reasonably insoluble in mineral acids as long as the concentration does not exceed $0.1 \mathrm{M}$. It is also relatively insoluble in sodium hydroxide solution. Early British reports $[7,19]$ indicated that the solubility of hydrous titanium oxide in flowing seawater is undetectable; however, the solubility of hydrous titanium oxide in seawater which had been shaken with the hydrous titanium oxide for 72 hours was found to be $0.1 \mathrm{mg}$ per liter. More recent British work has shown a much improved solubility for hydrous titanium oxide in seawater (see section 15.1). In a 16 month test, losses of hydrous titanium oxide, including mechanical attrition losses, were less than $5 \%$ per year. This statement attests to the fact that, when properly made, hydrous titanium oxide can withstand significant contact with both seawater and a proper eluant.

The solubility of hydrous titanium oxide in the eluant is greater than its solubility in seawater. This is illustrated by Table $6.2-\overline{3}$, wherein the solubility of hydrous titanium oxide was reported in various eluants [19]. 
Table 6.2-3 Solubility of hydrous titanium oxide in eluants

Eluant

Solubility

(mg Ti/l eluant)

(Hydrous titanium oxide precipitate shaken for $\overline{3}$ days)

1.OM sodium carbonate

0.5

$0.5 \mathrm{M}$ ammonium carbonate

1.4

1.0M ammonium carbonate

14.1

(Hydrous titanium oxide granules in flowing eluant)

1.0M sodium carbonate

0.1

1.0M ammonium carbonate

11.4

Mechanical attrition in the form of physical loss of the hydrous titanium oxide adsorbent has been a problem in experiments conducted in an actual seawater environment. Many of the hydrous titanium oxide adsorbents that have been produced have been able to either attain high uranium loadings or be structurally sound, but very seldom have both properties been simultaneously attained in the same sample. Obviously there is some tradeoff involved in that a high loading is of very little value if the material is physically being lost at a fairly rapid rate, thus necessitating a sizeable periodic replacement of the bed.

In addition to uranium, hydrous titanium oxide also adsorbs several other elements from seawater [15]. Table 6.2-4 lists concentration factors for a hydrous titanium oxide adsorbent, i.e., the mass of the element per unit mass of titanium divided by the mass of the element per unit volume of seawater, or, stated another way, the ratio of the concentrations of an element in hydrous titanium oxide to its natural concentration in seawater. 
Table 6.2-4 Concentration factors in hydrous titanium oxide ( 30 days contact with seawater)

\begin{tabular}{ccr} 
Element & $\begin{array}{c}m g \text { element } \\
\text { per kg Ti }\end{array}$ & $\begin{array}{r}\mathrm{mg} \text { element/kg Ti per } \\
\text { mg element/ml seawater }\end{array}$ \\
\cline { 2 - 3 } $\mathrm{Cr}$ & 49 & $1,000,000$ \\
$\mathrm{~V}$ & 490 & 250,000 \\
$\mathrm{U}$ & 320 & 97,000 \\
$\mathrm{Mn}$ & 170 & 85,000 \\
$\mathrm{Fe}$ & 730 & 73,000 \\
$\mathrm{Ni}$ & 120 & 60,000 \\
$\mathrm{Ba}$ & 730 & 24,000 \\
$\mathrm{Ge}$ & 49 & 16,000 \\
$\mathrm{Al}$ & 120 & 12,000 \\
$\mathrm{Se}$ & 12,000 & 4,000 \\
$\mathrm{Sr}$ & 2,800 & 300 \\
$\mathrm{Ca}$ & 73,000 & 180 \\
$\mathrm{Mg}$ & 24,000 & 18 \\
$\mathrm{Na}$ & 17,000 & 1.6
\end{tabular}

\subsection{FLOWSHEET CRITERIA}

A study such as this can only begin with a series of assumptions drawn from the available literature. So much has been published on the many facets of this subject that it was necessary to draw up the flowsheet criteria to formally assure that there would be a common basis for the process design. Since the criteria were drafted early in the study, some changes were required during the design due to engineering considerations. Also some changes were made based upon more recent information that became available. Thus, this section records the finalized criteria:

- The uranium concentration of seawater was taken to be 3.35 micrograms of uranium per liter of seawater that has a salinity of 35 parts per thousand [26].

- The plant capacity was set at a nominal 500 tonnes $\mathrm{U}_{3} \mathrm{O}_{8}$ per year. This capacity was thought to be realistic with respect to the volume of water to be handled and of fered a size that might be varied a factor of two either way to bracket probable plant sizes as they vary due to site conditions.

- An on-stream load factor of $90 \%$ for a continuous fluidized bed or $75 \%$ for a batch bed operation was considered reasonable by a 
number of experienced operations engineers. (75\% of the year is 274 calendar days; $90 \%$ of the year is 329 calendar days).

- Hydrous titanium oxide was chosen as the adsorbent. Al though other adsorbents were mentioned in the literature, none has been applied as successfully as hydrous titanium oxide nor was there adequate engineering design data available for the adsorbents other than hydrous titanium oxide. This selection is covered in greater depth in Section 5.4.2.

- The reported adsorption efficiences for hydrous titanium oxide covered a wide range (see Table $6.2-1$ ), but a specific value had to be set before process design could be started. An efficiency of $80 \%$ was assumed, based upon an Oak Ridge document [27], including the experimental measurements described in Appendix A-1 of that document. This efficiency was confirmed as being conservative in a discussion with Keen (see Section 15.1.4).

- The adsorbent capacity was taken to be $210 \mathrm{mg} \mathrm{U} / \mathrm{kg} \mathrm{Ii.} \mathrm{This}$ capacity assumed the $240 \mathrm{mg} \mathrm{U} / \mathrm{kg} \mathrm{Ti}$ value cited by Davies [19] in his initial article in 1964, but also recognizes that, in the first cycle, complete elution is not observed. Thus the effective capacity per cycle was taken to be $210 \mathrm{mg} \mathrm{U} / \mathrm{kg} \mathrm{Ti}$. Subsequent discussions confirmed this as a conservative value (see Section 15.1).

- The elution efficiency was initially assumed to be about $95 \%$, but, with a four hour elution period, a $97 \%$ uranium elution is now projected.

- The concentration of the eluant and formation of a uranium product suitale for introducing into a fluorination plant would be achieved with a $91 \%$ efficiency.

- The sizing of the adsorption beds was important for establishimg engineering design parameters. The size cited by Harringtom et al. [27] was submitted for engineering design consideration and was found suitable. The area of each bed is 11,500 square meters and a mean flow rate of $0.4 \mathrm{~cm} / \mathrm{s}$ is projected.

- Each seation of the plant contains a bed of such a dimension that four tonnes of $U_{3} O_{8}$ per year can be collected. Hence $1<5$ beds are required for a 500 tonne/year plant. 


\subsection{CO-PRODUCT FLOWSHEET}

Co-product flowsheet considerations were limited to those trace elements in seawater that also adsorb onto hydrous titanium oxide under uranium adsorption conditions. A second co-product recovery process using a different extraction technique was not considered, because such a design would have required a duplication of the stuay on uranium with respect to each co-product. Even if there were adequate information on another specific trace element recovery, the design of a second extraction plant and the impact of its operation upon the primary recovery operation for uranium would have materially extended this study.

Trace elements of potential value that are co-adsorbed upon hydrous titanium oxide are chromium, vanadium, manganese and nickel $\lfloor 15 \mathrm{~J}$. Table 6.4-1 compares the quantity of these elements that would be adsorbed upon the hydrous titanium oxide per unit quantity of uranium adsorbed, $\mathrm{k} 1$, and the quantity of these elements that can be eluted from the hydrous titanium oxide per unit quantity of uranium eluted, $k 2$.

Table 6.4-1 Trace elements adsorbed on and eluted from hyarous titanium oxide

\begin{tabular}{cccc} 
Element & $\begin{array}{c}\text { Concentration in } \\
\text { seawater }(\mathrm{mg} / \mathrm{I})\end{array}$ & $\mathrm{R} 1$ & $\mathrm{R}$ \\
\cline { 2 - 3 } & 0.00005 & 0.15 & 0.00 \\
$\mathrm{Cr}$ & 0.002 & 1.5 & 0.6 \\
$\mathrm{Mn}$ & 0.002 & 0.53 & 0.2 \\
$\mathrm{Ni}$ & 0.002 & 0.38 & 0.2
\end{tabular}

Adsorption conditions: Seawater in contact with hydrous titanium oxide for 30 days.

R1 = tonne trace element adsorbed/tonne uranium adsorbed

$R 2=$ tonne trace element eluted/tonne uranium eluted

The ammonium carbonate $\in$ luant partially removes these trace metals from hydrous titanium oxide, according to discussions held with German and British researchers (see Section 15.1). in the absence of precise data, a $40 \%$ elution was assumed for these values. This yielded an eluate product solution with the quantity of trace elements described in the last column in Table 6.4-1. 
Upon steam stripping the eluate to recover ammonia and carbon dioxide, a weakly ammoniacal solution of the trace elements resuits. After the uranium has been recovered according to the flowsheet in Section 7.2, the trace elements can be accumulated as an aqueous concentrate that may be sold as a raw material on the metals market. It is anticipated that up to $80 \%$ of the market value for each metal would be consumed in its isolation and purification.

A detailed discussion on the subject of co-products is found in Chapter 9 . 
CHAPTER 7

PLANT DESIGN

\section{1 GENERAL DESIGN CRITERIA}

The process and site selections reported in Chapters 5 ano 0 provided the basis for a conceptual design from which capital and operating costs could be derived. The following is a summary of the general design basis and criteria used in this study.

The adsorbent material selected for uranium recovery is hyarous titanium oxide. Based on recent studies by the Japanese, British, and Italians, hydrous titanium oxide is still considered to be the best adsorbent material (see Sections 15.1 and 15.2). The formula of the adsorbent was presumed to be $\mathrm{TiO}_{2} \cdot 2 \mathrm{H}_{2} \mathrm{O}$.

Laboratory data reported in URNL-TM-4757 L27] was used as the basis for determining the physical characteristics of the adsorbent material. Particle behavior characteristics were assumed to be similar to values used for the design of sand filters in water treatment [20]. A summary of assumed bed material properties is as follows:

$\begin{array}{ll}\text { Titanium content of the bed } & 220 \mathrm{~kg} \mathrm{Ti} / \mathrm{m}^{3} \\ \text { Particle size of adsorbent } & 80 \mathrm{to} 100 \mathrm{mesh} \\ \text { Particle composition } & \text { Agglomerates } \\ \text { Dry bulk density } & 0.53 \mathrm{~g} / \mathrm{cm}^{3} \\ \text { Wet particle density } & 1.5 \mathrm{~g} / \mathrm{cm}^{3} \\ \text { Hydrate solid density } & 2.1 \mathrm{~g} / \mathrm{cm}^{3} \\ \text { Void fraction between particles } & 0.40 \\ \text { Sphericity } & 0.80\end{array}$

Hydrous titanium oxide has been reported in the literature $115 \mathrm{~J}$ to have a maximum adsorption capacity of $550 \mathrm{mg} \mathrm{U} / \mathrm{kg} 7 \mathrm{i}$ on 100 to 150 mesh particles. The Oak Ridge report [27] assumed an adsorption capacity of $240 \mathrm{mg} \mathrm{U} / \mathrm{kg} \mathrm{Ti}$ at an $80 \%$ adsorption efficiency. An effective adsorption capacity of $210 \mathrm{mg} \mathrm{U} / \mathrm{kg} \mathrm{Ti}$ at $80 \%$ efficiency for a contact time of $\mathrm{b}$ seconds was selected as a reasonable design basis, as discussed in the Flowsheet Criteria, Section 6.j. 
Initial studies by the British [15] indicated that the efficiency of the adsorbent bed dropped to half of its original value after eight cycles. Current unpublished information indicates that the aosorbent can be used nearly indefinitely without any significant loss of efficiency provided the bed is occasionally eluted for an extended time period to remove calcium and magnesium (see Section 15.1).

The replacement of adsorbent is considered to be a major operating cost. The loss of the adsorbent was presumed to be a combination of solubility occurring during the elution cycle and physical abrasion. As indicated in Sections 6.2.2 and 15.1.4, the British are current1y reporting a $5 \%$ to $10 \%$ loss of hydrous titanium oxide material per year for a 10-day cycle. Similarly, the Japanese are reporting a loss of $0.1 \%$ per cycle on a 12-day cycle period. A $0.5 \%$ per cycle loss of hydrous titanium oxide was selected for this work as a conservative estimate of the adsorbent replacement requirements.

The size criteria for planning a uranium recovery piant was set at nominal production rate of 500 tonnes per year of $\mathrm{U}_{3} \mathrm{O}_{8}$. The plant was designed with multiple seawater/adsorbent contact units. Based upon the adsorbent capacity of $210 \mathrm{mg} \mathrm{U} / \mathrm{kg} \mathrm{Ti}$, seawater throughput requirements, and practical bed operating considerations, the throughput of each contact unit was found to be 5.45 million cubic meters of seawater per day.

The Oak Ridge report ORNL-TM-4757 [27] was used as a guideline in determining the wash and elution requirements of the bed materials. The report suggested as a minimum three bed volumes of fresh water to displace seawater and four bed volumes of the eluant, $1 M$ ammonium carbonate solution, to extract the uranium from the adsorbent. Five bed volumes of fresh water were assumed to be necessary in the postwash with all of the water recycled in the make-up of new eluant solution and as fresh water in the prewash.

The elution step was calculated to recover $9 \%$ of the uranium captured by the adsorbent based on the following: Table A-b of ORNL-TM-4757 [27] shows that, based on laboratory data, 4.5\% of the uranium was recovered in the postwash. Approximateiy 60\% of the postwasn was planned to be used as prewash. The uranium dissolved in this prewash will return to the sea. The resulting net loss from the prewash was calculated to be $2.7 \%$. The remaining $0.3 \%$ loss was attributea to the lost adsorbent.

Ammonium carbonate was chosen for the eluant not only because of its high elution efficiency, but also because it is easily recoverable for reuse. The process for recovering the uranium from the adsorbent was assumed to be similar to the pressure leaching process developed by Battelle Memorial Institute [13]. The ammonium carbonate and $\mathrm{U}_{3} \mathrm{O}_{B}$ can be reclaimed by a two-stage thermal decomposition process. The first stage of the process will thermally decompose the uncombined ammonium carbonate in solution and eliminate some of the possible precipitates of magnesium, 
calcium and lithium. The second stage thermally decomposes the ammonium uranyl carbonate complex, strips excess water, and precipitates a relatively pure yellowcake. The planned recovery of uranium from processing the eluate is estimated to be $90 \%$ to $92 \%$. The overall plant recovery of uranium from seawater is then calculated to be approximateiy $70 \%$.

The physical plant design was based on a pumped flow feed system and on the geographical characteristics of the best location found in the United States and its possessions as determined by the site selection criteria and studies reported in XN-RT-14, Volume I L26j. The plant site chosen was the Guayanes River Valley in southeastern Puerto Rico. This site has many features that make it attractive for a uranium from seawater recovery plant. These features include: a good access to strong ocean currents; a large low plain adjacent to the ocean; low tides; adequate fresh water supplies; high mountain valleys suitable for water reservoir construction; and a reasonably good land access to other industrial centers.

\subsection{PROCESS DESIGN}

\subsubsection{Adsorption Process}

Four process methods for contacting the adsorbent with seawater were investigated. The methods can be categorized into two basic concepts, static beds and dynamic beds. The static bed systems are batch operations with the washing and elution of the adsorbent occurring in situ within the contact structure. The dynamic bed systems are continuous operations that have the bed materials continuously transported to a remote washing and elution area for processing and then recycled back to the contact structures.

The dynamic bed systems have several advantages over the more conventional static beds. The dynamic beds can be operated almost continuously without interruption; therefore fewer contact structures would be required for the plant. Secondly, the continuous washing and elution of bed materials eliminates the large water, eluant, and eluate storage facilities necessary to meet the variable flow requirements of a batch plant. Also, pump stations, piping, storage facilities and supporting equipment can be reduced in size because of lower peak flow requirements. Another advantage of the continuous system is that separate piping systems to the contact structures for each of the wash, eluant, and eluate solutions can be replaced by a pair of slurry piping systems. Finally, the continuous system would not require the extra wash water or eluant quantities needed to fill the underdrain system of a static bed design. 
Some of the disadvantages of a dynamic bed system are that the washing and elution equipment would be relatively expensive, the siurry line flow velocities would have to be maintained, automated equipment would be required and the losses of the adsorbent due to particle attrition might be somewhat greater. Ihe British claim the attrition of particles should not be substantial and can be controlled by the method of manufacturing the adsorbent (see Section 15.1).

Flow diagrams for the various process methods considered are shown in Figures $7.2-1 \mathrm{~A}, 7.2-1 \mathrm{~B}$, and $7.2-1 \mathrm{C}$. A static bed system and a dynamic bed system were compared to evaluate the cost of construction.

\subsubsection{Static beds}

\subsection{Downflow beds}

The downflow bed consists of a contact structure containing a layer of adsorbent placed over an underdrain system. Seawater flows over the surface of the bed, through the adsorbent and out the underarain.

The contact structure may $\in$ ither be an open concrete tank or a lined earth-diked lagoon. The optimum sidewall depth for this type of structure is $4.5 \mathrm{~m}$. Costs of structures with deeper sidewall depths increase rapidly.

The bed size and capacity were developed from the chemical flowsheet requirements and a preliminary evaluation of the initial hydraulic head requirements. The Blake-Kozeny equation [28] was used to calculate the bed area of 19,600 square meters and bed depth of 0.24 meters to satisfactorily comply with design conditions. For this static bed design, the loading time is 360 hours for a $210 \mathrm{mg} \mathrm{U} / \mathrm{kg} \mathrm{Ii}$ adsorbent capacity.

The downflow bed has several major design problems. One problem is that the bed material will function as a filter and remove large quantities of solids from the seawater. The process would require the installation of a large water filtration plant. A second problem would be the application of seawater across the face of the bed without disturbing the bed depth. An extensive launder and weir system would be required for the application of seawater. Furthermore, a iarge launder and weir system would interfere with the loading and unloading of $b \in d$ materials. 
Table 7.2-1 Flow line designations for Figures $7.2-1 \mathrm{~A}, 7.2-1 \mathrm{~B}$, and $7.2-1 \mathrm{C}$

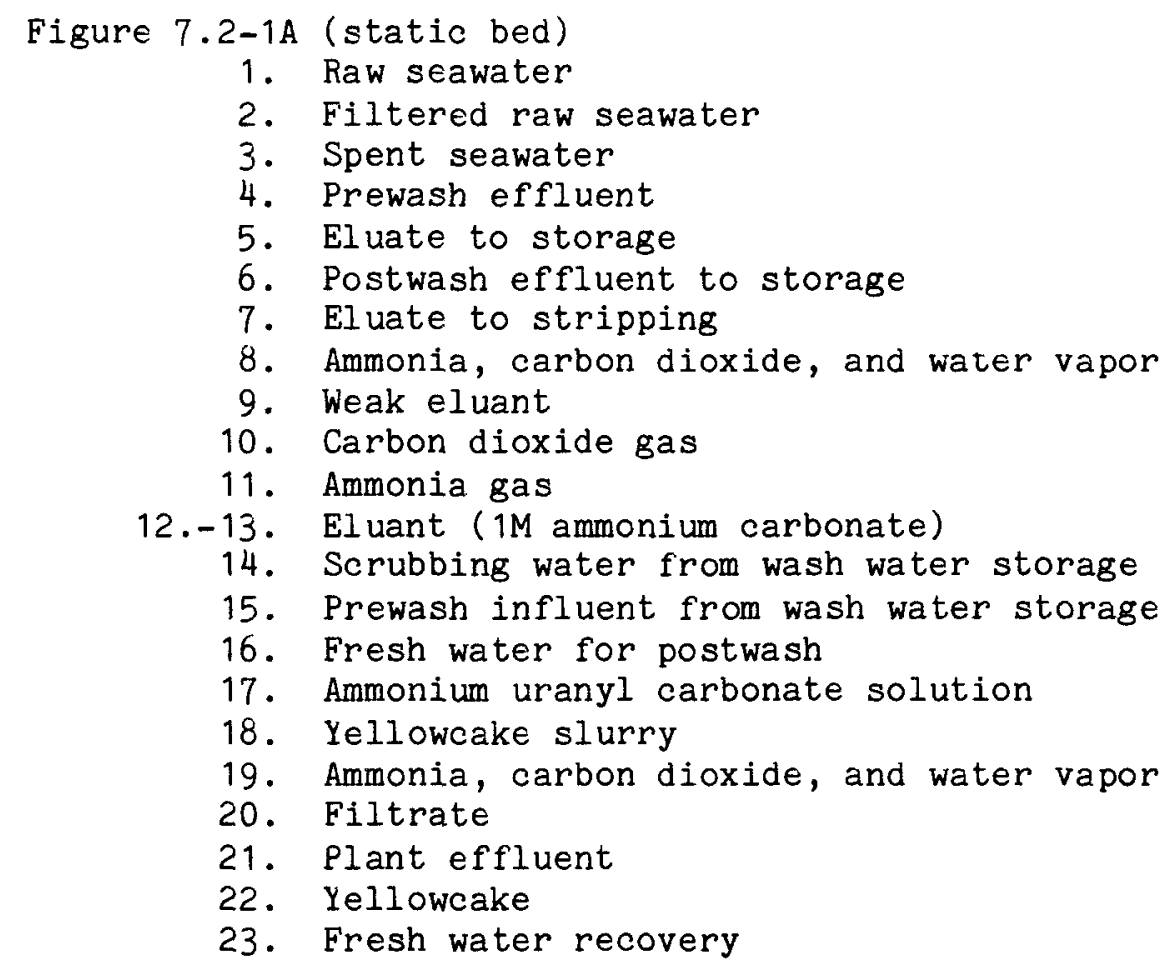

Figure 7.2-1B (continuous slurry bed); Figure 7.2-1C (continuous fiuidized bea)

1. Raw seawater

2. Filtered raw seawater

3. Seawater/adsorbent dilute slurry (Figure 7.2-1B)

Seawater and prewash effluent (Figure 7.2-1C)

4. Spent raw seawater

5. Adsorbent slurry

6. Carrier water

7. Adsorbent

8. Prewashed adsorbent

9. Eluted adsorbent

10.-11. Postwashed adsorbent

12. Fresh adsorbent

13. Adsorbent slurry

14. Fresh water

15. Prewash influent

16. Prewash effluent

17. Scrubbing water

18. Ammonia, carbon dioxide, and water vapor

19. Weak eluant

20. Eluant

21. Eluate

22. Ammonium uranyl carbonate solution

23. Yellowcake slurry

24. Ammonia, carbon dioxide, and water vapor

25. Filtrate

26. Carbon dioxide

27. Ammonia

28. Yellowcake

29. Fresh water recovery 


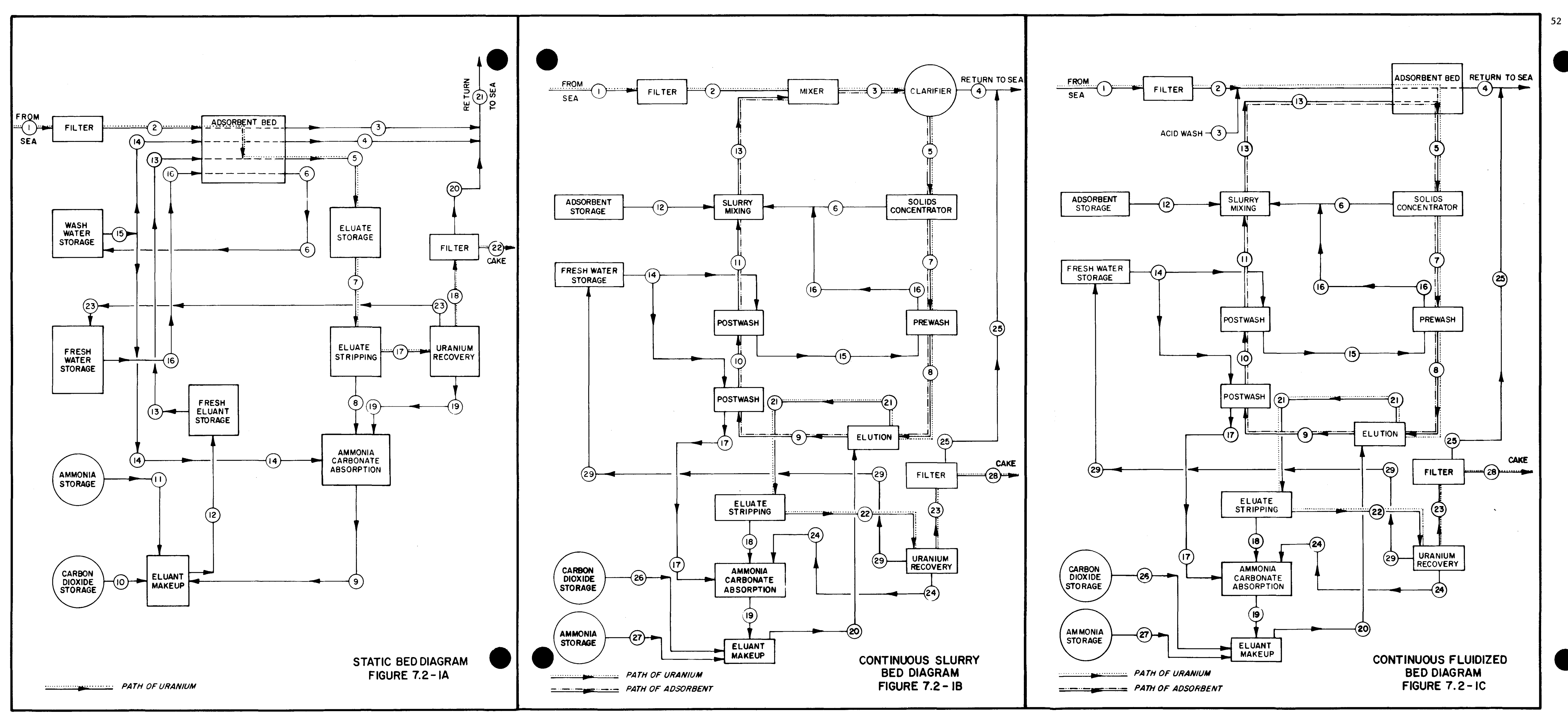


Because of operating costs from hydraulic head losses ana the aforementioned design problems, the downflow system was judged to be less economical. Therefore, the investigation of the downflow bed system was discontinued.

\subsection{Upflow beds}

The only difference between the downflow and upflow bed systems is the direction the seawater flows through the beds. The upflow velocity was selected to fluidize all the particles in the bed without scouring the particles into an overflow weir system. Based on calculated settling rates, seawater velocities can range from 0.1 to $0.6 \mathrm{~cm} / \mathrm{s}$. A seawater velocity of $0.4 \mathrm{~cm} / \mathrm{s}$ was selected as a reasonable basis for designing the floor area of the contact structure.

A lined earth-diked lagoon with 3 to 1 side slope was judged to result in an economic configuration for a large contact structure. Figure 7.2-2 shows the plans for a typical bed design. The floor area required was calculated to be 15,800 square meters. A bed depth of $0.4 \mathrm{~m}$ was judged to be a good practical depth for placing the adsorbent. Total volume of adsorbent was estimated to be 6,440 cubic meters. The expanded depth (when fluidized) was calculated to be $0.75 \mathrm{~m}$, which would give a seawater contact time of over three minutes. The head loss through the bed was calculated to be about $0.1 \mathrm{~m}$. The sidewall depth above the top of the underdrain for the contact structure was designed to be $2.5 \mathrm{~m}$ above the top of the underdrain, with the weir level set at $2.0 \mathrm{~m}$.

The underdrain system of the contact structure consists of a sublayer of small rock, a layer of gravel, and a heavy fabric topped by a protective steel grid. The holes in the grid are filled with a high density particle such as ground garnet to prevent the fine adsorbent particles from blinding the fabric and escaping into the underdrain. Overflow weirs and launders are placed around the perimeter of the contact structures to permit a clear working space for heavy construction equipment.

The underdrain piping was designed with multiple port entry to reduce the required depth. The piping is connected directly to the influent channel, and the flow to the beds is controlled by sluice gates for each port.

The launder and weir system was sized to prevent excessive density currents from washing the adsorbent from the contact structure. An overflow of 870 cubic meters per meter of weir length per day was judged to be a reasonable upper limit. Each launder is designed with two weirs and was equipped with a sluice gate at the discharge of the $\in$ f f 1 uent channel for isolating the contact structure. 


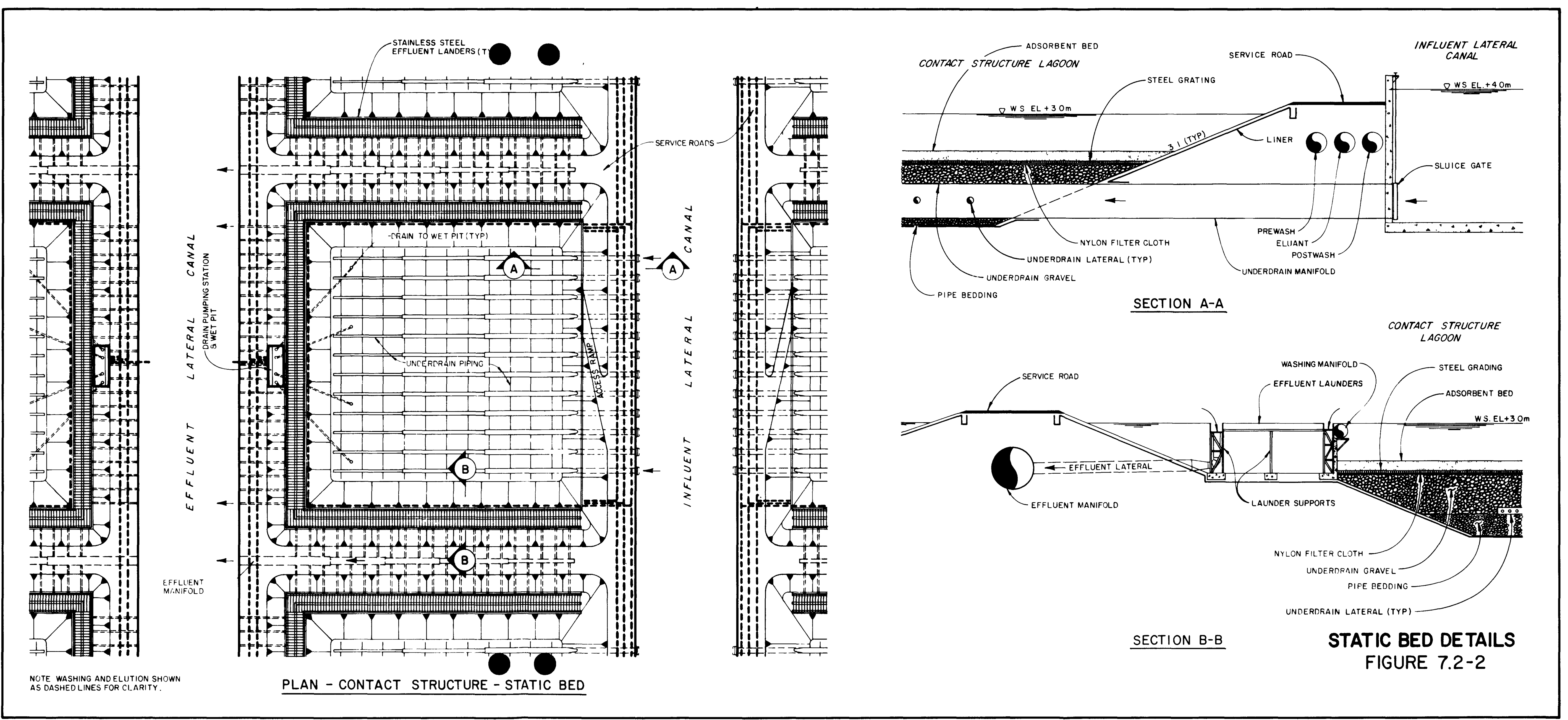


The washing and elution of the adsorbent bed is completed by filling from above the bed and pumping the solution from the underdrain. A crain pump station with a manifold at each contact structure is planned for pumping spent seawater and prewash to the effluent channel, and eluate and postwash to respective storage booster pump stations.

The void of the underdrain system must be filled before effective washing or elution of the adsorbent can occur. The calculated void volume of the underdrain is 15,500 cubic meters. The required volumes of prewash, eluant, and postwash per cycle to allow for filling of the underdrain volume and to provide the number of bed volumes called for by the chemical flowsheet are 34,$800 ; 41,200$; and 47,700 cubic meters, respectively. Table 7.2-2 shows the daily requirements of each solution:

Table 7.2-2 Average solution requirements

$\begin{array}{ll}\text { Prewash } & 161,000 \text { cubic meters/day } \\ \text { Eluant } & 191,000 \text { cubic meters/day } \\ \text { Postwash } & 221,000 \text { cubic meters/day }\end{array}$

The seawater/adsorbent contact time for the bed was estimated to be 490 hours for an adsorbent capacity of $210 \mathrm{mg} \mathrm{U} / \mathrm{kg} \mathrm{Ti}$. The time for prewash, elution, postwash, draining the underdrain system, quality control, and maintenance of the equipment was estimated to be 160 hours. The total estimated cycle time for the process is 650 hours, or 13.5 cycles per year. The expected annual yield of $\mathrm{U}_{3} \mathrm{O}_{8}$ for a 125 bed plant is nominally 520 tonnes.

\subsubsection{Dynamic beds}

\subsection{Continuous slurry bed concept}

The concept of the continuous slurry bed was developed to make more effective use of the seawater-adsorbent contact structures and support equipment. By providing separate equipment for the wash and elution steps, the adsorption step can be operated continuously. The operational time of the contact structures and support equipment was assumed to be 
90\%; 105 contact structures operating at a seawater flow of 5.45 million cubic meters per day can then be calculated to produce 500 tonnes of $U_{3} \mathrm{C}_{8}$ annually.

The operational concept of a continuous slurry bed is to mix the adsorbent solids with fresh seawater to obtain the uranium transfer in standard mixing equipment and recover the solids by either a screening or settling process, followed by countercurrent stages for prewashing, elution, and postwashing of the adsorbent. The processed adsorbent is continuously returned to the mixing system.

A variety of screening and settling devices were evaluated. The devices included microscreens, wedge-wire screens, hydrasieves and clarification equipment. Clarifiers with settling tubes appeared to be the most economical method of separation.

A disadvantage of clarifiers is that the mechanisms currently on the market are limited to a diameter of 60 meters. Multiple parallel units would be required for process unit flows of 5.45 million cubic meter $p \in r$ day. Flow distribution channels between the clarifiers of a process unit would require careful design to prevent the premature settling of the adsorbent particles.

Preliminary evaluation showed that fluidized beds could be operated continuously in a process scheme similar to slurry beds, but without certain of the costly mechanized equipment. Study of the continuous slurry bed concept was discontinued at this point.

\subsection{Continuous fluidized bed concept}

The behavior characteristics of a fluidized bed can be likened to those of a viscous liquid (or quicksand) which should be pumpable from one end of the bed as a slurry to create a cross flow pattern. The fluidized bed can then be washed and eluted in separate continuous operations and returned as a slurry to the opposite end of the bed. Bed dimensions with a 5 to 1 length-width ratio were selected as a design basis to minimize the possibility of short circuiting unsaturated adsorbent through the wash and elution system. All other design criteria, bed dimensions, seawater flow rate, weir height and head ioss, were assumed to be the same as determined for the upflow static bed concept.

Support equipment for the continuous fluidized beds consists of a slurry pumping system (see Figure 7.2-3). The solids content of the fluidized adsorbent was estimated to be $30 \%$ to $35 \%$ by volume. The pumping system was planned to dilute the solids to $10 \%$ by volume with spent seawater entering one side of a bifurcated suction to the pump. The support piping to and from the beds was planned to maintain a 


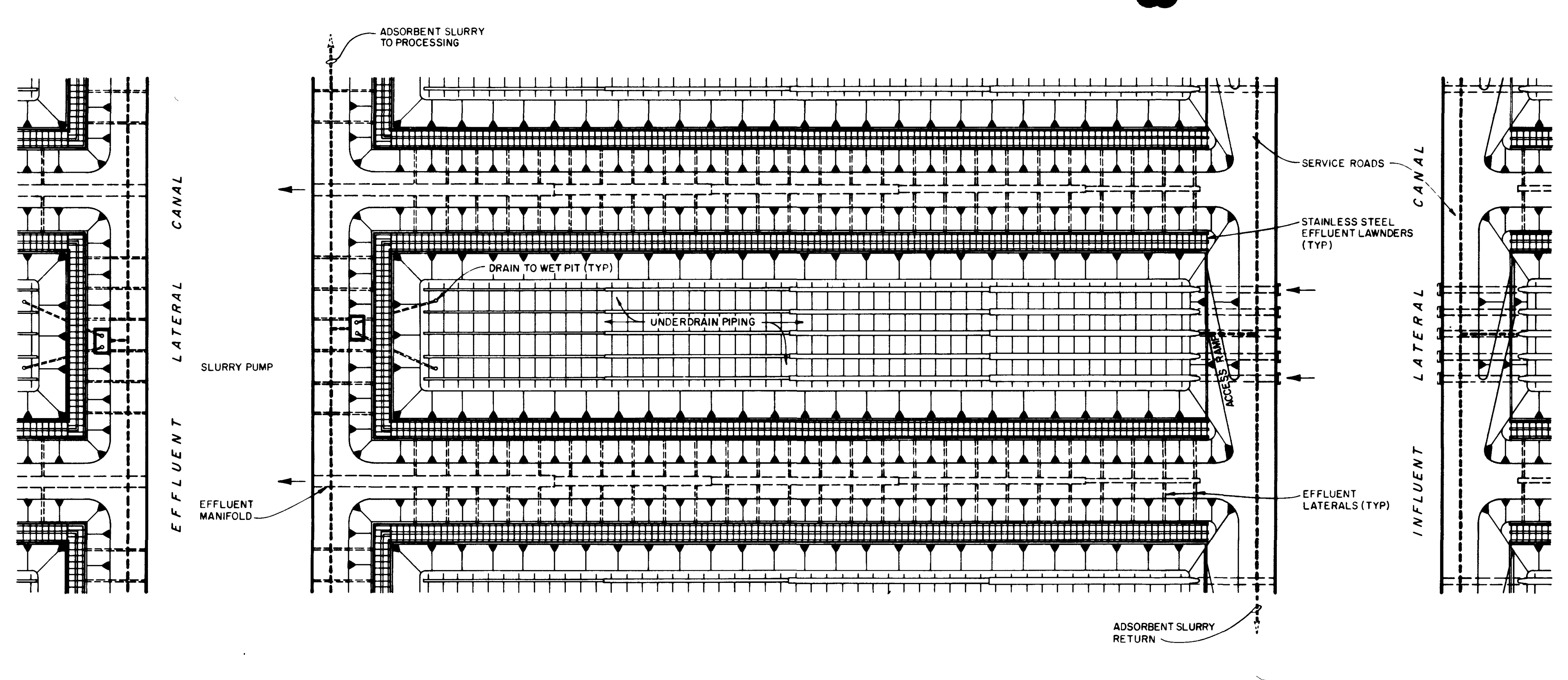


scouring velocity sufficient to prevent settling of adsorbent solids. The piping was sized to keep the flow velocities in the pipe between 0.9 and $1.5 \mathrm{~m} / \mathrm{s}$.

The slurry drawoff rate is dependent on the uranium capacity of the adsorbent and has been calculated to be 2200 iiters per minute per bed for an adsorbent capacity of $210 \mathrm{mg} \mathrm{U/ \textrm {kg }} \mathrm{Ti}$. Detention time of solids in the bed is approximately 20 days.

Based on preliminary economic data and engineering judgment, the continuous fluidized bed concept was selected for the continuation of the feasibility

\subsubsection{Elution and washing processes}

The process for washing and elution of the adsorbent for a dynamic bed system includes a solids separation from the carrier water, three countercurrent extraction and washing steps, and a remixing of the solids with water (see Figure 7.2-4). The solids are assumed to be transferred by screw conveyor or similar equipment.

The postwash extraction step was divided into two separate stages. The second stage postwash water, containing the least ammonium carbonate, is transferred to the prewash extraction step. Water from the prewashing step is used to supplement the carrier water in transferring the adsorbent back to the beds. The first stage postwash water, containing the highest ammonium carbonate concentration, is used as scrubbing water for ammonium carbonate adsorption in the eluate processing plant.

Separation of the solids from the $10 \%$ by volume siurry is accomplished by a static separator similar to a hydrasieve. Optimum separation for these devices occurs at approximately 5\% solids. A recirculation pump is included in the design to recycle the carrier water and improve the efficiency of the separation.

Liquid-solid extraction equipment is currently custom manufactured. Several types of equipment were evaluated for washing and elution. Oil seed extraction equipment was determined to provide the longest solids detention time. Several extractor devices that may prove suitable are the Kennedy extractor, the Crown solvent extractor, or the Rotocel extractor. Equipment costs used in this study were based upon price quotations from the Crown Iron Works Company, Minneapolis, Minnesota.

The extraction equipment for the prewash and postwash steps was estimated to provide a minimum solids detention time of 30 minutes. The elution step was planned for four hours. Solids detention time and equipment limitations required that the step be divided into two stages. 


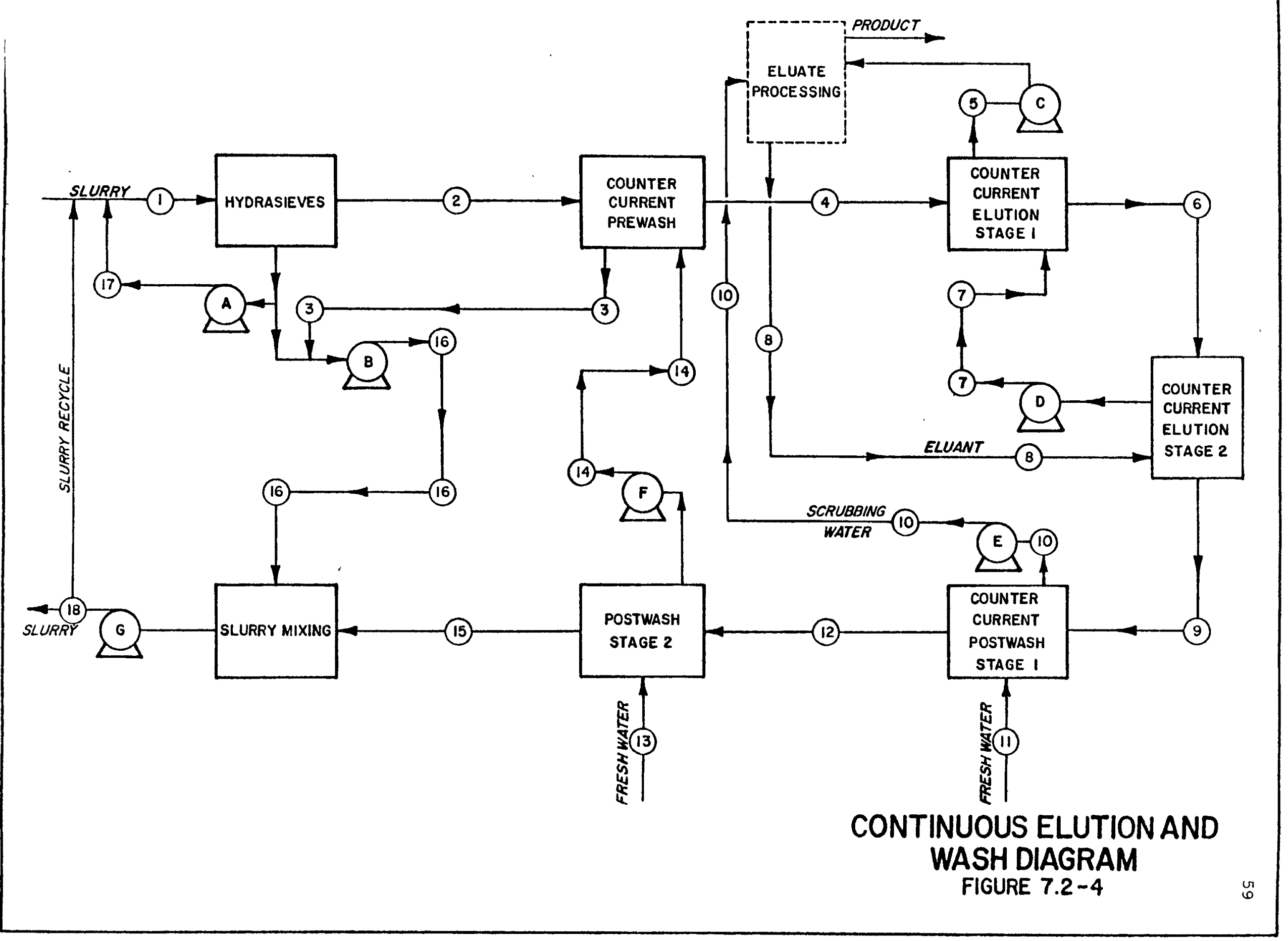


A $10 \%$ recycle through this system was planned to provide the extended contact time recommended for maintaining the adsorbent surface activity.

The average volume of solids to the extraction equipment was estimated to be 30,000 cubic meters per day. Table $7.2-\overline{3}$ shows the average daily solution requirements for the extraction process.

Table 7.2-3 Average daily solution requirements for a $210 \mathrm{mg} \mathrm{U} / \mathrm{kg} \mathrm{Ti}$ loading

Prewash

Eluant

Postwash
90,000 cubic meters

120,000 cubic meters

150,000 cubic meters

\subsubsection{Eluate Recovery}

The eluate stripping process was based on the system described in a Battelle Memorial Institute paper [13], where the pressure leaching of uranium ores is discussed. The stripping process recovers ammonia and carbon dioxide for reabsorption to form fresh eluant.

Losses in the system of approximately $1 \%$ of the ammonia and $6 \%$ of the carbon dioxide are assumed in the Battelle flowsheet. This appears to be optimistic for a true plant operating environment. For design purposes, the ammonia and carbon dioxide losses were assumed to be $2 \%$ and $7 \%$, respectively, and these losses would occur as combined salts.

In the proposed system, the eluate solution is pumped from the elution process step (see Figure 7.2-5) to the stripping towers. The eluate is preheated to approximately $60 \mathrm{C}$ under pressure by hot evaporator condensate (scrubbing water). The eluate enters the top of a sieve plate tower. The tower is equipped with a steam heated, forced circulation reboiler for adding energy to decompose the uncombined ammonium carbonate to its elemental gases. The bottom liquor is recirculated through the tubes of the reboiler to lessen the maintenance problems of scale formation caused by salts with inverted solubility (magnesium, calcium, lithium). The overhead vapor from the stripping 


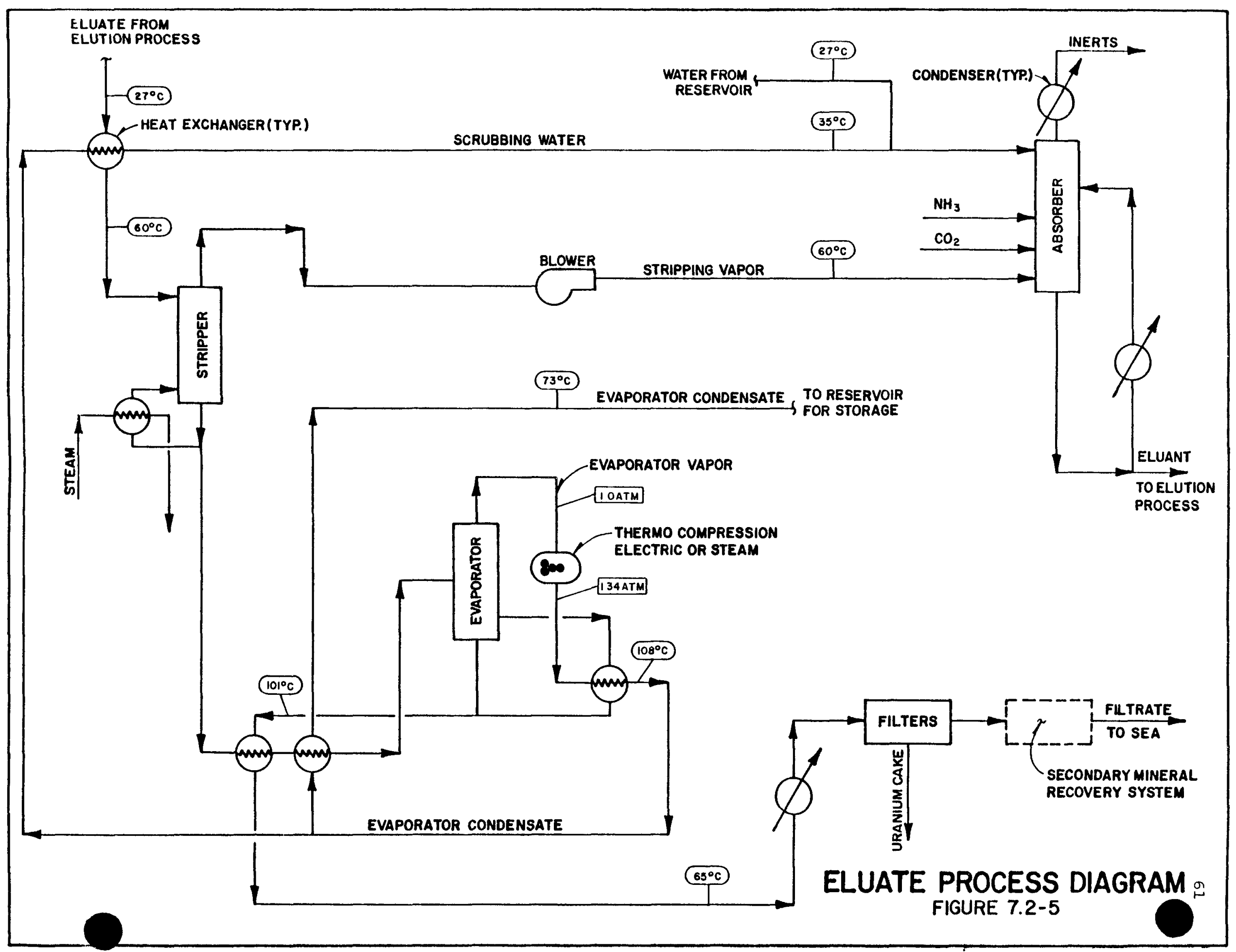


tower is transferred to the bottom of a Rashig ring packed absorber tower through a heated line to prevent condensation of salt crystals.

Additional ammonia and carbon dioxide necessary for the make-up of fresh eluant are also added to the bottom of the tower. The cooled scrubbing water and make-up water are pumped to the top of the tower for the countercurrent absorption of the gases. Part of the absorber bottom flow is recirculated through a cooler and the tower to control the absorber temperature.

The heights of both the stripping and absorber towers were designed based on equilibrium data for an ammonia-water system. Adequate equilibrium data for the ammonia-carbon dioxide-water complex were not readily available in the literature.

Live steam was not used to heat the stripper as reported in the Battelle report [13]. The additional water from steam condensation would decrease the concentration of uranium in solution and increase costs of product recovery.

\subsubsection{Clean-up and Concentration of Uranium Product}

The liquid (stripper bottoms) from the bottom of the stripping tower contains the uranium as ammonium uranyl carbonate, $\left[\left(\mathrm{NH}_{4}\right)_{4} \mathrm{UO}_{2}\left(\mathrm{CO}_{3}\right)_{3}\right]$. According to the Battelle paper [13], precipitation of uranium occurs when the $\mathrm{pH}$ is 7.3 and the solution concentration is above an apparent equilibrium value of $0.005 \mathrm{~g} \mathrm{U} / 1$. The stripper bottoms of less than 0.05 $\mathrm{g} U / 1$ must be concentrated by evaporation to obtain at least a $90 \%$ uranium yield in the eluate processing. Table 7.2-4 compares the estimated concentration of uranium in the stripper bottoms between the static and dynamic systems at an adsorbent capacity of $210 \mathrm{mg} \mathrm{U} / \mathrm{kg} \mathrm{Ti}$.

Table 7.2-4 Uranium concentration in the stripper bottoms

$$
\begin{array}{ll}
\text { Static bed } & 0.006 \mathrm{~g} \mathrm{U} / 1 \\
\text { Dynamic bed } & 0.010 \mathrm{~g} \mathrm{U} / 1
\end{array}
$$

Because the eluant volume was assumed to be four times the volume of the bed materials, an increase in the adsorbent capacity of the bed material will proportionally increase the concentration of uranium in the 
eluant and decrease the steam consumption to process the eluate. Adequate equilibrium data were not readily available to fully evaiuate the effect of reducing the volume ratios of eluant to bed materials. The stripper bottoms liquid was planned to be concentrated by a thermo compression, forced circulation, evaporation unit. The unit was assumed to be operated similarly to a Kleinschmidt portable unit (developed by the armed forces). The vapor from the evaporator is compressed and reused as the heating medium for the evaporator. Heat exchangers are installed to recover the maximum amount of energy between the evaporator influent and effluent flows.

The concentrated liquor from the evaporator is cooled and filtered to remove the uranium from the filtrate. The filtrate is pumped to a secondary mineral recovery system.

\subsubsection{Material and Energy Balance of the Chemical Process}

A complete chemical process material and energy balance was made for the continuous fluidized bed system. Table $7.2-5$ shows the approximate volume flow rates for the streams shown in Figure $7.2-1 \mathrm{C}$ and the ammonia and carbon dioxide content. Figure 7.2-5 shows the significant temperature and operating pressures of the eluate recovery system. The energy consumption for thermo compression was calculated for a mechanical compression system operating at $60 \%$ efficiency and converted to kilograms of steam consumed. The estimated daily steam consumption is 4.6 billion kilograms and 8.1 billion kilograms for stripping and evaporation, respectively.

\subsection{PHYSICAL DESIGN}

\subsubsection{Site Plan Layout}

Based on the process design considerations which establish the basic structural, equipment, flow, and area requirements, conceptual plant layouts were proposed for both the static bed system (Figure 7.3-1) and for the continuous fluidized bed system (Figure 7.3-2) at the selected reference site in Puerto Rico.

As mentioned previously (see Section 7.2.1.2.2), the continuous fluidized bed concept was selected as the most promising, and the following descriptive material relates to this concept. 
Table 7.2-5 Continuous fluidized bed material balance

Flow line

Daily flow (cubic meters)

$510,000,000$

$510,000,000$

1. Raw seawater

2. Filtered raw seawater

3. Acid wash

4. Spent raw seawater

5. Adsorbent slurry

6. Carrier water

7. Adsorbent

8. Prewashed adsorbent

9. Eluted adsorbent

10. Postwashed adsorbent

11. Postwashed adsorbent

12. Fresh adsorbent

13. Adsorbent slurry

14. Fresh water

15. Prewash influent

16. Prewash effluent

17. Scrubbing water

18. Ammonia, carbon dioxide, water vapor

19. Weak eluant

20. Eluant

21. Eluate

22. Ammonium uranyl carbonate

23. Yellowcake slurry

24. Scrubbing water

25. Filtrate

26. Carbon dioxide (Iiquid)

27. Ammonia (liquid)

28. $\mathrm{U}_{3} \mathrm{O}_{8}$

29. Fresh water recovery
$510,000,000$

300,000

270,000

30,000

30,000

30,000

30,000

30,000

90

390,000

150,000

90,000

90,000

60,000

$6,700,000$

120,000

120,000

120,000

114,000

24,000

54,000

24,000

665

870

$1,370 \mathrm{~kg}$

36,000
Component balance

730,000

710,000

$2,050,000$

360,000

170,000

360,000

190,000

190,000

$1,690,000$

$2,060,000$

$4,550,000$

$5,280,000$

$3,230,000$

370,000

570,000

370,000

730,000
1,720,000

0 50,000

460,000

630,000

170,000

170,000

$1,0 y 0,000$

$2,280,000$

$3,510,000$

4,000,000

$2,300,000$

80,000

80,000

80,000

710,000

Reference: Figure 7.2-1C

Basis: Overall plant daily average rates for an adsorbent capacity of $210 \mathrm{mg} \mathrm{U} / \mathrm{kg} \mathrm{Ti}$ 


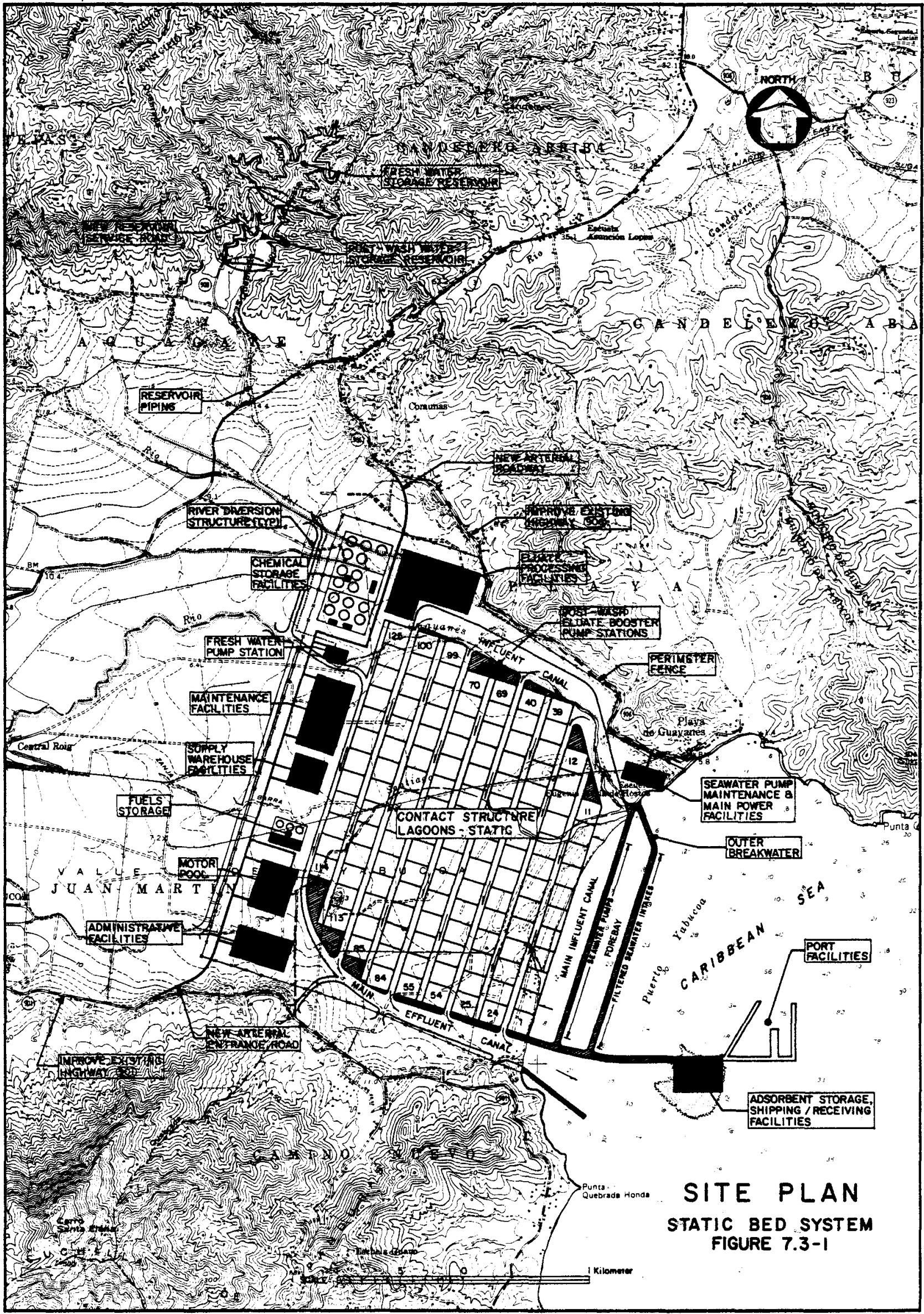




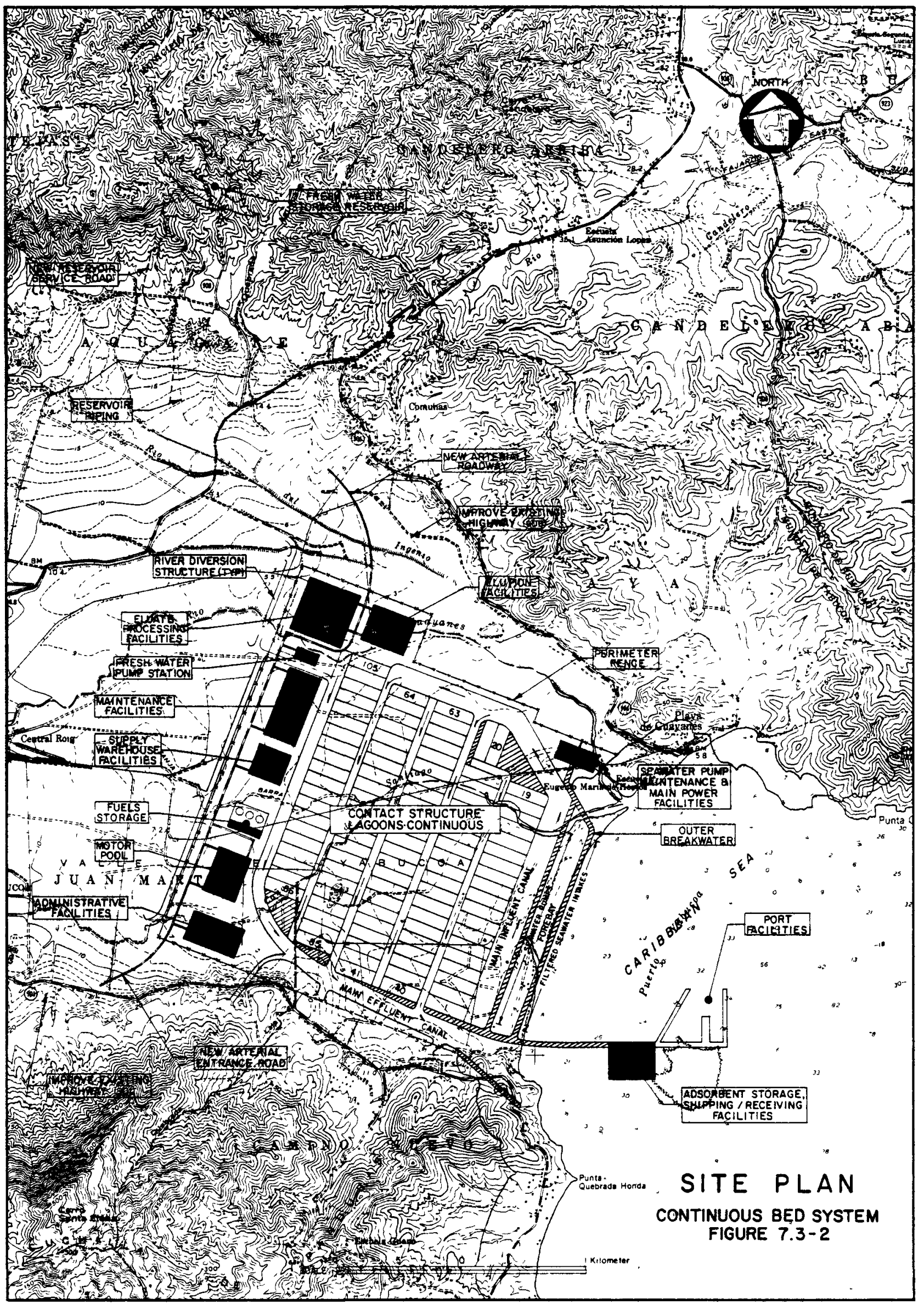




\subsubsection{Seawater Feed System}

\subsubsection{Seawater pump description}

Vertical turbine pumps were selected as the best available equipment for pumping large quantities of seawater. The specified pumps have been developed for large, low hydraulic head irrigation systems and are currently operating in Brazil. Each pump is designed for a flow capacity of 41.3 cubic meters per second. The efficiency of the pump is 094 and the minimum net positive suction is $5.5 \mathrm{~m}$.

Seawater service requires that the pumps be constucted of $316 \mathrm{~L}$ stainless stee1. The suction and discharge of the pump are $6 \mathrm{~m}$ and $\mathrm{j} .7$ $\mathrm{m}$, respectively. The weight of the pump is 102 tonnes.

Each pump requires a 3500 horsepower, vertical open arip-proof motor. The power to the motor must be 3 phase, 00 cycle and 4160 volts.

\subsubsection{Seawater pump installation}

For meeting peak flow and spare equipment requirements for a 500 tonne per year plant with a 10\% surplus capacity, 160 pumps are needed. The seawater pumps are used to maintain a constant head differential between a forebay and an adsorbent bed influent canal system (see Figure 7.3-3). The required head differential above sea level was calculated to be four meters. Variations in flow rate are adjusted by the number of pumps in operation.

Each pump requires a separate bay. The approach velocity to the pumps must be controlled between 0.3 and $0.4 \mathrm{~m} / \mathrm{s}$ and turning vanes must be installed in each bay to reduce flow turbulence. The spacing between pumps was set at $9 \mathrm{~m}$. The total required length of the seawater pump structure is $1470 \mathrm{~m}$.

A water elevation in the forebay of approximately one meter below sea level (see Figure 7.3-3) will permit hydraulic flow through a seawater filter system. The water depth in the forebay is deepened to keep the water velocity less than $0.3 \mathrm{~m} / \mathrm{s}$. The bottom of the forebay must be covered with washed gravel to prevent the resuspension of solids into the filtered seawater.

A large custom-built, rail-mounted crane is required to remove the seawater pumps from their bays for maintenance. The pumps will be transported by rail flatcars to a seawater pump maintenance facility. 


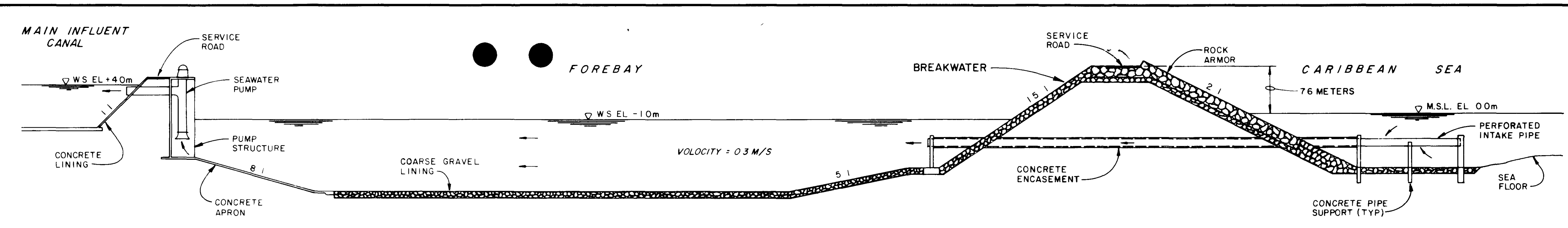

SECTION THRU BREAKWATER AND FOREBAY

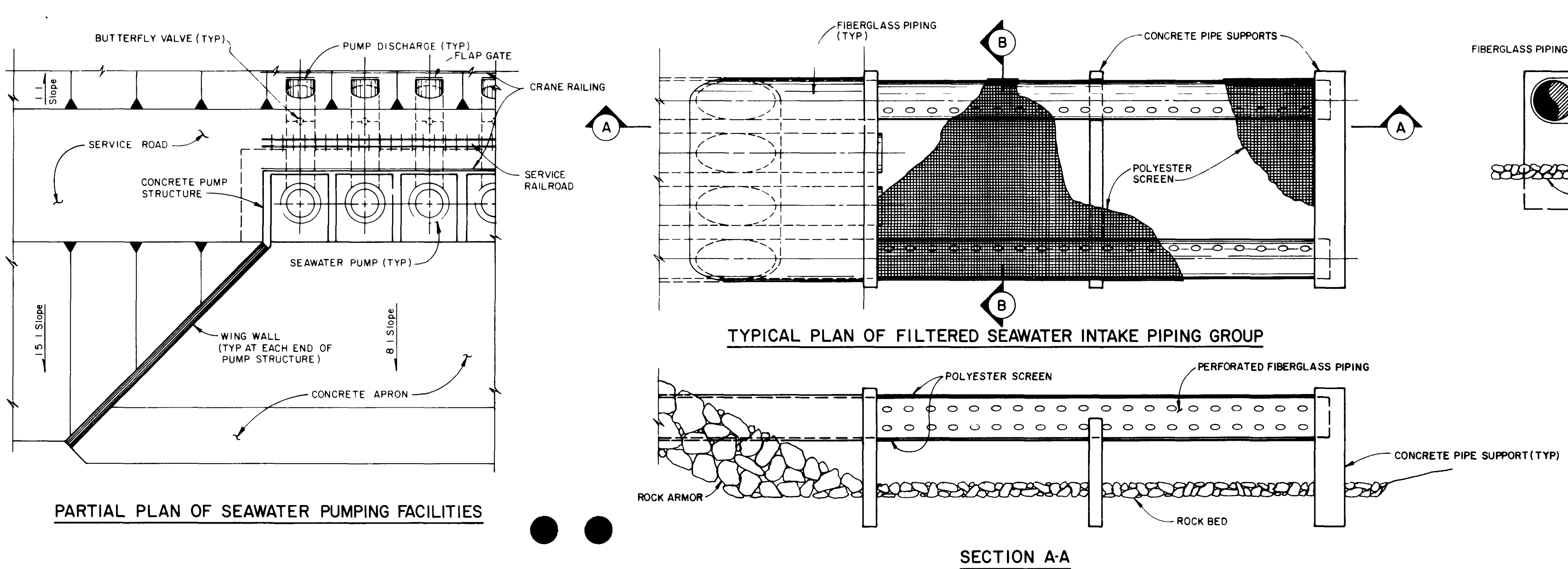

PLANS FOR FILTERS

AND FOREBAY 


\subsubsection{Seawater pretreatment}

The water in the Carribean Sea is predominantly the warm surface waters from the strong equatorial currents of the Atlantic ucean $[20\rfloor$. These waters are nearly void of the nutrients necessary to produce large quantities of biological growth. The solids content of the water has been $r \in$ ported to be 30 micrograms per kilogram of water. The particle size distribution of the solids is bimodal with the majority of the particles less than 10 microns. Approximately $10 \%$ of the particies are reported to be greater than 32 microns. The estimated wet volume of solids, as $20 \%$ dry weight, is 150 liters per million cubic meters of water.

A seawater flow velocity of $0.4 \mathrm{~cm} / \mathrm{s}$ through the adsorbent bed was calculated to be capable of flushing 50 micron sand particles from the adsorbent. The value of 50 microns was selected as the maximum particle size that could be pumped to the beds. A 278 mesh fabric screen was determined to be suitable for the pretreatment of the seawater.

The areas of the screen and the intake pipes (see Figure $7 \cdot \overline{3}-\bar{j}$ ) were sized to limit head loss between the ocean and forebay to $1 \mathrm{~m}$ when $80 \%$ of the effective screen surface was blocked. The daily accumulation of solids was estimated to be 7.6 cubic meters per day. A crew of divers with barges and equipment were included in the operational estimates to maintain the screens.

\subsubsection{Seawater transport}

Open canals (see Figure 7.3-4) were determined as the most cost effective method of carrying large quantities of seawater to the adsorbent beds. Using canals $6 \mathrm{~m}$ deep and approximately $180 \mathrm{~m}$ wide results in a maximum velocity of $5 \mathrm{~m} / \mathrm{s}$. A concrete or asphalt lining must be installed in the canals to prevent erosion. Larger canals resulting in a lower flow rate were considered, but some form of sidewall protection would still be required to minimize erosion from wave action.

\subsubsection{Fresh Water System}

\subsubsection{Source and availability}

The proposed plant site is located over the Yabucoa Valley alluvial aquifer in southeastern Puerto Rico [26]. The aquifer is reported to 


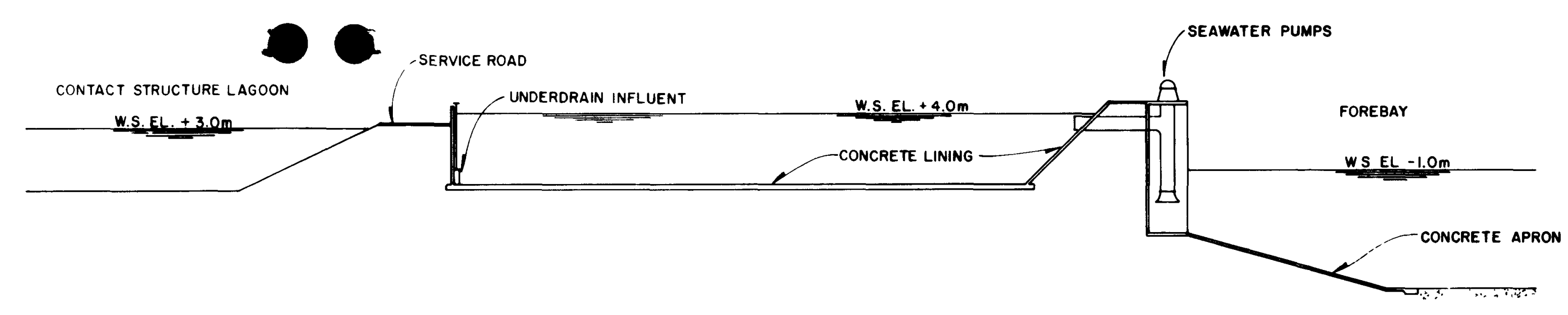

SECTION THRU MAIN INFLUENT CANAL

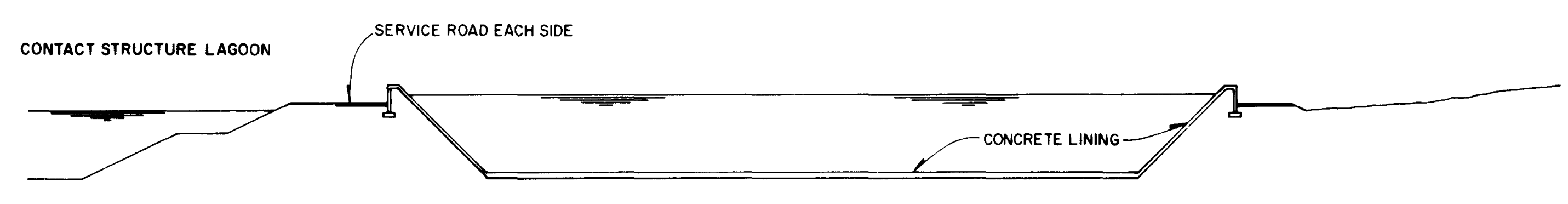

SECTION THRU INFLUENT CANAL

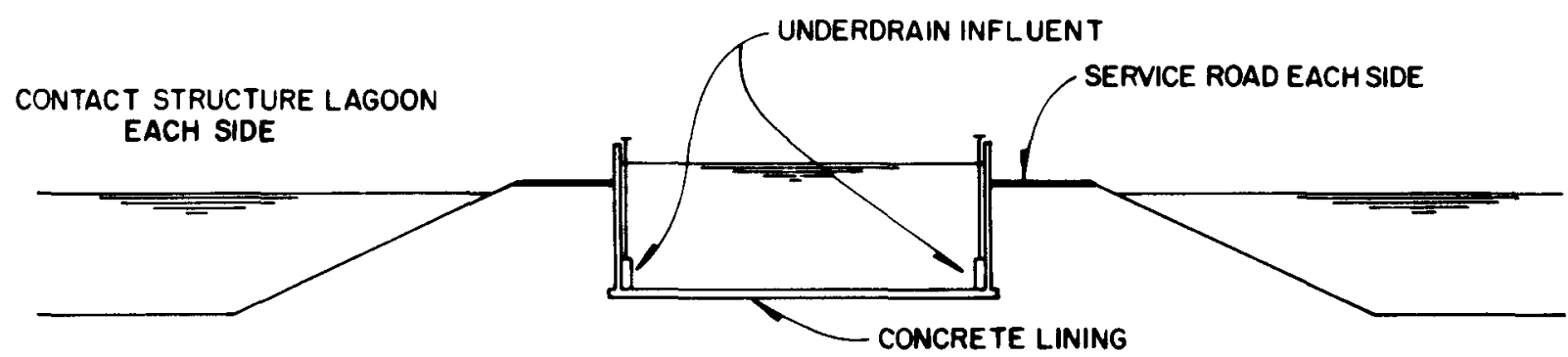

SECTION THRU INFLUENT LATERAL CANAL

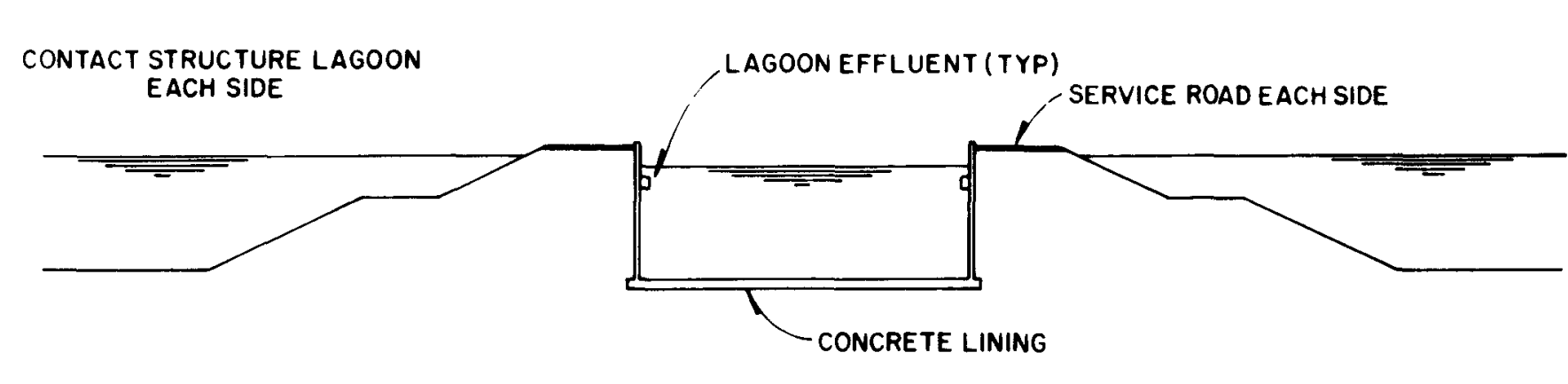

SECTION THRU EFFLUENT LATERAL CANAL

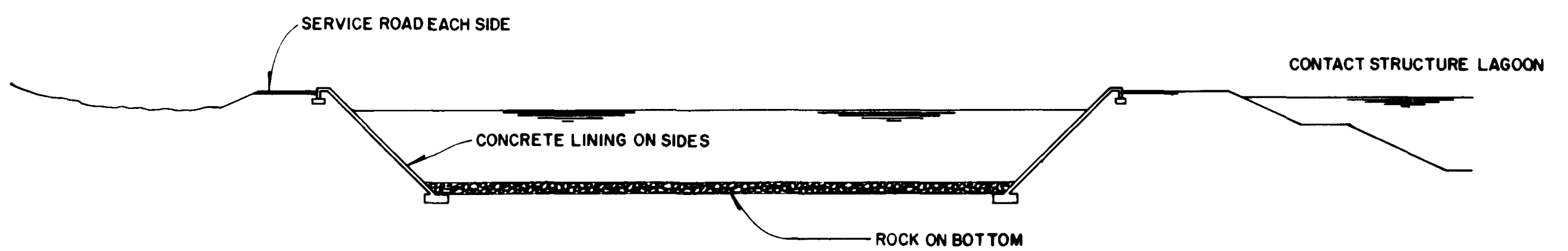

SECTION THRU MAIN EFFLUENT CANAL
INFLUENT AND EFFLUENT

CANALS

FIGURE $7.3-4$ 
contain approximately 230 million cubic meters of fresh water $129 \mathrm{~J}$. The average daily net discharge and recharge of the aquifer is 11,000 cubic meters per day. The total fresh water recharge potential of the aquifer is estimated to be 75,000 cubic meters per day.

The aquifer is recharged by the net runoff in the kio Guayanes Basin. The basin contains approximately 12,800 hectares of land surface and receives approximately $215 \mathrm{~cm}$ of rainfall annually $[30,31]$. The annual evapotranspiration for the basin is estimated to be $105 \mathrm{~cm}$. The annual stream runoff is estimated to be 100 million cubic meters per year. The average daily stream flow is 274,000 cubic meters per day.

The dry period for Puerto Rico occurs from mid-December to April. About $16 \%$ of the rainfall occurs during this period. The reported minimum stream flow to the Yabucoa Valley is approximately 70,000 cubic meters per day, which normally occurs in March.

\subsubsection{Plant fresh water requirements}

A material balance of the flow streams show that the plant will require 114,000 cubic meters of fresh water per day. Potentially, the river system, consisting of the Rio Guayanes, Rio deI Ingenio, and Cano Santiago, can supply $68 \%$ of the fresh water requirements on a year-round basis and all of the requirements during the wet period. During the dry period, fourteen wells pumping from the aquifer can supplement the stream flow to satisfy the demands of the plant.

\subsubsection{Fresh water pumping system}

The fresh water pumping system is planned to meet a peak flow of 200,000 cubic meters per day with one pump out of service. The system is designed to pump from a stream-fed wet well to a pressure balancing ana storage reservoir. The system includes major water pipes, mechanical filtration equipment, chlorination equipment, and pressure regulation equipment.

\section{$7 \cdot 3 \cdot 3.4$ Water storage}

The water storage is an earthen-diked reservoir located in a stream bed on the Yabucoa Valley hillside. The land area of the reservoir is approximately 80 hectares. The storage capacity is $1,410,000$ cubic meters. The reservoir provides approximately 12 days emergency storage for the plant. 


\subsubsection{Waste Water}

7.3.4.1 Sources

The waste water within the plant is derived from three sources: sanitary sewage, spent seawater from the beds, and waste water from the process equipment. The sum of these waste streams becomes the return effluent to the sea.

The sanitary sewage is to be treated by individual package treatment units within the plant. These units are sized to handle 1j0 liters of waste water flow per employee per day. The solids loading per employee per day of the waste is assumed to be $0.08 \mathrm{~kg}$ of biological oxygen demand $\left(\mathrm{BOD}_{5}\right)$ and $0.09 \mathrm{~kg}$ of suspended solids. The total daily sanitary discharge to the plant effluent was estimated to be 91 cubic meters of flow, $8.4 \mathrm{~kg}$ of $\mathrm{BOD}_{5}$, and $9.5 \mathrm{~kg}$ of suspended solids.

Spent seawater from the beds will extract ammonium and carbonate ions contained in the adsorbent returning from the elution and wash process system. The quantities were estimated from Figure A-1 of ORNL-TM-4757 [27] and were assumed to be $70 \mathrm{mg}$ of ammonia and $25 \mathrm{mg}$ of carbon dioxide per gram of titanium. The plant effluent was calculated to receive $460,000 \mathrm{~kg}$ of ammonia and $170,000 \mathrm{~kg}$ of carbon dioxide per day from this source.

The process waste water has two primary sources: the prewash effluent and the yellowcake filtrate. The prewash effluent contains ammonium and carbonate ions extracted from the bed in the final postwash. The concentrations of both are based upon ORNL-TM-475\% [27]. The daily prewash effluent of 90,000 cubic meters was calculated to contain 170,000 $\mathrm{kg}$ of ammonia and $190,000 \mathrm{~kg}$ of carbon dioxide. The filtrate returning to the sea was assumed to contain all the ammonia and carbon dioxide losses from the eluate process system. These daily losses contained in 24,000 cubic meters of flow were estimated to be $80,000 \mathrm{~kg}$ of ammonia and $370,000 \mathrm{~kg}$ of carbon dioxide.

\subsubsection{Waste impact}

Seawater is reported to contain 0.005 to $0.05 \mathrm{mg}$ per liter of ammonia and $28 \mathrm{mg}$ per liter inorganic carbon [32j. The plant effluent will have the largest effect on the ammonia content. The Caribbean seawater is nearly depleted of nutrients; therefore, the lower ammonia concentration $(0.005 \mathrm{mg} / 1)$ was assumed. The plant effluent is estimated to increase the ammonia concentration in the ambient sea by $28 \%$. 


\subsubsection{Raw Materials}

\subsubsection{New adsorbent storage}

The adsorbent inventory is assumed to lose $0.3 \%$ of the material tranferred to the wash and elution equipment. The loss is calculated to be 90 cubic meters daily, or 33,000 cubic meters annually. Approximately 3.5 shipments per year by medium sized ore carrier would be required to maintain the adsorbent inventory. Storage is planned for 12,000 cubic meters to prevent excessive demurrage of the carrier and is located in the planned warehouse on the reef near the port facilities.

\subsubsection{Adsorbent handling}

The adsorbent is assumed to be handled by heavy construction loaders and moved around the site by large trucks. A summary of the required equipment is included in the mobile equipment inventory.

\subsubsection{Liquid gas handling}

The ammonium carbonate eluant is assumed to be manufactured from liquified ammonia and carbon dioxide. These are to be brought into the port facilities by bulk tankers and pumped to the bulk storage sites as shown on the site plan (see Figure 7.3-2). The material estimates for the transporation system were based on a pipeline inside of an evacuated casing to prevent excessive heat gain into the liquified material.

\subsubsection{Ammonia storage}

The ammonia is stored as a liquid in insulated, cylindrical, atmospheric storage tanks. Compressors to compress the vapors and maintain a constant temperature for the liquified gas are included in the estimate. Four tanks of 6,800 cubic meters each were estimated to provide a 30 day plant supply. 


\subsubsection{Carbon dioxide storage}

Carbon dioxide is either a solid or a gas at atmospheric pressure. The Iiquified gas must be handled at pressures above 5 atmospheres to prevent solidification.

The liquified gas is planned to be stored in eighteen 1,100 cubic meter insulated gas spheres. Compressers are included to maintain adequate pressure and temperature. It is estimated that the spheres will provide a storage of 30 days.

\subsubsection{Eluant and eluate pumping and storage}

The continuous plant concept is assumed to be capable of manufacturing eluant and processing eluate on a demand basis. Spare equipment with pumps to meet the peak daily demand with one set of process units shut down are included in the estimate. No extra tankage for surge control is included in the estimate.

\section{$7 \cdot 3 \cdot 5 \cdot 7$ Other material}

Extra warehouse floor space is planned for the receiving and shipping of miscellaneous materials. The warehouse space was located on the reef near the port facilities.

\subsubsection{Support Facilities}

\subsubsection{Electrical systems}

The electrical estimate is based on the site receiving approximately $450 \mathrm{MW}$ at 13,800 volts, three phase from a local utility. The power would be transmitted to the various facilities on site at 13.6 kilovolts and stepped down to the utilization voltage level as required. All pumps larger than 250 horsepower would be operated at 4,800 volts. Buildings would be supplied power at $480 Y / 277$ volts. 


\subsubsection{Maintenance areas}

An inventory of the operating equipment and site facilities was made for the proposed plant. From this inventory an estimate was made of the type and size of maintenance area required to maintain the plant. Five maintenance shops were considered: seawater pump maintenance, site maintenance, instrumentation maintenance, vehicular and heavy mobile equipment maintenance, and a process facilities maintenance. These shops provide space and facilities for lubrication, inspection, general repair and replacement of major assemblies, painting, welding, cleaning, and minor parts fabrication. They also house the support functions, such as maintenance control, tool room, parts room, toilets, locker room, and administrative office. Except for the seawater pump maintenance facility, all maintenance shops are centrally located on the west side of the site. The seawater pump maintenance facility is located at the north end of the seawater pump dike, because the bulk of the pumps makes it impractical to transport the pumps a great distance.

\subsubsection{Port facilities}

The port facilities (see Figure 7.3-5) are designed as a receiving area for the construction and operation of the plant. The harbor is formed by constructing three rock-mound breakwaters in a triangular shape, and a pier which extends from the south breakwater. The two-berth pier would accomodate two medium sized ships with a draft of $11 \mathrm{~m}$. The shallow portion of the harbor, with a minimum depth of $5.5 \mathrm{~m}$, is allocated for ship-docking tugs and small boats. Two rail-mounted cranes would be placed on each side of the pier for the unloading of the cargo ships. The transit buildings located on the pier would store approximately two cargo shiploads of material. This would later be transported to the supply warehouse facility and other areas of the plant. An open storage area for items not needing protection from the elements would be located west of the site.

\subsubsection{Site transportation}

The plant would require a main arterial roadway which runs through the west portion of the plant from Road No. 901 to Road No. 906, and secondary plant roads between and around support and process facilities, around lagoons, and along main canals and dikes. Since the volume of truck traffic would increase along Roads No. 901 and 906 , improvement of these roads was assumed to be necessary. Asphalt concrete pavement, bituminous surface treatment, and gravel roadways are considered the required surfacing, depending on the size and volume of traffic. 


\subsubsection{Storm drainage}

A river diversion structure runs along the west boundary of the proposed plant. This structure would divert the flow of the major rivers and the surface water west of the plant to the fresh water pump station, allowing full utilization of the surface water for plant use. All surface areas within the site would be sloped toward the canal system to allow for storm runoff.

\subsubsection{Offices}

An administrative facility would be located in the southwest corner of the site to house the main administrative personnel. The administrative facility would house management personnel, accounting personnel, purchasing, site engineering, records, health and safety, environmental control, and other administrative personnel, as well as a cafeteria and a quality control laboratory.

Other office facilities are control buildings. These buildings include plans for lunchrooms and sanitary facilities.

\subsubsection{Geographical area requirement and site development}

The total geographical area requirements are: 8,000 hectares for the basic plant area; 200 hectares for pipelines and roadway rights of way; 200 hectares for port and storage facilities; 900 hectares for a fresh water reservoir; and 1,000 hectares of sea floor for the forebay and miscellaneous areas.

The site would be developed and facilities laid out to take full advantage of the natural site contours and the plant operations. The major item in the site development is the contact structure lagoons. Huge quantities of earthwork at near sea level conditions require extra costs in dewatering and well pointing. The lagoons must be located adjacent to the sea, as shown on the site plans, Figures $7 \cdot 3-1$ and $7.3-2$, to reduce the energy required for pumping large volumes of seawater and to minimize the length of the main seawater transmission system.

The lagoons are laid out in rows with two rows sharing an influent and effluent canal. This arrangement decreases the number of canals required. The flow in the lagoons is from north to south, which is the same direction as the predominant sea current. This allows the effluent to be discharged down current from the seawater intake. The port facility and the port transportation dike would act as a barrier between the influent and effluent canals. 
The port facility would be located to take advantage of the natural sea canal and the coral reef. The shallow area would be filled in to make a man-made island which would house the Adsorbent Storage Facility and an open storage area (see Figure 7.3-5 for plan and sections of the port facilities).

The forebay parallels the influent channel to reduce dredging costs. The outer forebay dike houses the filters required to purify the seawater and would act as a breakwater which would shelter the seawater pumps and contact structures.

The Process and Support Facilities would be located to the west of the lagoons to take advantage of the higher ground and more sheitered location.

The eluate process areas would be located on the northwest corner of the site so that the process piping from the beds and fresh water supplies can be minimized. They would be close to the secondary access road, Road No. 906 .

The fresh water pump station would be located next to the Rio Guayanes. All of the other surface water would be directed to this facility by storm diversion channels. This would enable the pump station to utilize the majority of the surface water from the valley.

The Vehicle, Site Engineering, Instrumentation, and Process Maintenance shops would be located in the area designated Maintenance Facilities. All of these facilities would be located together to make a central maintenance area for the majority of the maintenance requirements.

The seawater pump maintenance shop would not be located in the maintenance shop cluster, because the bulk of the pumps makes it impossible to transport them a great distance.

The Supply Warehouse Facility would be located near the Maintenance and Process Facilities. This would make it centrally accessible to all facilities requiring shipping and receiving services.

\subsubsection{Mobile equipment}

There are five types of mobile equipment necessary for plant operation: personnel transportation, site maintenance, material handling, general use, and miscellaneous mobile equipment. An estimate of the equipment required is outlined in Table 7.3-1. 
Table 7.3-1 Mobile equipment

TYPE

NUMBER REQUIRED

Personnel Transportation

Sedan

20

Pickup truck

Site Maintenance

Compactor (ditch)

Water truck

Backhoe

Grader

Front end loader

Paving machine

Roller - road

Self-propelled rotary sweeper

Tractor

Dump truck

Truck mounted crane

Mobile compressor

Lawn mower

Towed mower

Mobile power unit

Mobile welding truck

Lubrication truck

100-tonne mobile crane

Material Handling

Warehouse crane

Semitrailer flat bed

Flat bed truck

Forklift

Dump truck

General Use

Ambulance

Refuse truck

Fuel truck

Telephone and communication truck

Wrecker truck

Fire truck

Miscellaneous

Ship docking tugboat

Small personnel transport boat

Barge tugboat

Sea filter waste barge

Sea filter cleaning barge 
A motor pool which would distribute and care for plant sedans and pickups would be located between the administrative facility and fuels storage.

\subsection{CAPITAL ESTIMATING BASIS}

In addition to the drawings referred to and incorporated in this report, extensive material take-off sheets were prepared by the process and plant designers as a basis for extension to a complete capital cost estimate by personnel having many years of experience with major industries on large international projects.

\subsection{OPERATING COSTS - ESTIMATING BASIS}

The unit cost estimates for raw materials, power, steam, and labor required for plant operations were derived as shown in Tables $7.5-1,7.5-2$, and $7.5-3$.

Table 7.5-1 Chemical and energy unit cost summary

Ad sorbent: $\$ 1.10 / \mathrm{kg}$

Estimated 1979 cost. Estimate arrived at through discussion with Glidden Pigments Corporation and by reference to the Chemical Marketing Reporter, January 8, 1979.

Ammonia: $\$ 120 / \mathrm{ton}$, or $\$ 0.13 / \mathrm{kg}$

Quoted in Chemical Marketing Reporter, January $6,1979$.

Liquid carbon dioxide: $\$ 50 /$ ton, or $\$ 0.055 / \mathrm{kg}$

Estimated 1979 cost. Estimate arrived at through discussion with AirCo Products.

Process steam: $\$ 4.50 /$ million BTU, or $\$ 4.27 / 1000 \mathrm{MJ}$

Electricity: $\quad \$ 0.0218 / \mathrm{kW}-\mathrm{hr}$

Data from Exxon Research and Engineering 
Table 7.5-2 Labor cost summary

\begin{tabular}{|c|c|c|c|}
\hline Category & $\begin{array}{c}\text { Average Annual } \\
\text { Salary PI us } \\
\text { Burdenen } \\
\end{array}$ & $\begin{array}{c}\text { Staff } \\
\text { Required } \\
\end{array}$ & Annual Cost \\
\hline $\begin{array}{l}\text { Supervision and } \\
\text { Administrative } \\
\text { Support }\end{array}$ & $\$ 30,000$ & 176 & $\$ 5,280,000$ \\
\hline Highly Skilled & 17,500 & 219 & $3,8>2,500$ \\
\hline Semi-skilled & 12,500 & 211 & $2,637,500$ \\
\hline Unskilled & 7,500 & 94 & 705,000 \\
\hline & & 700 & $\$ 12,455,000$ \\
\hline
\end{tabular}


Table 7.5-3 Plant staffing requirements

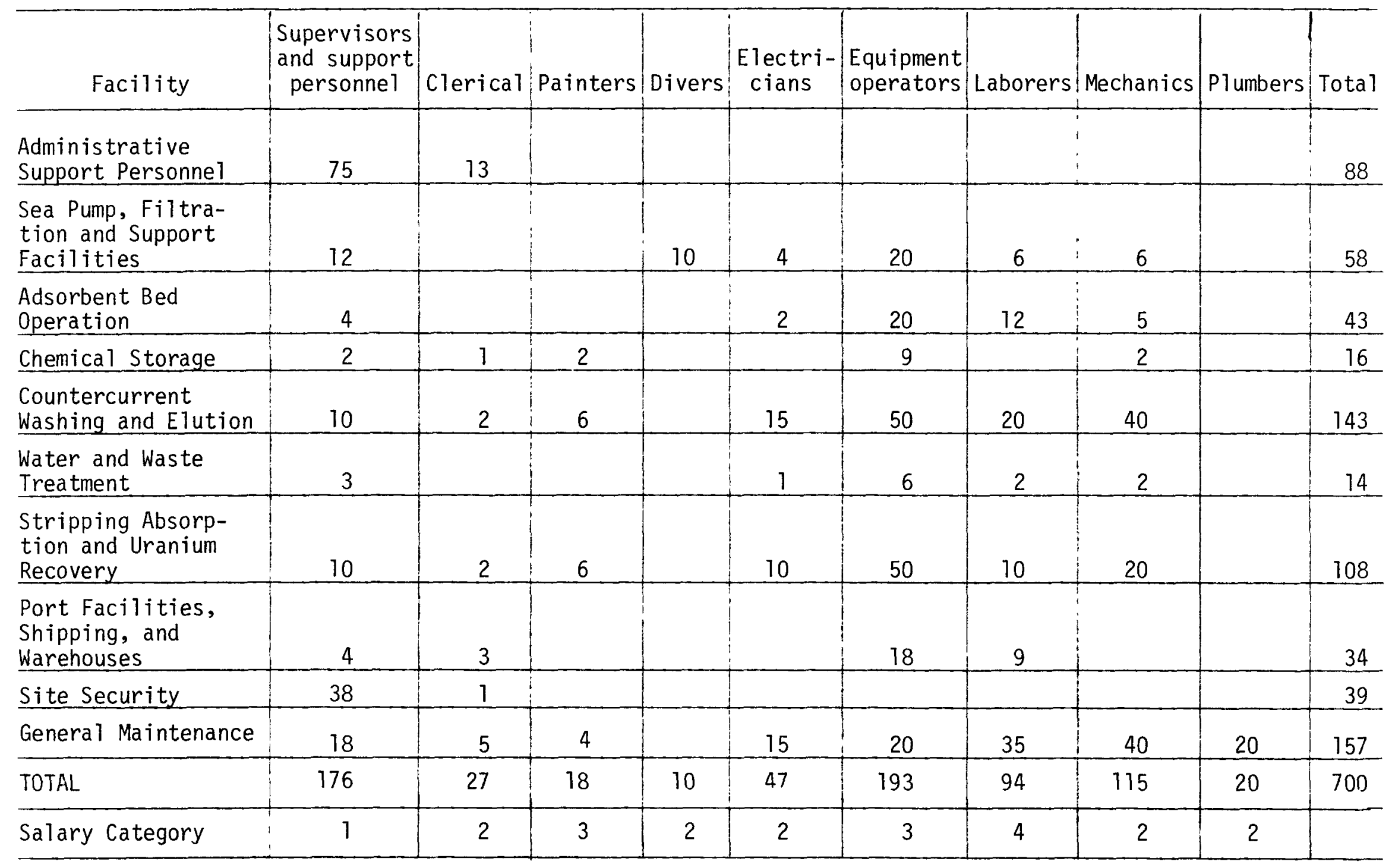


CHAPTER 8

CAPITAL COST ESTIMATE - CONTINUOUS FLUIDIZED BED SYSTEM

The capital cost for the conceptual design of the continuous fluidized bed uranium recovery facility, utilizing adsorbent beds with a loading capacity of $210 \mathrm{mg} \mathrm{U} / \mathrm{kg} \mathrm{Ti}$, is estimated to be $\$ 6.2$ billion ( 1978 dollars). The estimate was based on the engineering study and concepts described in the previous chapters and is qualified in the following sections. A summary of the capital cost estimate is presented in Table 8.0-1.

An overall summary of major material quantities required is presented in Table 8.0-2 which illustrates the very large amounts of materials which must be handled and constructed for this facility.

Published cost information relative to large water handing facilities such as waste water treatment plants can be used to develop a rough verification of the order of magnitude capital costs developed herein. Scaling factors for the construction cost of various unit operations utilized in waste water treatment plants have been published by the Environmental Protection Agency, of fice of Water Operations, in document EPA 430/9-77-013, "Construction Costs for Municipal waste water Plants 1973-1977", prepared by Dames \& Moore Water Pollution Control Engineering Services, Denver, Colorado. The following equation for roughly estimating the construction costs for water filtration (presumed to refer to sand filters) is extracted from Table 6.10 of EPA 430/9-77-013.

$$
C=1.85 \times 10^{5} \times Q^{0.84}
$$

where $C$ is the construction cost in dollars and $Q$ is the water flow rate in millions of gallons per day. Using this equation, a filtering plant handling a water flow rate of 135,000 million gallons/day would be expected to cost about:

$$
\left(1.85 \times 10^{5}\right)(135,000)^{0.84}=\$ 3.8 \text { billion }
$$


Table 8.0-1 Cost estimate (Puerto Rico Site)

(Continuous fluidized bed with $210 \mathrm{mgU} / \mathrm{kg} \mathrm{Ti}$ loading)

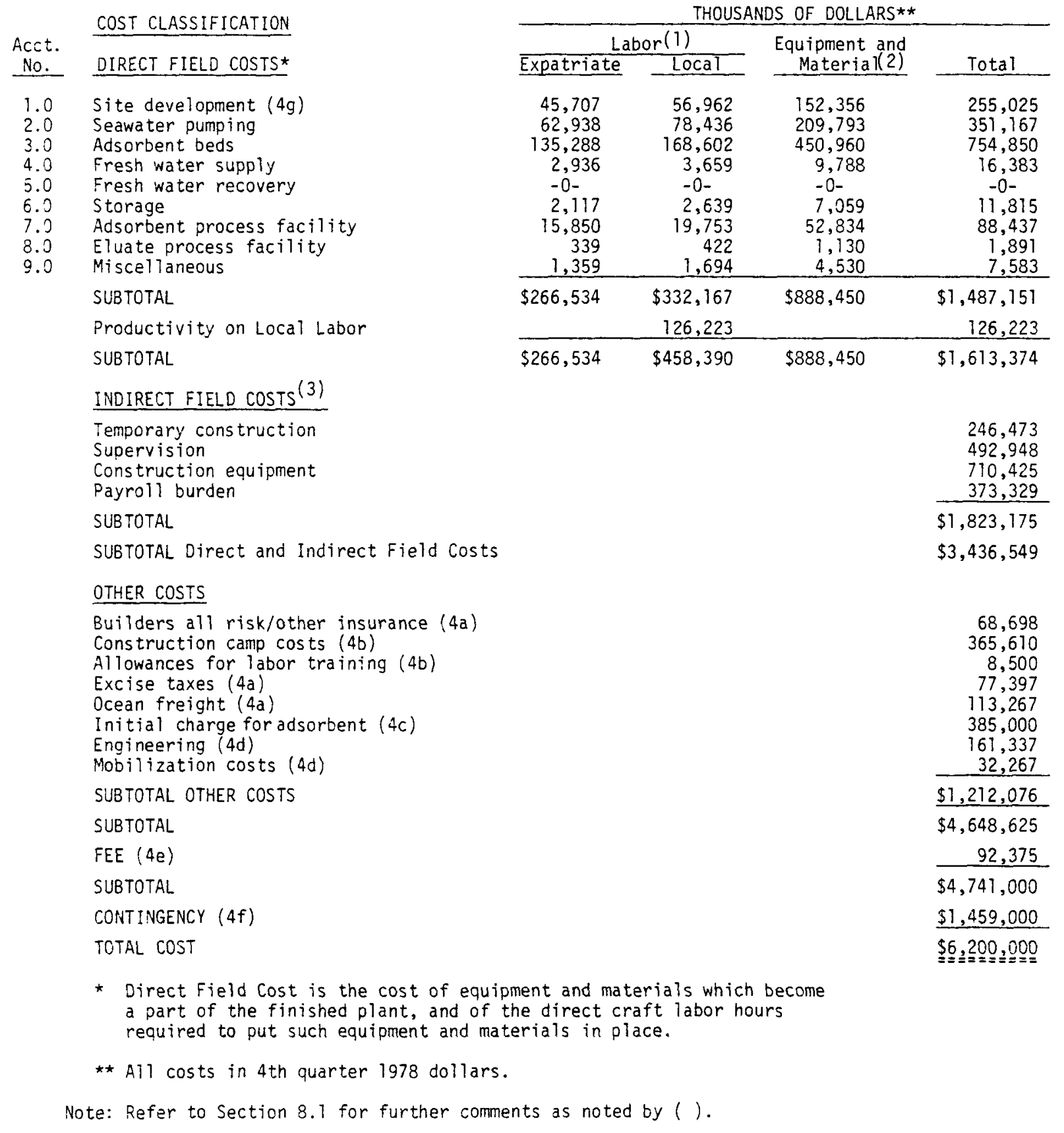


This can then be compared to the cost of the adsorbent beds in the uranium recovery plant design. From the cost data given in Table $8.0-1$, it was calculated that the adsorbent beds represent about $47 \%$ of the total constructed cost of $\$ 6.2$ billion, or approximately $\$ 2.9$ billion.

Table 8.0-2 Summary of estimated quantities (reference case)

Item

Clearing and grubbing

Excavation and grading

Rockfill (all types)

Paved roads

Other roads

Bridges

Drainage piping

Drainage ditches

Coffer dams

Dewatered area

Concrete

Buildings

Fencing

Piling

Sheet

Other

Rock anchors

Stainless steel grating (adsorbent beds)

Stainless steel plate (adsorbent beds)

Structure steel (adsorbent beds)

Piping

Reinforced plastic

Carbon steel

Crane rail
Approximate Quantity

780 hectares $36,644,000$ cubic meters $13,700,000$ cubic meters 580,000 square meters

472,000 square meters 14

12,000 meters

30,000 meters

635,000 square meters

710 hectares

$1,82 \overline{3}, 000$ cubic meters

282,000 square meters

9,000 meters

161,000 square meters

228,000 meters

817,000 cubic meters

$15,030,000$ square meters

20,700 tonnes

14,000 tonnes

356,000 meters

64,000 meters

9,300 meters

\subsection{BASIS FOR ESTIMATE}

The capital cost estimate was developed from the preliminary flowsheets, drawings, and material quantity summaries defined by the conceptual design study. 
This estimate represents a present-day total erected cost at the Puerto Rico location. It includes the costs for engineering services, procurement and delivery of all materials to the site, and the construction of the facility through the mechanical completion and checkout phases. The facility basis includes the construction of reservoirs for fresh water, but assumes that purchased electric power and steam will be available at the site perimeter.

The basic pricing data used in this estimate were adjusted to fourth quarter 1978 cost levels and were derived as follows:

(1) Direct labor costs were based on the use of both local and expatriate labor for construction. Approximately $85 \%$ of the total labor requirement would be met by use of Puerto Rican labor. The labor costs were developed from current average wage rate data for Puerto Rico and U. S. Gulf coast locations, and reflect a 40-hour week, one shift construction operation.

(2) Major plant equipment and bulk materials costs were based on supply of all materials from U. S. locations and transportation by ocean freight to the Puerto Rico site location.

(3) Indirect field costs are factored as a percentage of direct labor costs and include temporary construction, consumable materials, field supervisory staff, payroll burden, and construction equipment.

(4) Other costs:

(a) Allowances for Builders All Risk Insurance, ocean freight and marine insurance, and local excise taxes were included in the estimate based on the material cost included.

(b) Allowances for a construction camp to serve the construction force and for training of the craft labor group were included in the estimate.

(c) The estimate included the initial charge of the hydrous titanium oxide adsorbent material as a capital cost.

(d) Allowances for engineering services and mobilization costs were included as a percentage of the total field costs estimated for the facility.

(e) An allowance for a construction fee was inciuded, based on the total value of the project.

(f) An estimated contingency of $30 \%$ was also applied to cover risks and uncertainties associated with the process basis and the preliminary nature of the project definition.

(g) Allowance for land costs at approximately $\$ 5000 /$ hectare was included with the costs for site development. 


\subsection{ESTIMATE EXCLUSIONS}

Costs for the following major items related to the development of this project were excluded from the capital cost estimate:

- Research and development costs to resolve process uncertainties prior to the start of detailed engineering for the facility

- Costs for initial site evaluation and alternative site studies necessary to adequately define site characteristics as a basis for definitive engineering

- Costs for purchase and removal or relocation of any existing facilities or housing which may be located on the planned site

- Owner's costs for all required process royalties, permits, licenses, and environmental surveys and reports necessary to obtain approval for construction of the facility

- Special labor premiums or overtime allowances for construction

- All financing costs which may be associated with design and construction of the facility

- Allowances for spare parts and materials

- Allowance for future cost escalation

8.3 COST ESTIMATE ASSUMING $2100 \mathrm{mg}$ U/kg Ti ADSORBENT LOADING CAPACiTY

It was early recognized that the adsorbent loading capacity has a direct relationship to the frequency, or rate, at which the adsorbent must be processed through the wash and elution cycle, and, therefore, on overall production costs. Also, there are some indications in the literature that an adsorbent might be developed with a greatly increased loading capacity. The Technical Review Committee for this project therefore suggested that construction and operating costs be considered on the postulation of an adsorbent with a ten-fold increase in loading capacity, i.e., $2100 \mathrm{mg} \mathrm{U} / \mathrm{kg} \mathrm{Ti}$. 
Table 8.3-1 Cost estimate (Puerto Rico Site)

(Continuous fluidized bed with $2100 \mathrm{mg} \mathrm{U} / \mathrm{kg} \mathrm{Ti}$ loading)

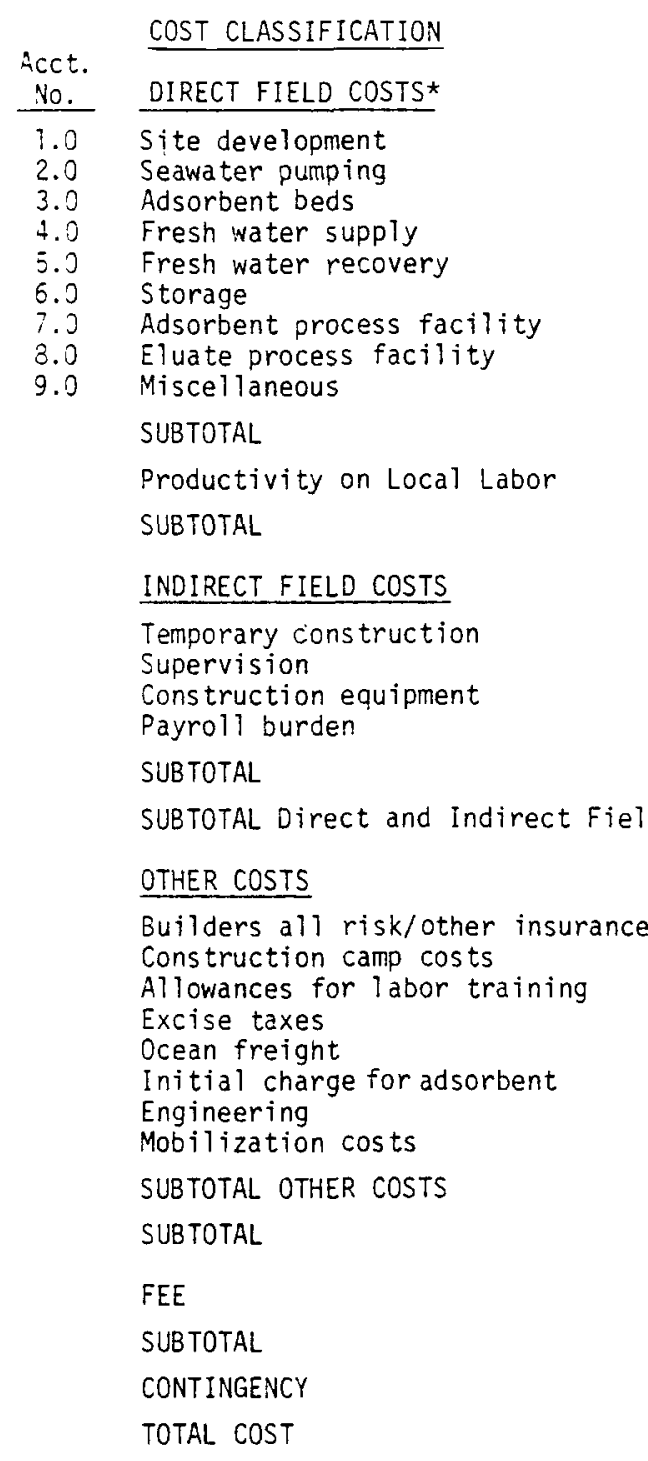

INDIRECT FIELD COSTS

Temporary construction

Supervision

Payroll burden

SUBTOTAL

SUBTOTAL Direct and Indirect Field costs

OTHER COSTS

Construction camp costs

Allowances for labor training

Excise taxes

Initial charge for adsorbent

Engineering

Mobilization costs

SUBTOTAL OTHER COSTS

FEE

TOTAL COST

THOUSANDS OF DOLLARS**

\begin{tabular}{|c|c|c|c|}
\hline \multicolumn{2}{|c|}{ Labor } & \multirow[b]{2}{*}{ Materia1 } & \multirow[b]{2}{*}{ Total } \\
\hline Expatriate & Loca 1 & & \\
\hline $\begin{array}{r}45,707 \\
62,938 \\
134,920 \\
2,546 \\
-0- \\
562 \\
2,502 \\
339 \\
1,359 \\
\end{array}$ & $\begin{array}{r}56,962 \\
78,436 \\
168,143 \\
3,173 \\
-0- \\
701 \\
3,119 \\
422 \\
1,694 \\
\end{array}$ & $\begin{array}{r}152,356 \\
209,793 \\
449,732 \\
8,488 \\
-0- \\
1,876 \\
8,342 \\
1,130 \\
4,530 \\
\end{array}$ & $\begin{array}{r}255,025 \\
351,167 \\
752,795 \\
14,207 \\
-0- \\
3,139 \\
13,963 \\
1,891 \\
7,583 \\
\end{array}$ \\
\hline \multirow[t]{2}{*}{$\$ 250,873$} & $\$ 312,650$ & $\$ 883,247$ & $\$ 1,399,770$ \\
\hline & 118,489 & & 118,489 \\
\hline$\$ 250,873$ & $\$ 431,139$ & $\$ 883,247$ & $\$ 1,518,259$ \\
\hline
\end{tabular}

$$
\begin{array}{r}
231,884 \\
463,768 \\
668,371 \\
275,357 \\
\hline \$ 1,639,380 \\
\$ 3,157,639
\end{array}
$$

63,640

317,670

7,209

73,592

125,437

385,000

151,825

30,365

$\$ 1,148,738$

$\$ 4,306,377$

86,127

$\$ 4,392,504$

$\$ 1,317,496$

$\$ 5,710,000$

* Direct Field Cost is the cost of equipment and materials which become a part of the finished plant, and of the direct craft labor hours required to put such equipment and materials in place.

* All costs in 4 th quarter 1978 dollars. 
Table 8.3-1 shows the capital cost for this hypothetical situation. There is about an $8 \%$ reduction compared to the reference design case. Associated production costs are discussed in Chapter 10. Table $6 . \bar{j}-\bar{z}$ presents a summary of major material quantities required for this design.

Table 8.3-2 Summary of estimated quantities (increased loading)

Item

Clearing and grubbing

Excavation and grading

Rockfill (all types)

Paved roads

Other roads

Bridges

Drainage piping

Drainage ditches

Coffer dams

Dewatered area

Concrete

Buildings

Fencing

Piling

Sheet

Other

Rock anchors

Stainless steel grating (adsorbent beds)

Stainless steel plate (adsorbent beds)

Structure steel (adsorbent beds)

Piping

Reinforced plastic

Carbon steel

Crane rail

\author{
Approximate Quantity \\ 780 hectares \\ $36,644,000$ cubic meters \\ $13,700,000$ cubic meters \\ 580,000 square meters \\ 472,000 square meters \\ 14 \\ 12,000 meters \\ 30,000 meters \\ 71,000 square meters \\ 710 hectares \\ $1,825,000$ cubic meters \\ 31,300 square meters \\ 9,000 meters \\ 18,000 square meters \\ 226,000 meters \\ 817,000 cubic meters \\ $1,670,000$ square meters \\ 20,700 tonnes \\ 13,600 tonnes \\ 356,000 meters \\ 64,000 meters \\ 9,300 meters
}


8.4 COST ESTIMATE FOR A STATIC BED DESIGN ASSUMING $210 \mathrm{mg} \mathrm{U} / \mathrm{kg}$ Ti LOADING CAPACITY

As mentioned in Section 7.2.1.2.2, the continuous fluidized bed concept was selected for the reference design on the basis of a preliminary judgment of relative costs. Subsequent to this decision, a material takeoff for a static bed design was prepared which was extended to the full cost estimate shown in Table 6.4-1. Total capital requirements are estimated to $b \in \$ 7.1$ billion, as compared to $\$ 0.2$ billion for the $r \in f e r e n c e$ case (continuous fluidized bed). Table 6.4-2 presents a summary of major material quantities required for this design. 
Table 8.4-1 Cost estimate (Puerto Rico Site)

(Static bed with $210 \mathrm{mg} \mathrm{U} / \mathrm{kg} \mathrm{Ti}$ loading)

\begin{tabular}{ll} 
Acct. & COST CLASSIFICATION* \\
No. & DIRECT FIELD COSTS \\
\hline 1.0 & Site development \\
2.0 & Seawater pumping \\
3.0 & Adsorbent beds \\
4.0 & Fresh water supply \\
5.0 & Fresh water recovery \\
6.0 & Storage \\
7.0 & Adsorbent process facility \\
8.0 & Eluate process facility \\
9.0 & Miscellaneous \\
& SUBTOTAL \\
& Productivity on local labor \\
& SUBTOTAL
\end{tabular}

INDIRECT FIELD COSTS

Temporary construction

Supervision

Construction equipment

Payroll burden

SUBTOTAL

SUBTOTAL Direct and Indirect Field costs

OTHER COSTS
THOUSANDS OF DOLLARS**

\begin{tabular}{|c|c|c|c|}
\hline \multicolumn{2}{|c|}{ Labor } & \multirow[b]{2}{*}{ Material } & \multirow[b]{2}{*}{ Total } \\
\hline Expatriate & Local & & \\
\hline $\begin{array}{r}45,865 \\
62,938 \\
174,561 \\
6,600 \\
891 \\
2,729 \\
-0- \\
4,312 \\
1,359 \\
\end{array}$ & $\begin{array}{r}57,160 \\
78,436 \\
217,546 \\
8,225 \\
1,111 \\
3,401 \\
-0- \\
5,374 \\
1,694 \\
\end{array}$ & $\begin{array}{c}152,884 \\
209,793 \\
581,869 \\
22,000 \\
2,972 \\
9,098 \\
-0- \\
14,375 \\
4,530 \\
\end{array}$ & $\begin{array}{c}255,909 \\
351,167 \\
973,976 \\
36,825 \\
4,974 \\
15,228 \\
-0- \\
24,061 \\
7,583 \\
\end{array}$ \\
\hline$\$ 299,255$ & $\begin{array}{r}\$ 372,947 \\
141,720\end{array}$ & $\$ 997,521$ & $\begin{array}{r}\$ 1,669,723 \\
141,720\end{array}$ \\
\hline$\$ 299,255$ & $\$ 514,667$ & $\$ 997,521$ & $\$ 1,811,443$ \\
\hline
\end{tabular}

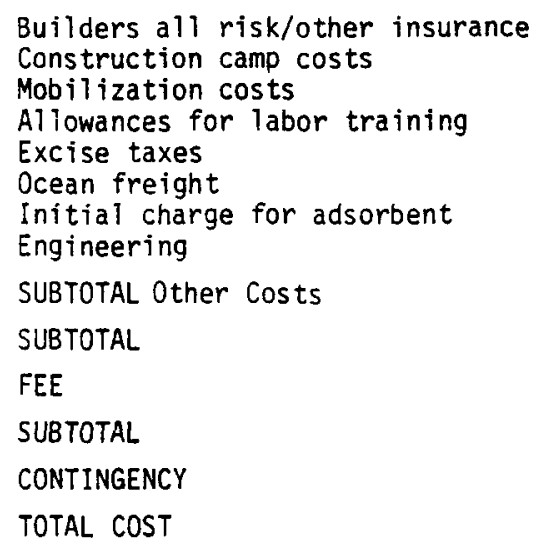

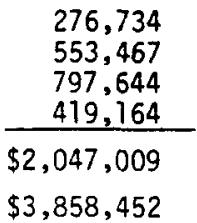

67,000

610,000

36,000

12,000

85,000

150,000

385,000

182,000

$\$ 1,527,000$

$\$ 5,385,452$

107,709

$\$ 5,493,161$

$\$ 1,647,949$

$\$ 7,141, ? 10$

* Direct Field Cost is the cost of equipment and materials which become a part of the finished plant, and of the direct craft labor hours required to put such equipment and materials in place.

$\star \star A 11$ costs in 4 th quarter 1978 dollars. 
Table 8.4-2 Summary of estimated quantities (static bed)

Item

Clearing and grubbing
Excavation and grading
Rockfill (all types)
Paved roads
Other roads
Bridges
Drainage piping
Drainage ditches
Coffer dams
Dewatered area
Concrete
Buildings
Fencing
Piling
$\quad$ Sheet
$\quad$ Other
Rock anchors
Stainless steel grating (adsorbent beds)
Stainless steel plate (adsorbent beds)
Structure steel (adsorbent beds)
Piping
$\quad$ Reinforced plastic
Carbon steel
Crane rail
Approximate Quantity

970 hectares
$41,003,000$ cubic meters
$15,134,000$ cubic meters
696,200 square meters
539,300 square meters
18 meters
12,000 meters
30,000 meters
71,000 square meters
710 hectares
$2,573,000$ cubic meters
31,400 square meters
10,000 meters
18,000 square meters
412,000 meters
$8,164,000$ cubic meters
$2,050,000$ square meters
25,900 tonnes
11,700 tonnes
580,000 meters
90,300 meters
9,300 meters


CHAPTER 9

CO-PRODUCTS

At the outset of this investigation, consideration was given to the feasibility of recovering uranium from seawater as a co-product of such other products as salt, bromine, magnesium hydroxide, etc. These products were considered in two contexts. Firstly, was it possible that the uranium extractant (adsorbent in this case) would also adsorb other valuable materials which could be simultaneously or sequentially eiuted from the adsorbent during uranium elution. Conversely, did existing processes such as those above also selectively separate and concentrate uranium from the seawater. Secondly, was it possible to append the uranium recovery process to the existing processes that pump seawater and thus recover uranium at a modest incremental cost.

With respect to the possibility that hydrous titanium oxide also adsorbs other valuable materials in addition to uranium, Section 6.2.4 lists concentration factors for some materials for hydrous titanium oxide and Section 6.4 presents a co-product flowsheet. Four elements, chromium, vanadium, manganese, and nickel may be recovered in a concentrate solution that could be sold to a refiner. (It is assumed that up to $80 \%$ of the market value for each metal would be consumed in isolation and purification.)

Consideration for obtaining uranium from an existing process such as those mentioned in the introduction to this chapter yielded no technical reason to expect a uranium concentration factor (of the order of 100,000) that would signal a potential for the recovery process. Nor did the amount of uranium that might be available from these processes appear significant enough to warrant a recovery operation.

- Isolation of bromine from ocean water requires four essential steps: (1) oxidation of bromide to bromine; (2) removal of bromine vapor from the solution; (3) condensation of the vapor or fixation; and (4) purification of the product. Seawater is acidified with sulfuric acid, then chlorinated. Free bromine is collected in a "blowing-out" process. The most probable reaction for the uranyl tricarbonate ion is conversion to the uranyl sulfate or chloride salt, which is quite soluble. 
- Magnesium recovery from seawater is carried out by precipitating magnesium hydroxide by addition of lime. There is some reason to expect this to produce a scavenging action for the uranyl tricarbonate complex. Assuming a $100 \%$ uranium scavenge in a 100,000 tonne magnesium/year plant, less than $1 / 4$ tonne of uranium would be collected in the magnesium hydroxide precipitate. Uranium was thus not considered a significant co-product in the magnesium recovery process.

- Salt $(\mathrm{NaCl})$ is obtained from solar evaporation by bringing the seawater to saturation concentration in concentrating ponds areas. Further evaporation in crystallizing areas results in the crystallization of salt. The major brine constituents, other than salt, remain in solution and are discarded as bitterns. The uranyl tricarbonate complex would remain in the bitterns. United States salt production by solar evaporation is roughly one million tonnes per year. The bitterns from this process would contain about $1 / 5$ tonne of uranium. Consequently, uranium was not considered a significant co-product in the solar evaporation process for recovering salt from seawater.

The above summary of processes for recovering materials from seawater also shows that there is no incentive for processing the seawater as it is pumped to recover uranium due to the minor quantities of uranium that could be recovered.

Cooling water would be drawn from the sea for the U. S. nuclear power facilities cited in Table 9.0-1. The estimated uranium recovery assumes perfect conditions, for instance:

- A $100 \%$ recovery efficiency is assumed versus the projected processing efficiency of $70 \%$ cited in this report

- Fresh feed (seawater undepleted in uranium) is assumed at the cooling water intake. These plants were not sited with this feature in mind and more than likely this is not the case.

- A constant uranium value of $3.35 \mathrm{ppb}$ is assumed, but quite possibly the seawater drawn from near the coast will be diluted with fresh water, further reducing the uranium recovery potential.

- Industrial waste could be present in the waters causing fouling and saturation of the adsorption sites, thus further reducing uranium recovery.

For the above reasons, plants that draw cooling water from the ocean must be evaluated site by site. Actual uranium recovery efficiencies could fall in the $25-40 \%$ yield region when the above constraints are taken into account. Furthermore, the modest uranium recovery per year discounts the value of such locations for co-product recovery. 
Since this project would provide clean seawater in great volume ( 510 million cubic meters per day), the availability of this water could attract other facilities such as power plants, mineral recovery (magnesium, bromine, salt, etc.) from seawater feed, desalinization plants, etc., to use the waste seawater that would be conveniently available from the uranium extraction plant.

Table 9.0-1 Nuclear power facilities using seawater from open coastal points or reasonably open bays

\author{
Location (Number of units) \\ Seawater Source \\ Estimated \\ Wiscassot, ME (1) \\ Montsweag Bay \\ Atlantic Ocean \\ Cape Cod Bay \\ Atlantic Ocean \\ Tonnes U Per Year \\ Seabrook, NH (2)* \\ Plymouth, MA (2)* \\ Charlestown, RI (2)* \\ Atlantic Ocean \\ Atlantic Ocean \\ Pacific Ocean \\ Pacific Ocean \\ 1.9 \\ 3. 7 \\ 2.4 \\ 3.7 \\ $3 \cdot 3$ \\ 3.3 \\ 3.2 \\ Diablo Canyon, CA (2)* \\ 4.5 \\ Total Units 61 \\ Total Uranium 26 tonnes per year \\ *Indicates not all units were operational at date of listing. \\ Calculations were based on $100 \%$ efficient recovery, 365 days per year. \\ The estimated amount of uranium per year processed by each plant was \\ calculated from coolant flow rates for the plants [26].
}


CHAPTER 10

ECONOMICS

10.1 INTRODUCTION AND SUMMARY

The purpose of this section is to convert the engineering cost estimates for the uranium extraction plant into projected unit costs $(\$ / 1 b)$ * for the recovery of uranium from seawater. In addition, it was desired to examine the validity of these projections in terms of uncertainties in both economics and process assumptions. Those parameters which potentially might provide the largest opportunity for lowering production costs are identified.

The approach was to utilize the design developed in Chapter 7 and costed out in Chapter 8 as the primary reference design case. By using the estimates of the most probable set of economic conditions through 1995, the year in which the plant could be in operation, it was found that, for a government backed facility, the production cost of $\mathrm{U}_{3} \mathrm{O}_{8}$ would be of the order of $\$ 2,500 / 1 b$ in 1995 dollars. Expressed in constant 1978 dollars, the unit production costs are projected to be about \$1,400/Ib. The capital cost of the project dominates the production cost, representing over two-thirds of the cost. It was found from sensitivity studies that reducing the contact time between seawater and adsorbent would lead to cost reductions. Accordingly, iterations on the reference design case were made to attempt to identify the magnitude of cost reductions achievable with a more finely tuned and optimistic design. The results of these iterations are discussed below.

Presented below is a brief description of a computer model used to analyze production costs and to perform sensitivity studies of the influence of the various parameters upon the projected production costs. The results of the sensitivity studies, the process iterations, and some comments regarding the implications of the results are also presented.

* For the convenience of the reader, costs are expressed in $\$ / 1 \mathrm{~b}$ rather than $\$ / \mathrm{kg}$. Costs in $\$ / \mathrm{kg}$ can be determined by multipiying costs in $\$ / 1 \mathrm{~b}$ by a factor of 2.205 . 


\subsection{METHODOLOGY FOR PROJECTING UNIT PRODUCIION COSTS AND FOR PERFORMING SENSITIVITY STUDIES}

In order to readily determine the unit production costs for various possible plant designs, economic assumptions, and process variations, a simplified computer model of the process was developed.

\subsubsection{Economic/Cost Model}

The model was designed to utilize capital cost estimates for each major plant component together with the associated capacities of each plant component that were developed by the detailed engineering and cost estimations performed in other portions of the program. The engineering design defines the process, the capital costs, and the component capacities as external inputs to the economic model. In particular a reference design case was developed (Section 7.2.1.2.2) whose components and capital costs are presented in Table 10.2-1. Based upon this design, various process parameters were defined. Some of the more important process parameters are summarized in Table 10.2-2. The reference design plant was estimated to require 15 years to construct, with the earliest date of commercial operation being 1995. Accoraingly, it was necessary to estimate the escalation rates for both capital facilities during the period of construction, the interest rates during construction, and the expected costs of operating expenses in 1995 and beyond. Table 10.2-3 summarizes the economic assumptions necessary to compute interest during construction, and the major operating and maintenance costs associated with producing uranium beyond the 1995 plant startup period. Some of the essential details of how the model arrives at these costs are presented below. 
Table 10.2-1 Plant capital cost

\begin{tabular}{|c|c|c|}
\hline Account & \multicolumn{2}{|l|}{ Description } \\
\hline 10 & \multicolumn{2}{|c|}{ Adsorbent beds and handling equipment } \\
\hline 11 & \multicolumn{2}{|l|}{ Seawater handling facilities } \\
\hline 12 & \multicolumn{2}{|l|}{ Freshwater handling facilities } \\
\hline 14 & \multicolumn{2}{|l|}{ Elution equipment and facilities } \\
\hline 15 & \multicolumn{2}{|c|}{$\mathrm{U}_{3} \mathrm{O}_{8}$ concentration/packaging equipment } \\
\hline 20 & \multicolumn{2}{|c|}{ Site development and land costs } \\
\hline & \multicolumn{2}{|l|}{ Subtotal } \\
\hline \multicolumn{3}{|c|}{ Escalation during construction } \\
\hline \multicolumn{3}{|c|}{ Interest during construction } \\
\hline \multicolumn{3}{|c|}{ Total Capital Cost in Year of Plant St } \\
\hline \multicolumn{3}{|c|}{ *Summary of Assumptions } \\
\hline \multicolumn{2}{|c|}{$\begin{array}{l}\text { Interest } \\
\text { Escalation rate (Type } 10 \text { accounts) } \\
\text { Escalation rate (Type } 20 \text { accounts) } \\
\text { Years to complete }\end{array}$} & $\begin{array}{l}0.0800 \\
0.0700 \\
0.0700 \\
15\end{array}$ \\
\hline
\end{tabular}

\begin{tabular}{|c|c|c|}
\hline \multicolumn{2}{|c|}{$\begin{array}{l}\text { Design Estimate } \\
\text { Year ( } \$ \text { billion) }\end{array}$} & $\begin{array}{l}\text { Capacity Adjusted } \\
\text { Year of Start (\$ billion) }\end{array}$ \\
\hline 1978 & $1980^{*}$ & $1980^{*}$ \\
\hline 3.147 & 3.603 & 3.603 \\
\hline 1.464 & 1.676 & 1.698 \\
\hline 0.1175 & 0.1345 & 0.1384 \\
\hline 0.3687 & 0.4221 & 0.4352 \\
\hline 0.0100 & 0.01745 & 0.01145 \\
\hline 1.093 & 1.251 & 1.251 \\
\hline \multirow[t]{4}{*}{6.200} & 7.098 & 7.137 \\
\hline & & 5.086 \\
\hline & & 5.634 \\
\hline & & 17.86 \\
\hline
\end{tabular}


Table 10.2-2 Reference design process parameters*

Plant Capacities

Adsorbent bed volume

$21,600,000$ cubic feet

Pumping capacities

Seawater

Fresh water

Eluant

$93,800,000$ gallons/minute

776,000

220,000

477,500 horsepower

3,160

Plant construction time

15 years

Bed Data

Adsorbent loading

Prewash

Elution

Postwash

Total cycle time

16,600 bed volumes

3

4

5

19.5 days

Other Data

Adsorbent loading capacity

$86 \times 10^{-6} 1 \mathrm{~b}$ U/Ib adsorbent

Adsorbent density

$33 \mathrm{lb} / \mathrm{cubic}$ foot

Removal efficiency of $80 \%$ uranium from seawater

Uranium concentration

$3.35 \mathrm{ppb}$

in seawater

* English units are used in this table since the computer code used was written for input in these units. 
Table 10.2-3 Reference design case - economic data summary

$\$$ Niilion
$(1978$ Dollars $)$ $\begin{gathered}\text { Escaiation } \\ \text { Rate }\end{gathered}$

Fixed Costs

Adsorption beds and handling equipment

Seawater facilities

Fresh water facilities

Elution facilities

$\mathrm{U}_{3} \mathrm{O}_{8}$ concentration/packaging

Site development/land/support facilities

Interest rate

Labor

Annual fixed charge rate @ $10 \%$ pa

$\begin{array}{cc}\$ 3147 . & 7 \% \\ 1464 . & 7 \% \\ 117.5 & 7 \% \\ 368.7 & 7 \% \\ 10.0 & 7 \% \\ 1093 . & 7 \% \\ 12.5 \mathrm{pa} & 7 \% \\ 1115 \mathrm{pa} & 7 \%\end{array}$

Variable (Operation and Maintenance) Costs

Capital replacement

Electrical e $\$ 0.0218 / \mathrm{kW}-\mathrm{hr}$

Adsorbent $e \$ 1.1 / \mathrm{kg}$

Ammonia @ $\$ 0.13 / \mathrm{kg}$

Carbon dioxide e $\$ 0.006 / \mathrm{kg}$

Steam $€ \$ 4.27 / 1000 \mathrm{MJ}$

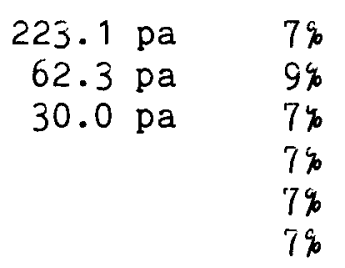

Total Chemical

$97.9 \mathrm{pa}$

Plant factor - $90 \%$

Total Annual Cost (1978 dollars)

$\$ 1549 \quad$ pa

pa $=$ per annum 
10.2.1.1 Capacity adjustment

The model assumed that the total adsorbent bed volume as specified by the reference engineering design case was invariant. Using the process data (specified in Table 10.2-2), the code computed the volume of seawater that must be pumped through the adsorbent in order to load the adsorbent to the specified loading capacity, with the specified adsorbent-seawater contact time and the specific percentage of uranium removed from the seawater. Similarly from the specified contact times and bed volume equivalent amounts of fresh water and eluant required to perform the adsorbent washing and elution functions, the code computed the total cycle time to load-wash-elute-wash a unit amount of adsorbent. From the total cycle time and the volumes of seawater, fresh water, and eluant required, the respective time-averaged pumping rate capacity requirements were determined. These calculated pumping rate capacities were compared to the input capacities to arrive at capacity scaling factors. If the reference design case were being computed, the capacity scale factors would be expected to be near unity (this would confirm that the model is computing quantities consistent with the engineering design calculations) and, in fact, all capacity factors agree to better than \pm $5 \%$.

The purpose of the scale factors is to allow a process variable to be altered and then use the code to adjust the size of the plant and the costs that would occur if a new engineering design had been performed. Here approximations must be made, and capital costs were assumed to scale by the capacity scale factor raised to the 0.7 power. The major purpose of the code was to permit changes in the design to be analyzed in terms of changes in capital costs, operating costs, and plant outputs without undertaking a completely new engineering design and cost estimate. For small changes from the design condition, this code has proven very useful, but large changes, where a new design concept might be aesirable, are not as accurate and the code tends to underestimate the effect of the change, i.e., in general it will overestimate the uranium production cost.

\subsubsection{Escalation}

Another important feature of the model is that it permits all cost factors (capital and operating) to be entered in any year dollars and the code will adjust these costs to the appropriate year via escalation rates entered into the code. Consider the reference design case as an example. Virtually all costs were estimated in 1970 dollars. The plant is scheduled to startup in 1995, so construction starts in 1980 . The code escalated the 1978 cost estimates to 1980. It then performed the capacity adjustments by scaling the capacity scale factors to the 0.7 power and multiplying by the 1980 costs to provide a 1980 adjusted cost 
for each capital component. (In the reference case virtually no cost adjustment occurred.) Using the expenditure stream during the construction period as input the code computed the interest during construction, the escalation during construction, and the total projected capital cost of the plant in 1995. An example is shown in Table 10.2-1.

The code has the capability to handle two different payment streams; that is, type 10 accounts (see Table 10.2-1) and type 20 accounts can have separate construction schedules. Type 30,40 , and 50 accounts were built into the code to accommodate co-product capital facilities, but, as discussed in Chapter 9, this was determined to be uneconomic and therefore was not included in the reference design case.

\subsubsection{Variable costs}

Variable costs are those whose quantities, hence costs, are a function of the plant output. These include electric power, chemical make-up, and adsorbent losses. Electrical costs are determined by converting the adjusted pumping rates to horsepower using separate conversion factors derived from the engineering studies for the seawater, the fresh water, and the eluant pumping heads. From the total required horsepower, the capacity factor of the plant, and the escalated cost of power in $\$ / \mathrm{kW}-\mathrm{hr}$ for the year of interest, the electrical power costs are developed.

Chemical costs include the make-up costs of ammonia, carbon dioxide, and steam requirements of the plant. The code allows specification of the molarity of the ammonium carbonate eluant, and the fractional loss of ammonia and carbon dioxide expected per cycle of adsorbent. The steam requirements are from the engineering design. The actual costs are computed on the basis of the requirements (adjusted for capacity and plant factor), and the escalated unit cost of the individuai chemicals.

Adsorbent costs are computed on the basis of the specified cost of the adsorbent (escalated to the year of interest) and the specified fraction of adsorbent that is lost per cycle of the adsorbent through the process. The code has the provision to specify a certain number of cycles for the adsorbent, at which point the adsorbent is removed for reconstitution. The cost of adsorbent reconstitution and a credit for removed adsorbent can be accommodated by the code. In the reference design case it was assumed that no adsorbent reconstitution was necessary. 
10.2.1.4 Fixed costs

In this model it was assumed that labor costs are independent of plant output and therefore fixed. Provisions were made to accommodate four separate labor categories with separate manpower, rates, and escalation rates.

Non-labor maintenance costs are accounted for as a specified fraction of the plant capital cost, called the capital replacement factor. Al though the total plant capital cost is sunk at the time of plant start, provisions are made to allow escalation effects to be included in the capital replacement cost.

The capital fixed charge rate is a method whereby capital depreciation, taxes, return on investment, carrying charges, overheads, etc., can be accounted for by charging an annual cost equal to the f'ixed charge rate multiplied by the total plant capital cost. The fixed charge rate will depend upon the type of financing of the plant, required return on investment, risk, and expected plant life. This rate will differ for a government sponsored project or a commercial venture. For a government sponsored project where capital recovery is the major objective, the fixed charge rate is equal to $i(1+i)^{n} /(1+i)^{n}-1$, where $i$ is the applicable interest rate and $\mathrm{n}$ is the life of the plant in years. For an interest rate of $8 \%$ and a 30 year plant life, the capital recovery rate would be 9\%. On the other hand, a commercial venture would probably require an after-tax return on investment of between $6 \%$ and $15 \%$, depending upon the perceived degree of risk. If the commercial project is assumed to be financed at $50 \%$ debt at $8 \%, 50 \%$ equity, an overall return on investment of $12 \%$, a $50 \%$ tax rate, and a 40 year life, then the appropriate annual fixed charge rate would be about $15 \%$. For the reference design case a $10 \%$ annual fixed charge rate was chosen, assuming that a government sponsored project would be the most likely scenario.

\subsubsection{Uranium production cost}

The results for the unit production costs computed for the reference design case are presented in Table 10.2-4. This table breaks the production costs into six separate components which are presented in year of start up dollars (1995) and in constant 1978 dollars. Also shown are the percentage contributions of each cost component. 
Table 10.2-4 Uranium production costs for reference design case

$$
\text { Unit Production Cost }\left(\$ / 1 \mathrm{~b}-\mathrm{U}_{3} \mathrm{O}_{8}\right)
$$

\section{Cost Component}

Adsorbent losses

Chemical make-up

Power

Labor

Capital replacement/maintenance

Capital recovery (fixed charge)

TOTAL
1995 Dollars

\begin{tabular}{rr}
82 & $(3.1 \%)$ \\
269 & $(10.3 \%)$ \\
230 & $(8.8 \%)$ \\
34 & $(1.3 \%)$ \\
335 & $(12.7 \%)$ \\
1664 & $(63.8 \%)$ \\
\hline
\end{tabular}

$2613(100.0 \%)$
1970 Dollars

\begin{tabular}{rr}
20 & $(1.9 \%)$ \\
91 & $(0.4 \%)$ \\
58 & $(4.0 \%)$ \\
12 & $(0.0 \%)$ \\
200 & $(14.5 \%)$ \\
1040 & $(72.4 \%)$ \\
\hline
\end{tabular}

$1436(100.0 \%)$

\subsection{PARAMETRIC SENSITIVITY STUDIES}

In estimating the costs associated with a process such as recovering uranium from seawater, which is not well developed, does not have a reliable base of process information, and requires projecting these costs nearly 20 years into an uncertain future, the uncertainties potentially inherent in the projections must be appreciated. Because of these Iarge uncertainties, an obligation exists to attempt to identify the potential contributions of the many necessary assumptions to the overall uncertainty and to attempt to gauge the magnitude of the overail uncertainty.

It is for these reasons that two types of sensitivity studies were performed. The type of sensitivity study used here is termed a parametric studies in that parameters are varied one at a time and the change in the total production cost is observed. Cne convenient method to portray the results of this study is to utilize the concept of elasticity. In this case, elasticity is defined as the percentage change in the unit production cost $\left(\$ / 1 \mathrm{~b}-\mathrm{U}_{3} \mathrm{O}_{8}\right)$ divided by the percentage change in the parameter of interest. The reference design case was used as the base and nearly all of the significant parameters were changed (one at a time), the unit production cost calculated, and the elasticity

determined. The results are presented in Tabie 10.3-1. 
Table 10.3-1 Uranium production cost sensitivity

Parameter

Process Dependent Parameters:

Plant capacity factor

Extraction (uranium removal) efficiency

Plant capital cost

Adsorbent-seawater contact time

Adsorbent loading capacity

Adsorbent losses
Elasticity

$$
\begin{array}{r}
-0.8 \\
-0.6 \\
0.7 \\
0.6 \\
-0.1 \\
0.03
\end{array}
$$

Economic Assumptions:

Construction time

0.8

Fixed charge rate

0.6

Escalation rate

0.6

Interest rate

Two cautions are in order regarding the results. Firstiy, the model is not exact and any change in a process parameter that deviates significantly from the design case must be regarded as an approximation and generally results in underestimating the sensitivity. The reason is simple; a major change in a key process variable probably woula result in different plant design which would be more optimal, whereas this model makes no attempt at design optimization. Secondly, the effects of some parameters are not symmetric to the same percentage increase and decrease. For example, if the plant factor is increased from $80 \%$ to $90 \%$, the derived elasticity is -0.70 , but if it is reduced from $80 \%$ to $70 \%$, the derived elasticity is $\mathbf{- 0 . 8 2}$. In these cases a simple average of the derived elasticity on $\in$ ither side was used to present an effective value in Table 10.3-1.

It is seen that a number of parameters have a strong influence on the production cost. Unfortunately several of these do not of fer great potential for lowering production costs. The plant capacity factor has an elasticity of -0.8 but the design value is $90 \%$, so even if the plant capacity factor were raised to $100 \%$, the total production cost would oniy be reduced by at most 13\%. Similarly, the production cost is quite sensitive to the efficiency for removing uranium from the seawater passed through the adsorbent, but the reference design is posed on $80 \%$ removal; so even $100 \%$ removal would only lower costs about $20 \%$. The adsorbent/seawater contact time has an elasticity of 0.6 and is 1.67 minutes in the reference design. Reducing this time to 0.03 minutes 
results in lowering the costs by $30 \%$; however, to accomplish this probably requires a larger grain size adsorbent, a higher seawater head pressure, and the risk of lowering the extraction efficiency (which is counter-productive). This option will be discussed later.

Three economic assumptions, the construction time, the fixed charge rate, and the escalation rate, have significant elasticities. Of these, the construction time of 15 years is most conservative and perhaps could be reduced as much as $30 \%$ ( 10 years) which would lower construction costs by $25 \%$. The escalation rate is, of course, outside of any control, but if escalation drops by $20 \%$ over the time frame, then the production costs will be approximately $10 \%$ lower than projected. In the extreme case of zero escalation, the production costs would be about $45 \%$ lower.

The fixed charge rate, $10 \%$ in the reference case, is considered optimistic even for a government sponsored project due to the size and risk of the project. A commercial venture by private industry would require a fixed charge rate of $15-20 \%$ for a project with this potential risk, which would increase production costs from $35-60 \%$.

In summary, it is concluded that there are some opportunities to reduce costs, but on balance the reference design case is more likely to underestimate the costs than to overestimate them. Based upon the results shown, a $\pm 50 \%$ uncertainty in the reference design cost projection is estimated and the likelihood of an order of magnitude decrease in cost is near zero.

\subsection{DESIGN ITERATIONS}

Based upon the information obtained from the parametric studies and the knowledge that the uranium production costs from seawater are well above conventional sources of uranium, several options were pursued which might lead to improvements in the reference design case. It was observed from the parametric studies that the process parameter with the greatest potential for lowering costs is the adsorbent/seawater contact time. Contrary to expectations, it was discovered that passing seawater through the adsorbent faster was more advantageous than obtaining an adsorbent with a higher loading capacity.

\subsubsection{Design Based Upon Increased Flow Rate: Case 2}

From a practical point of view, increasing the seawater filow rate through the adsorbent bed can be accomplished in the continuous fluidized bed system only by increasing the settling rate of the bed particles, which must be balanced against the upflow of the seawater. The equation 
for the settling velocity $V$ of particles indicates that the velocity is proportional to the square of the particle diameter:

$$
V=(g / 18 z)(s-1.02) d^{2}
$$

where $g$ = gravitation constant

$\mathrm{z}=$ kinemetric viscosity of the fluid medium

$s=$ specific gravity of the particle

$d=$ particle diameter

With this insight, the impact of, say, doubling the adsorbent particle size can be analyzed and a projected production cost can be obtained which is somewhat more realistic than indicated by the first order scaling factors used in the parametric studies. The following changes resulted for this modified design basis:

(1) While maintaining the seawater pumping capacity of the reference design, the adsorbent bed cross section is reduced by a factor of four.

(2) To maintain the $75 \mathrm{~s}$ minimum contact time assumed necessary to reach $80 \%$ adsorbent efficiency requires increasing the expanded bed depth by a factor of 1.575 , or $0.6 \mathrm{~m}$, at the increased flow rate.

(3) Pumping head requirements increase by a factor of $5.6 / 5$, or about $12 \%$.

(4) Pumping horsepower increases proportionately, which results in a $12 \%$ increase in the capital cost of the motors (but not the pumps), and in the power costs.

(5) The combination of the reduced bed cross section and increased depth results in a reduction of bed volume, and adsorbent inventory, of about 55\%.

(6) The overall area requirements and peripheral roadways, flow channels, etc., are reduced due to the reduced adsorbent bed cross sections, as shown in Figure 10.4-1.

(7) Doubling the particle diameter requires doubling the volume of adsorbent to be processed in order to maintain the same surface exposure per unit of time. This requires doubling the size of the wash and elution equipment, as well as the equipment for product recovery from the eluate.

(8) Chemical losses and steam requirements are increased proportionately.

This design variation is shown in Figure 10.4-1. It is obvious from the above factors that there are of fsetting changes in the construction 


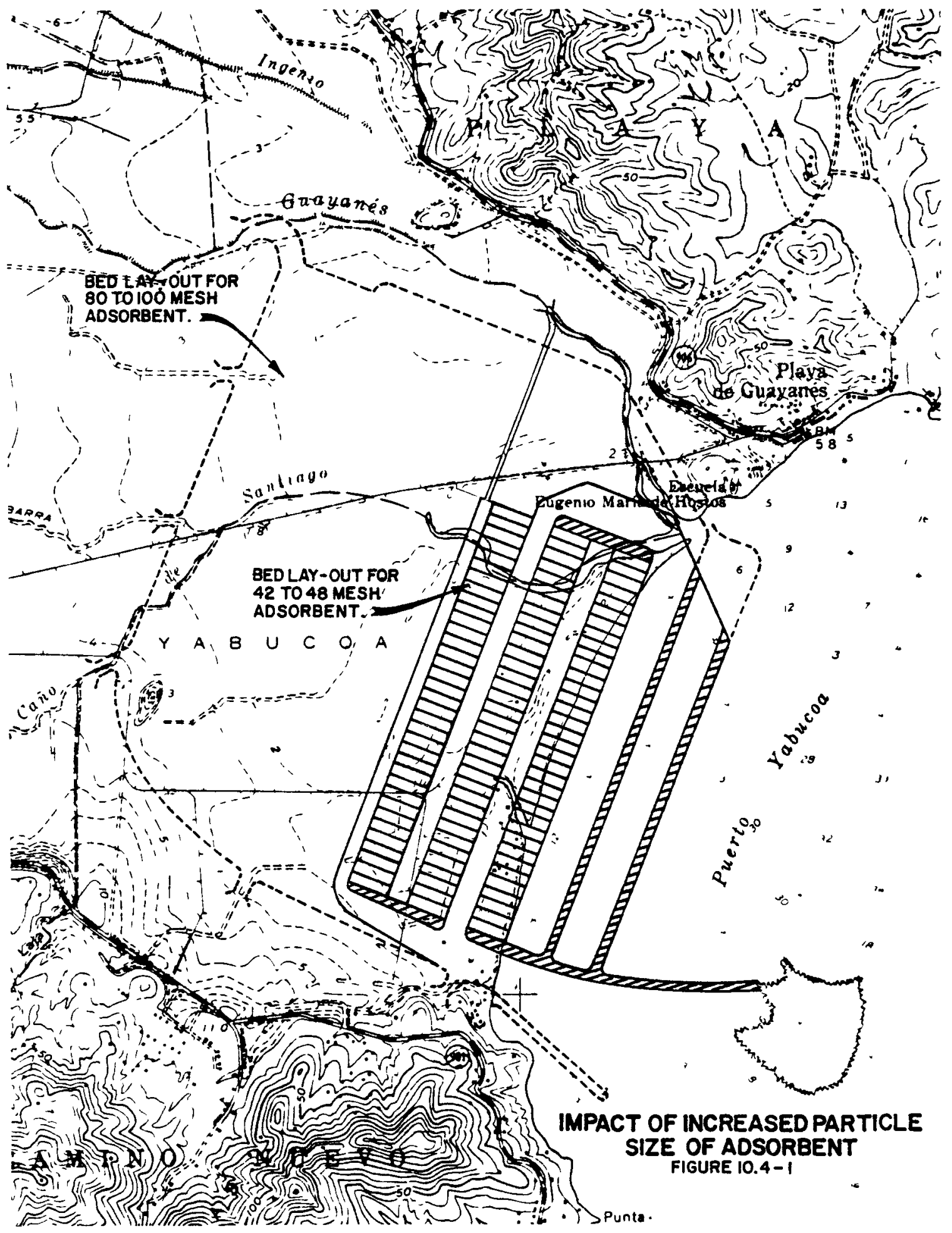


and operating costs which indicates that there is a practical limit to the range of diameters for which the settling velocity equation given above is applicable.

However, with these considerations in mind, it was felt to be feasible to project the probable cost impact of a doubling of the adsorbent particle diameter assumed for the reference design. Table 10.4-1 shows the capital costs which result from adjusting material takeoff quantities along the lines described above are $20 \%$ lower than for the reference design. However, Table 10.4-2 indicates that the overall production costs are reduced by only $4 \%$ due to the offsetting increase in consumables. This indicates that the one point chosen to look at is probably beyond the minimum in a series of possible choices and does not invalidate this approach in design optimization studies.

10.4.2 Design Based Upon Increased Flow Rate and Increased Loading Capacity: Case 3

From the parametric studies it was noted that if the adsorbent loading capacity increases, the adsorbent processing costs are reduced. Thus a combination of increasing the adsorbent particle diameter and increasing the loading capacity by a factor of ten might provide synergistic effects resulting in a superior design.

The projected results of doubling the particle size and the additional impact of increasing the adsorbent loading capacity by a factor of ten are shown in Table 10.4-2. 
Table 10.4-1 Cost estimates for

increased particle size of adsorbent by twice the diameter

CASE (SPECIAL)

\begin{tabular}{|c|c|}
\hline $\begin{array}{l}\text { Acct. } \\
\text { No. }\end{array}$ & $\begin{array}{l}\text { COST CLASSIFICATION } \\
\text { DIRECT FIELD COSTS* }\end{array}$ \\
\hline \multirow[t]{17}{*}{$\begin{array}{l}1.0 \\
2.0 \\
3.0 \\
4.0 \\
5.0 \\
6.0 \\
7.0 \\
8.0 \\
9.0\end{array}$} & $\begin{array}{l}\text { Site development } \\
\text { Seawater pumping } \\
\text { Adsorbent beds } \\
\text { Fresh vater supply } \\
\text { Fresh water recovery } \\
\text { Storage } \\
\text { Adsorbent process facility } \\
\text { Eluate process facility } \\
\text { Miscellaneous }\end{array}$ \\
\hline & SUBTOTAL \\
\hline & Productivity on Local Labor \\
\hline & SUBTOTAL \\
\hline & INDIRECT FIELD COSTS \\
\hline & $\begin{array}{l}\text { Temporary cons truction } \\
\text { Supervision } \\
\text { Construction equipment } \\
\text { Payroll burden }\end{array}$ \\
\hline & SUBTOTAL \\
\hline & SUBTOTAL Direct and Indirect Field Costs \\
\hline & OTHER COSTS \\
\hline & $\begin{array}{l}\text { Builders all risk/other insurance } \\
\text { Construction camp costs } \\
\text { Allowances for labor training } \\
\text { Excise taxes } \\
\text { Ocean freight } \\
\text { Initial charge for adsorbent } \\
\text { Engineering } \\
\text { Mobilization costs }\end{array}$ \\
\hline & SUBTOTAL OTHER COSTS \\
\hline & SUBTOTAL \\
\hline & FEE \\
\hline & SUBTOTAL \\
\hline & CONTINGENCY \\
\hline & TOTAL COST \\
\hline & REFERENCE CASE \\
\hline
\end{tabular}

\begin{tabular}{|c|c|c|c|}
\hline & sor & & \\
\hline Expatriate & Local & Material & Total \\
\hline $\begin{array}{r}32,424 \\
63,975 \\
81,351 \\
5,873 \\
-0- \\
2,117 \\
31,700 \\
678 \\
1,359 \\
\end{array}$ & $\begin{array}{r}40,409 \\
79,728 \\
101,384 \\
7,318 \\
-0- \\
2,639 \\
39,506 \\
845 \\
1,694 \\
\end{array}$ & $\begin{array}{c}108,082 \\
213,249 \\
271,169 \\
19,575 \\
-0- \\
7,059 \\
105,666 \\
2,259 \\
4,530 \\
\end{array}$ & $\begin{array}{r}180,915 \\
356,952 \\
453,904 \\
32,766 \\
-0- \\
11,815 \\
176,872 \\
3,782 \\
7,583 \\
\end{array}$ \\
\hline \multirow[t]{2}{*}{$\$ 219,477$} & $\$ 273,523$ & $\$ 731,589$ & $\$ 1,224,589$ \\
\hline & $\$ 103,938$ & & 103,938 \\
\hline$\$ 219,477$ & $\$ 377,461$ & $\$ 731,589$ & $\$ 1,328,527$ \\
\hline
\end{tabular}

INDIRECT FIELD COSTS

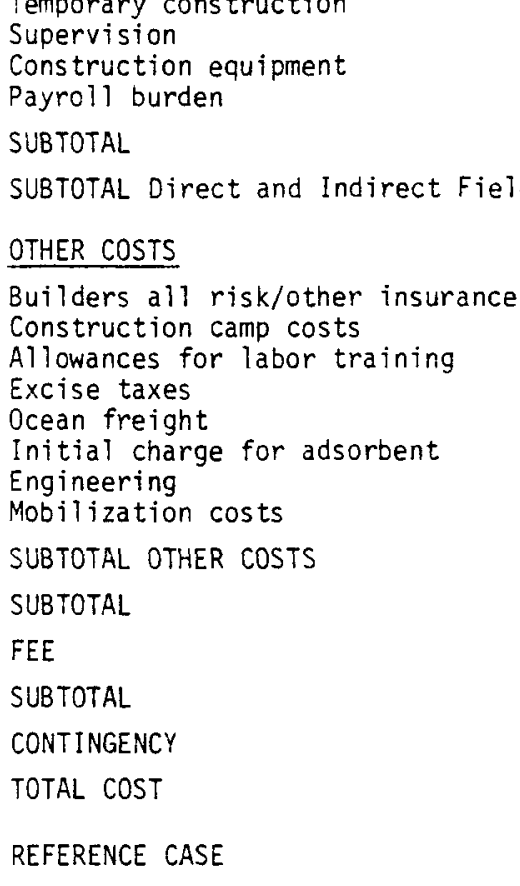

$$
\begin{array}{r}
202,958 \\
405,917 \\
584,999 \\
241,575 \\
\hline \$ 1,501,292 \\
\$ 2,829,819
\end{array}
$$

$\begin{array}{r}52,000 \\ 317,000 \\ 26,570 \\ 8,300 \\ 67,000 \\ 109,430 \\ 173,000 \\ 132,700 \\ \hline \$ 886,000 \\ \hline \$ 3,715,819 \\ 74,181 \\ \hline \$ 3,790,000 \\ \$ 1,137,000 \\ \hline \$ 4,927,000 \\ \$=2= \pm=== \\ \$ 6,200,000 \\ \hline \$ 1,273,000\end{array}$

* Direct Field Cost is the cost of equipment and materials which become a part of the finished plant, and of the direct craft labor hours required to put such equipment and materials in place.

$\star \star A 11$ costs in 4 th quarter 1978 dollars. 
Table 10.4-2 Production cost improvements due to increasing the adsorbent particle size and adsorbent loading capacity

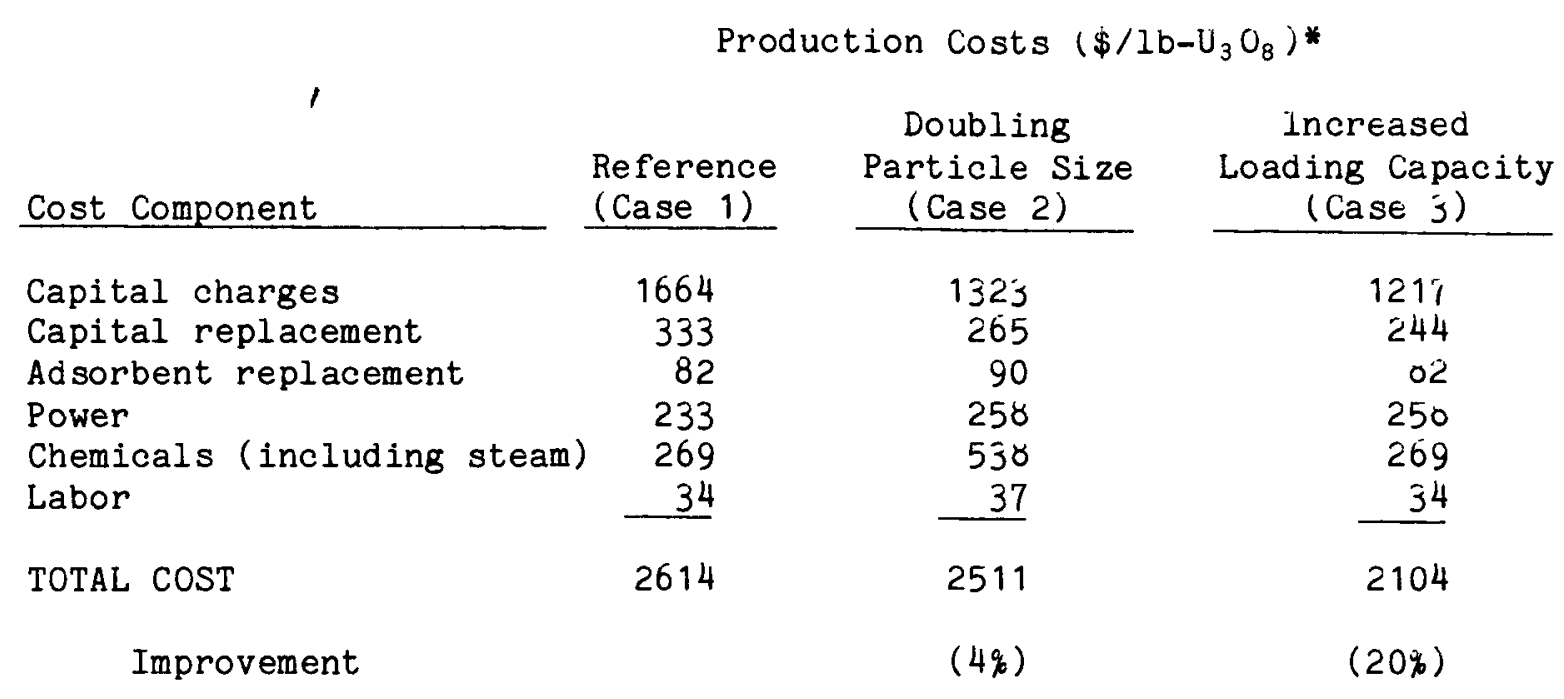

*Values quoted in 1995 dollars

10.4.3 Most Optimistic Case

In the spirit of attempting to establish a lowest conceivable production cost, one "hypothetical design" was establishea consisting of the most optimistic value for each important parameter. It is important to recognize that this is not an achievable design nor is it based upon a consistent engineering analysis. The objective is to guess the ultimate attainable performance should (1) several major technical breakthroughs occur (without specifically identifying these breakthroughs); (2) the most favorable economic climate prevail; and (3) the government choose to finance the project on a strictly cost recovery basis with no allowance for risk or contractor fees. The bases and results for this case are shown in Table 10.4-3. 
Table 10.4-3 Most optimistic case (hypothetical)

\begin{tabular}{|c|c|c|}
\hline Cost Component & $\begin{array}{l}\text { Production } \\
\text { Reference Design } \\
\text { Case in } 1995 \$ \\
\end{array}$ & $\begin{array}{l}\text { Costs }\left(\$ / 1 \mathrm{~b}-\mathrm{U}_{3} \mathrm{O}_{8}\right) \\
\text { Most Optimistic } \\
\text { (Hypothetical) in } 1990 \$\end{array}$ \\
\hline Capital charges & 1664 & 384 \\
\hline Capital replacement & 333 & 96 \\
\hline Adsorbent replacement & 82 & 10 \\
\hline Power & 233 & 121 \\
\hline Chemicals (including steam) & 269 & 78 \\
\hline Labor & 34 & 9 \\
\hline TOTAL COST & 2614 & 698 \\
\hline
\end{tabular}

Assumptions:

Contact time (minutes) $\quad 1.67$

Loading capacity (mg U/kg Ti) 210

0.75

$210 \quad 420$

Adsorber loss per cycle

Interest (q)

Escalation rate $(\%)$

Construction time (years)

Fixed charge rate $(q)$

0.005

8

Capital cost (1980 start)

7

15

10

$\$ 7.1$ billion
0.0025

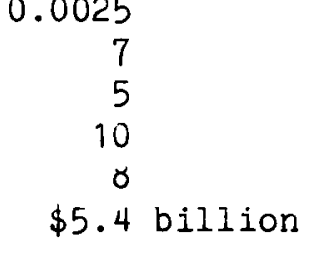

10.5 DISCUSSION OF RESULTS

It is clear from all considerations that a process to extract uranium from seawater is very capital intensive and that capital related charges account for two-thirds or more of the uranium production costs. Maintenance charges (capital replacement) and power each contribute roughly $10 \%$ of the total cost, whereas costs related to chemicals, adsorbent loss, and labor appear to be minor. In fact, these latter three cost components combined probably do not equal the uncertainty inherent in the capital charge estimate.

Because a plant of this magnitude could not be operational before 1990, the unit production costs were presented in the year of plant startup dollars. In order to assess these unit costs relative to current uranium prices, it is desirable to express all prices in common year doliars. For convenience, this is presented in Table 10.5-1 in terms of 1978 and 1995 dollars. 
Table 10.5-1 Summary and comparison of uranium costs in 1978 and 1995 dollars

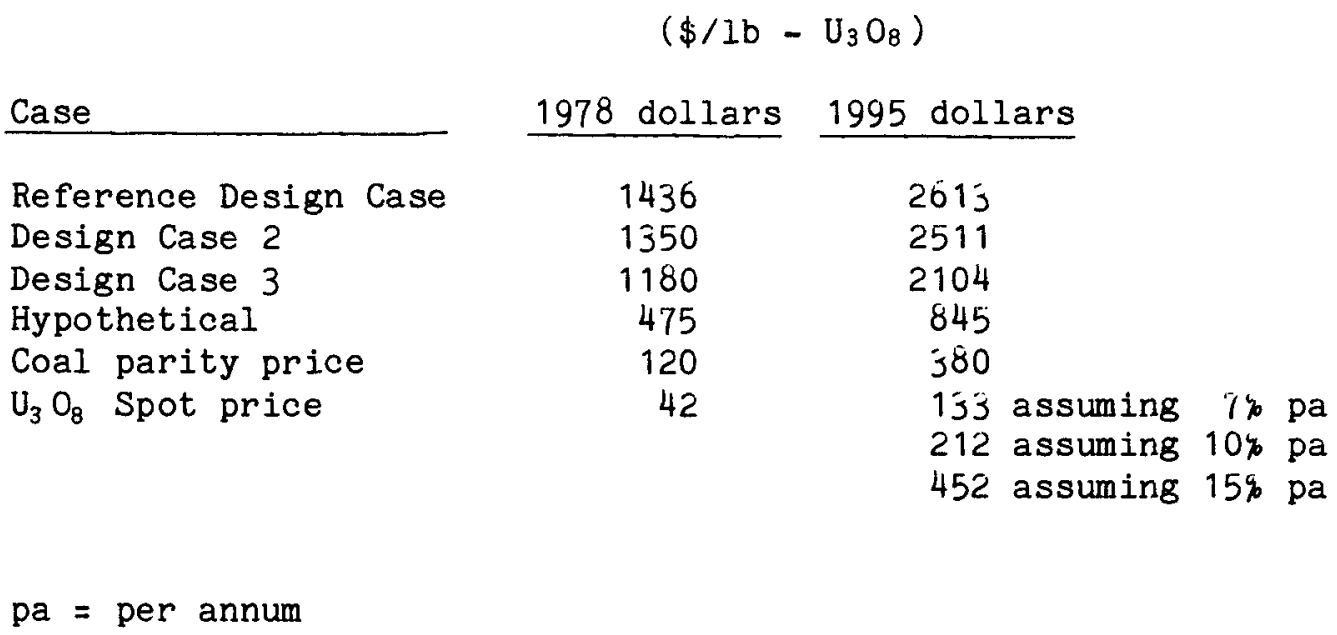

Also shown in Table $10.5-1$ are the spot price of $\mathrm{U}_{3} \mathrm{O}_{8}$ in 1978 $(\$ 42 / 1 b)$ and a coal parity price, which is the estimated price a utility could pay for $\mathrm{U}_{3} \mathrm{O}_{8}$ such that the electrical production cost from nuclear plants is equal that for coal plants. Based upon information reported for the Commonwealth Edison system [33], it can be estimated that in $19 \%$ dollars a $\mathrm{U}_{3} \mathrm{O}_{8}$ price of $\$ 120 / 1 \mathrm{~b}$ would establish break-even for the bus-bar generating costs for future plants. This estimate is based upon information contained in Tables 7 and 8 of Reference [33].

To assess the economic feasibility of a uranium from seawater extraction plant, the issue of production costs versus market price must be addressed. Uranium prices have historically been extremely difficult to forecast and probably will remain so into the future; however, many forecasts assume uranium price escalation rates to range between $\%$ and $10 \%$ per year in nominal terms. This would indicate a $\mathrm{U}_{3} \mathrm{O}_{8}$ price range of \$133-212 per pound in 1995. Even the coal parity price in 1995 is over a factor of two less than the projected production costs from the most optimistic hypothetical seawater plant. For the most favorable realistic production cost for uranium from seawater (Design Case 3), it was found that $\mathrm{U}_{3} \mathrm{O}_{8}$ prices must escalate at a rate in excess of $25 \%$ per year in order to obtain economic feasibility in 1995.

Given the above projections and recognizing that the production costs shown in Table 10.5-1 are based upon a fixed charge rate of 10\%, it is clear that present information would preclude any commercial, private venture into the uranium from seawater recovery business. On the other hand, a project of this nature is extremely capital intensive; thus once 
the costs of a plant are sunk, the production costs will escalate at a much lower rate than overall inflation. It can be shown that if the Design Case 3 plant began operation in 1995 and if $U_{3} \mathrm{U}_{8}$ prices escaiated at a rate of $15 \%$ per year, then, by the year 2015 , the production costs would be below the market price. 
CHAPTER 11

ENVIRONMENTAL IMPACT

The environmental impact of a project such as the extraction of uranium from seawater is expected to be primarily due to the large amount of land, fresh water, seawater, chemicals, and energy necessary for the process. The impacts could be far-reaching when related to the chemicals necessary such as hydrous titanium oxide and ammonium carbonate.

\subsection{EFFECTS OF SITE PREPARATION AND FACILITY OPERATION}

The large amount of land (approximately 10,000 hectares) necessary to be used for the plant site could result in a fairly large impact depending upon the site chosen. The most probable sites $126 j$ are along the southeast Atlantic coast and in Puerto Rico (see Section 5.3). The following items would most likely be among those impacting the site environment and thus would need consideration and possible mitigation:

- Removal of a large section of shoreline from the public domain

- Installation of seawater intake and discharge pipe lines 5 to $25 \mathrm{~km}$ out into the ocean

- Disposal of silt, sea grass, and other organic matter that are removed from the seawater prior to processing

- Disposal of process chemicals to the environment in an acceptable manner

- Removal of large amounts of fresh water from the regional area

- Obtaining necessary power and process steam

The exact effect of each of the above impacts is difficuit to define until a specific site and a specific process with given influents and 
effluents have been chosen. For example, currently the process flowsheets indicate a large amount of rinely divided calcium and magnesium carbonate precipitate that is discharged with the rinse waters. This could be discharged to the sea without harm if there is good dispersion; however, if necessary, this water could be recycied through settling ponds to remove most of the precipitate prior to disposal. The evaluation of a specific site would determine the method of precipitate disposal. As another example, the amount of fresh water available would determine if the design were to be a once through process for water or whether an extensive recycle to conserve water would be necessary. Thus, the site and process must be coordinated to minimize the environmental impacts.

\subsection{RESPONSIBILITY TO THE PUBLIC}

The building of such a large project would quite possibly be done by the federal government due to the large sums of money involved; hence, an environmental impact statement which would protect the public's interest and balance costs versus benefits would be required. It also woula be necessary for the project to comply with the rules and regulations as defined by federal (EPA, NRC, etc.) and state agencies. The fact that the final product is natural uranium would indicate that the involvement of the U. S. Nuclear Regulatory Commission (NRC) would be minimal. The agencies that would have the largest proportion of jurisdiction would most likely be the Environmental Protection Agency (EPA) and the Corp of Engineers.

The environmental assessment necessary would be determined by the specific site chosen. However, a general environmental program can be defined and the major items would be as follows:

- Perform a study of the area ecology

- Define the regional demography, land, and water use

- Evaluate the regional historic, scenic, cultural, and natural landmarks

- Define the geology, hydrology, meteorology, and seismology

The baseline ecology program would consist of (1) the water quality for both fresh water and seawater; (2) the aquatic ecology for the seashore out to 1 or $2 \mathrm{~km}$, the fresh water supply, and an estuary, if one were involved; and ( 3 ) the terrestrial ecology.

Studies of the current demography, land, and water use would be used to define the impact the facility would have on local recreation, public facilities (for example, schools, churchs, stores, police, etc.), and to 
determine if an adequate source of labor is available. The use of large quantities of fresh water could be one of the major impacts on the environment. The removal of millions of cubic meters of water from the region could cause changes (sometimes of a large magnitude) in the iand surface, subsurface (subsidence), vegetation, and recreational uses.

The archeological study would evaluate any historic or natural landmarks and define the type of mitigation, if necessary. In most cases this means the preservation of material or a site or the moving of the historic resource to a museum.

The geophysical program would most likely put large emphasis on the hydrology (fresh water supply) and meteorology of the area. In the case of the southeast Atlantic coast, the occurrence of hurricanes and tornadoes would be of importance. The seismology of the area would be important if there were a possibility that a seismic fracture of a large adsorbent bed could result in the loss of large quantities of adsorbent into the sea or prevent operation of the plant for a long period of time.

Once again, the environmental program would have to be defined to fit the specific site chosen. The program field work would have to be initiated at least two years ahead of submittal of the application for the license in order to gather enough information for the environmental report. Most elements of the program would require periodic monitoring long after the facility was in operation.

\subsection{ENVIRONMENTAL SUMMARY}

In summary, it appears that uranium can be removed from seawater by a process that can be made compatible with the environment within which it is located. The environment of the site would have to be evaluated prior to the start of detail design so that the environmental inputs could be used in the final design. Although there would be a major environmental impact due to the removal of uranium from seawater, these impacts appear to be amenable to mitigation by current technology. 
CHAPTER 12

RESEARCH AND DEVELOPMENT REQUIRED

In Chapter 10, economic projections were made for the recovery of uranium from seawater on the basis of the criteria established in Chapter 6 and the plant design chosen in Chapter 7 . As pointed out previously in those chapters, the cost of recovering uranium from seawater depends to some extent on the actual process used. Many assumptions had to be made, some based unavoidably on lack of concrete experimental data and others on established engineering judgment. Many of these factors need further investigation in order to more clearly understand the best way to extract uranium from seawater. This statement was confirmed by discussions with key foreign scientists whose programs are substantially ahead of the United States program for recovery of uranium from seawater (see Sections 15.1 and 15.2). In this chapter some of the key factors discussed in the companion report, XN-RT-14, Volume I [26] plus others will be presented that need further study in order to either improve the present understanding about the process of extracting uranium from seawater or to improve the cost of recovering uranium from seawater.

As an example, further work should be done on reconfirming the findings of Kennedy [34] and Starik [35] that the uranium exists in seawater in the uranyl tricarbonate form, since the association constants used for the calculations were not measured in seawater. Although it is suspected that they do not vary appreciably with the change of media, only direct measurements in seawater can verify this. Furthermore, the chemical state of uranium in seawater was only calculated at $35 \mathrm{C}$ due to the lack of association constant data at other temperatures. Laboratory measurements of association constants at various temperatures that cover the oceanic temperature range are needed.

An investigation is needed to determine which uranium-containing ion is actually adsorbed onto the adsorbent material. Because of the very low uranium concentration involved, this experiment is relatively complex. However, all of the present data in this area are based on two references $[34,35]$. 
One of the important factors in the overall recovery of uranium is the adsorbent material used. Although much of the work to date has been with hydrous titanium oxide, nonetheless there is still a need for investigating other adsorbents in view of the criteria presented in Section 5.4.1.1, particularly the overall effect of loading capacity, mechanical and chemical stability, and cost.

With regard to hydrous titanium oxide, considerably more information must be generated before a final conceptual engineering design can be prepared. While much information can be found in the literature, it cannot be drawn up in the form of a concise and credible specification because there was no common set of conditions observed by the various investigators. The following data must be generated under controlled conditions:

- Hydrous titanium oxide procedure

- Hydrous titanium oxide specifications, including tests for physical and chemical properties

- Kinetics of the adsorption mechanism with respect to temperature and contact time

- Kinetics of the desorption mechanism with respect to eluting chemical, eluant temperature, and contact time

- Potential for selective elution of uranium and other adsorbed cations

- Optimizing hydrous titanium oxide particle size, loading capacity, mechanical strength, and cost

Particular attention needs to be placed upon achieving a physical form in which the hydrous titanium oxide can be exposed to seawater, such as developing a tough hydrous titanium oxide coating on an inert spherical substrate. This form has the advantage of reducing the titanium inventory in the adsorbent bed while retaining essentially the same uranium loading, since the loading occurs primarily on the outer surface of the titanium. It is acknowledged that effective bonding of the hydrous titanium oxide onto the substrate material is not necessarily a simple process.

Additionally, techniques must be developed for either improving the form of hydrous titanium oxide or the handing methods, or both, so that the interstitial and intergranular solution retention is significantiy reduced. Such an improvement will, in turn, reduce the volume of rinse water and eluant required during the desorption of uranium and result in a substantial equipment cost reduction. It is possible that an alternate adsorbent might be more desirable than hyarous titanium oxide due to Its properties in this regard. 
An alternate eluant shouid be investigated to avoid the problems that ammonium carbonate create by blinding the adsorbent bed unless suitabie fresh water rinse volumes are used. A solution such as ammonium hydroxide, for example, might avoid this problem, although it is acknowledged that the elution efficiency parameters must be investigated thoroughly. However, in terms of actual costs, such an eluant might be economic, since the large amounts of fresh water rinse required could be reduced due to the fact that the prewash and postwash of the adsorbent bed would not be needed to remove the calcium carbonate buildup.

The continuous fluidized bed flowsheet is an adaptation from many authoritative sources based upon experienced engineering judgment, but a pilot plant operation must be carried out to test run the concept. This is especially necessary to establish the processing kinetics.

As alluded to in Chapters 6 and 9, more detailed work should be done to investigate the recovery of certain co-products that are adsorbed during the uranium extraction process. In particular, since it would be necessary to redesign portions of the plant in order to include processes to recover these materials, the actual economic value of co-product recovery may or may not be significant.

Since the $\mathrm{pH}$ and Eh of source seawater might affect the kinetics of adsorption, these values should be measured. Highly variable concentrations of trace metals, such as copper, must be measured and documented in order to assess their poisonous effects on the adsorbents.

The effect of plankton and other suspended material in the seawater needs to be experimentally investigated on at least a scale modei basis. It is anticipated that severe biological fouling, clogging, and scaling could occur in certain adsorbent bed designs, causing reduced seawater flow rates and lower uranium loadings. The important factors to monitor in this regard include calcium, alkalinity, nutrient and organic matter concentrations, plankton, and marine life densities load.

Uranium concentration in various strands of plankton and other marine organisms should be measured and those with high concentration factors should be cultured. This study would not only explore a potential means of concentrating uranium from seawater, but may also lead to a better understanding of the actual mechanisms of uranium extraction.

Construction materials, as well as the adsorbent beds, need to undergo tests to establish their resistance to seawater corrosion.

Long-term small-scale plant operation should be undertaken to discover other subtle operating problems which might arise in a full-scale uranium extraction plant.

It is known that the uranium concentrations in seawater vary Iinearly with salinity in the open oceans [26]. However, no detailed information is available on uranium concentration near selected plant 
sites. Direct measurements throughout the year are needed in order to obtain accurate data on the uranium concentration in the source seawater near the plant sites. The concentrations of potential co-products should also be measured.

Much more specific physical, chemical and biological oceanographic information is needed about the Puerto Rico site chosen (or, for that matter, any actual site which may be chosen for a future plant). Furthermore, there is very little understanding of the detailed nearshore currents such as would flow past a plant. I'he actual current flow pattern is an extremely important factor in the design of any type of uranium extraction plant for recovering uranium from seawater [26]. The seasonal variability in the flow direction and maximum, minimum, and average velocities of the nearshore currents are also poorly understood and should be studied in detail for regions near proposed plant sites.

Detailed information on the wind speed, wave height and other oceanographic characteristics, such as swell tides and possible storm surge, need to be collected for the geographic regions of interest.

In-depth local geological information for adequate civil and structural design is not available for the proposed sites. Collection of this information is one of the major steps preparatory to the construction of a plant.

The environmental effect of the plant outflow as it impacts the natural currents, the uranium concentration in seawater and the nearshore circulation patterns in the vicinity of the plant outflow needs to be investigated in much more detail. The large volume intake and outflow can form very strong local currents which might affect fishing and shipping activities. The discharge might also stir up the bottom sediments, erode beaches, and redistribute the resuspended particles. Detailed models must be developed to assess these effects.

Impingement and entrainment are potential problems for marine life. Careful studies must be conducted to make sure that no endangered species will be harmed by a uranium extraction plant. Every effort must be made to minimize the impact on marine life.

The redistribution of sediments might increase the turbidity of seawater and decrease the availability of solar energy below the surface. The resulting impacts upon productivity need to be studied.

The impact upon marine life of the residual discharge from the elution and the loss of adsorbent from either the normal processes or accidents must be studied. The chemical state and toxicity of titanium is poorly known and should be investigated.

Environmental monitoring programs must be initiated to achieve baseline information on the biological, chemical and physical characteristics of the surrounding region so that any impacts after a 
plant is in operation can be determined. The monitoring programs must be continuous in order to assess the long-term effects.

The success of such a project depends heavily upon the cooperation of the local community. Since public acceptance is essential, studies should be made to find out the possible reaction of the local community to the project.

Other potential sites for a plant outside the U. S. territorial waters should be considered. Those locations with good possibilities as a site should be compared with this study to assess their potential. If a site with outstanding potential is found, joint study with the nation controlling the site may be warranted.

Although the design of a uranium extraction plant based on ocean currents was beyond the scope of this study, nonetheless such a design would be an important contribution to the overall understanding of this technique especially in view of Japanese and German plans for extracting uranium from seawater (see Sections 15.1 .2 and 15.2.4.2.). It would be especially of interest to see how such a design would impact on the economic considerations of this type of uranium extraction.

This study represents a detailed technical and engineering study of how to concentrate uranyl ions by a factor of 100,000 on hydrous titanium oxide. Seawater is only one of what may be many potential feed streams for this technology. A thorough study should be made to identify other places where this technology could be applied. There may be several viable spinoffs. 
CHAPTER 13

FEASIBILITY OF URANIUM RECOVERY FROM SEAWATER

Feasibility of uranium recovery has four readily identifiable subdivisions: (1) technical feasibility; (2) engineering feasibility; (3) social feasibility; and (4) economic feasibility.

\subsection{TECHNICAL FEASIBILITY}

The two bibliographies $[1,35]$ with their total of over 800 separate references that constitute the Volume II portions of Reports XN-RI-14 and $\mathrm{XN}-\mathrm{RT}-15$ attest to the broad scope of technical studies that are available on this subject.

There exists international agreement that hydrous titanium oxide is a suitable adsorbent for extracting uranium from seawater (see Sections 15.1 and 15.2). Several modes of eluting uranium from hydrous titanium oxide and then recovering a uranium product have been tested to the point of confirming feasibility for that operation. Laboratory tests involving repetitive cycling over extended periods confirm dynamic operation.

From the viewpoint of the oceanographer, suitable sites can be identified where optimum conditions for fresh feed, waste discharge with minimal back mixing, water temperatures compatible with adsorption kinetics, suitable terrain onshore and offshore, ana fresh water availability exist. There exists a general base of information that confirms the uranium resource assessment from the macro point of view is correct. Uranium resource assessment from the micro point of view is less certain and requires site-specific study to truly establish those values. Detailed information on ocean current patterns between shore and the continental shelf also needs to be generated on a site-specific basis.

In summary, it is technically feasible to recover uranium from seawater, although there are a number of site-specific studies that should be conducted prior to site selection. 


\subsection{ENGINEERING FEASIBILITY}

The design presented in Chapter 7 of this document indicates that it is technically feasible to prepare a preliminary conceptual engineering design for the pumped flow recovery of uranium from seawater.

However, there are areas where insufficient information exists to prepare a final conceptual design. The most needed information falis in the following areas:

A better understanding of nearshore flow patterns of the ocean and the effect that large volume intake and outflow will have on these flow patterns is needed.

Physical and chemical properties of hydrous titanium oxide need to be established.

The continuous fluidized bed flowsheet is an adaptation from many authoritative sources based upon experienced engineering judgment, but a pilot plant operation must be carried out to test the concept.

The kinetics of the adsorption mechanism need to be studied and the process kinetics must be established.

In summary, it is not feasible from an engineering viewpoint to go beyond the preliminary conceptual design for a pumped flow or, for that matter, a tidal flow system, without performing the studies noted above. An ocean current feed system is still outside the preliminary conceptual design feasibility.

\subsection{SOCIAL FEASIBILITY}

The size of the plant would indicate a positive impact for the area in the sectors of business and labor. There would be a substantial impact on local governmental services (schools, police and fire protection, etc.). A large area of land and of fshore area would be withdrawn from the general public use category. However, the environmental impact on the population should be benign. There would be a considerable impact on the nearshore sea life. There would be little solid waste generated.

In summary, it would be socially feasibie to recover uranium from seawater as long as the plant site were in a low population area. 


\subsection{ECONOMIC FEASIBILITY}

It is concluded that the cost of extracting uranium from seawater in 1995 will range from $\$ 2100$ to $\$ 2600$ per pound of $\mathrm{U}_{3} \mathrm{O}_{8}$. The production cost is extremely capital intensive and, as such, the projected costs are sensitive to the method of financing the project. A private venture, without government support, could not produce uranium for under $\$ 2700 / 1 b$ and the most probable commercial cost would be $\$ 3600 / 1 b$.

Current $\mathrm{U}_{3} \mathrm{O}_{8}$ prices are about $\$ 42 / 1$ b today and likely will range from $\$ 130-220 / 1 b$ in 1995. It is projected that in 1995 a $\mathrm{U}_{3} \mathrm{O}_{8}$ price of $\$ 350-400 / 1 b$ could be sustained by the nuclear industry to maintain cost parity between coal and nuclear electrical generation plants. It is therefore concluded that without several major technical breakthroughs leading to significantly lower production costs and/or federal subsidy, a pumped seawater plant to extract uranium from seawater is not economically attractive.

Sensitivity studies have shown that production costs are quite sensitive to the economic conditions that prevail in the future. It was also shown that the cost sensitivities to process parameters are not sufficient to rationally expect production costs to be lowered by more than 50\%, even with significant technical breakthroughs. 
CHAPTER 14

REFERENCES

Only those citations referred to directly in the text of this document are listed below. The reader is referred to references $L 1 \mathrm{~J}$ and [36] below for a more bibliographic listing on the topic of extraction of uranium from seawater.

[1] Chen, A. C-T., Gordon, L. I., Rodman, M. R., and Binney, S. E., "Selected Bibliography for the Extraction of Uranium from Seawater: Evaluation of Uranium Resources and Plant Siting", XN-RT-14, Vol. II (1979).

[2] Ogata, N., "Recovery of Uranium from Seawater", Genshiryoku Kyoyo 16, No. 12, 19 (1970).

[3] Ogata, N., "Extraction of Uranium from Seawater (II)", Nippon Kaisui Gakkai-Shi 31, No. 3, 97 (1977).

[4] Kim, Y. S. and Zeitlin, H., "Separation of Uranium from Seawater by Adsorbing Colloid Flotation", Anal. Chem. 43, No. 11, 1390 (1971).

[5] Leung, G., Kim, Y. S., and Zeitlin, H., "An Improved Separation and Determination of Uranium in Seawater", Anal. Chim. Acta 60, No. 1, 229 (1972).

[6] Irish, E. R. and Reas, W. H., "The Purex Process - A Solvent Extraction Reprocessing Method for Irradiated Uranium", USAEC Report No. HW-49483A (1957).

[7] Davies, R. V., Kennedy, J., Peckett, J.W. A., Robinson, B. K., and Streeton, R. J. W., "Extraction of Uranium from Seawater. Part 1I: Extraction by Organic and Inorganic Absorbers", Atomic Energy Research Establishment Report No. R-5024 (1965).

[8] Laskorin, B. N., Metalnikov, S. S., and Terentiev, A. S., "Extraction of Uranium from Natural Water", Proc. UN Intern. Conf. Peaceful Uses At. Energy, and Geneva j, '́11 (1950). 
[9] Wooten, M. J., Hirayama, C., Panson, A. J., and Patton, J. T., "Uranium Recovery from Seawater", Electric Power Research Institute Report No. NP-132 (1976).

[10] Heide, E. A., Wagener, K., Paschke, M., and Wald, M., "Extraction of Uranium from Seawater by Cultured Algae", Naturwissenschaften 60 , No. $9,431(1973)$.

[11] Shigetomi, Y. and Kojima, T., "Basic Study on Uranium Extraction from Seawater. II. Extraction of U(VI) by Polyacrylamide Gel Containing Various Metal Hydroxides", J. Nucl. Sci. lechnol. 14, No. 11, 811 (1977).

[12] Keen, N. J., Miles, J. H., and Spence, R., "Extraction of Uranium and Other Inorganic Materials from Seawater", Atomic Energy Research Establishment Report No. R-5500, Vol. 2 (1967).

[13] Langston, B. G., MacDonald, R. D., and Stephens, Jr., F. M.,

"Ammonium Carbonate Pressure Leaching of Uranium Ores", J. of Metals (1957).

[14] Caddell, J. R. and Moison, R. L., "Mixed-Bed Deionization at High Flow Rates", Chemical Engineering Progress Symposium Series 50, No. 14, 1 (1954).

[15] Keen, N. J., "Studies on the Extraction of Uranium from Seawater", $\mathrm{J} . \mathrm{Br}$. Nucl. Energy Soc. 7, No. 2, 178 (1968).

[16] Amphlett, C. B., McDonald, L. A., and Redman, M. J., "Synthetic Inorganic Ion-Exchange Materials. II. Hydrous Zirconium Oxide and Other Oxides", J. Inorg. Chem. 6, 234 (1958).

[17] Inoue, Y. and Tsuji, M., "Hydrous Titanium Oxide Ion Exchanger. I. Method of Synthesis and Some Properties", J. Nucl. Sci. Technol. 13, No. 2, 85 (1976).

[18] Ryabinin, A. I., Doroshenko, G. A., and Lazareva, E. A., "Sorption of Uranium from Seawater on Titania Gel", J. Sov. Radiochem. 10, No. $1,113(1974)$.

[19] Davies, R. V., Kennedy, J., McIlroy, R. W., Spence, R., and Hill, K. M., "Extraction of Uranium from Seawater", Nature ¿05, 1110 $(1964)$.

[20] McKay, H. A. C., "By-products of Nuclear Power", Chem. Ind. (London), No. 7, 275 (1972).

[21] Khan, S., "Extraction of Uranium from Seawater as a By-product from Water Desalination Plants", Nucleus (Karachi) 9, No. 1-2, 39 (19'12).

[22] Kanno, M., "Problems to be Solved for Uranium Recovery from Seawater", Newer Metal Industry (Japan), No. 270 (1978). 
[23] Sugasaka, K., Katoh, S., Fujii, A., and Miyazaki, H., "Extraction of Uranium from Seawater", presented at the International Ocean Development Conference in Japan (1978).

[24] Haigh, C. P., "The Extraction of Uranium from Seawater", Central Electricity Generating Board Report No. R/M/N'787 (1976).

[25] Keen, N. J., "Recovery of Uranium from Seawater", Chem. Ind. (London), No. 14, 579 (1977).

[26] Rodman, M. R., Gordon, L. I., and Chen, A. C-T., "Extraction of Uranium from Seawater: Evaluation of Uranium Resources and Plant Siting", XN-RT-14, Vol. I (1979).

[27] Harrington, F. E., Salmon, R., Unger, W. E., Brown, K. B., Coleman, C. F., and Crouse, D. J., "Cost Commentary on a Proposed Method for Recovery of Uranium from Seawater", USAEC Report No. ORNL-TM-4/57 (1974).

[28] Humenick, M. J., Water and Wastewater Treatment, Calculations for Chemical and Physical Processes, Marcel Dekker, Inc., New York, N. Y. (1977).

[29] Robison, T. M. and Anders, R. B., "Electrical Analog Model Study of the Alluvial Aquifer in the Yabucoa Valley", United States Geological Survey report in cooperation with the Commonwealth of Puerto Rico (1973).

[30] U. S. Department of the Interior Geological Survey and the Commonwealth of Puerto Rico, "The Water Situation in Puerto Rico", Report to the U. S. Senate Select Committee on National Water Resources (1959).

[31] U. S. Department of the Interior Geological Survey, "Water Resources Data for Puerto Rico, Part I Surface Water Records", Annual report on Gage Station flows (1974).

[32] Hodgman, C. D., Weast, R. C., and Selby, S. M., "Handbook of Chemistry and Physics", 41st Edition, Chemical Rubber Publishing Company, 3374 (1959).

[33] Rossin, A. D. and Riech, T. A., "Economics of Nuclear Power", Science 201, 582 (1978).

[34] Kennedy, J., "Extraction of Uranium from Seawater. Part I: The Physical and Chemical States of Uranium in Seawater", Atomic Energy Research Establishment Report No. R-502j (1965).

[35] Starik, I. E. and Kolyadin, L. B., "The Occurrence of uranium in Ocean Water", Geochemistry, No. 3, 245 (1957). 
[36] Binney, S. E., Polkinghorne, S. T., Jante, M. R., Rodman, M. R., Chen, A. C-T., and Gordon, L. I., "Selected Bibliography for the Extraction of Uranium from Seawater: Chemical Process and Plant Design Feasibility Study", XN-RT-15, Vol. II; OSU-NE-7901, Vol. II (1979).

[37] Bettinali, C. and Pantanetti, F., "Uranium from Seawater: Possibilities of Recovery, Exploiting Slow Coastal Currents", reprinted from "Uranium Ore Processing", Proceedings of an advisory group meeting organized by the I.A.E.A., Vienna. Document No. IAEA-AG/33-4 (1976).

[38] Kanno, M., "Extraction of Uranium from Seawater", reprinted from "Nuclear Power and Its Fuel Cycle" Vol. 2, 1.A.E.A., Vienna. Document No. IAEA-CN-36/161 (1977).

[39] Kanno, M., "Technical Problems in Uranium Recovery from Seawater", Bul. of the Soc. of Seawater Science (Japan) 31, No. 4, 172 (1977).

[40] Kanno, M., "Summary: Uranium Recovery from Seawater", J. At. Energy Soc. Japan 19, No. 9, 586 (1977).

[41] Brochure issued by the Metal Mining Agency of Japan, "Technological Development for Uranium Recovery from Seawater in Japan", (about 1977 or 1978).

[42] Koyanaka, Y., "Collection of Uranium from Seawater by Galena", J. Nucl. Sci. Technol. 7, No. 8, 426 (1970).

[43] Ryabinin, A. I., Lazareva, E. A., and Doroshenko, G. A., "Sorption of Uranium from Black Sea Water by Anionites", Sov. Radiochem. 15, No. 3,439 (1973).

[44] Ogata, N., Personal communication, December, 1978.

[45] Keen, N. J., Personal communication, December, 1978. 
CHAPTER 15

APPENDICES

15. 1 EUROPEAN TRIP REPORT

15.1.1 Comitato Nazionale per I'Energia Nucleare (CNEN), Rome, Italy

During a visit on November 29, 1978, M. H. Campbell discussed the approach of the Comitato Nazionale per 1'Energia Nucleare (CNEN) to recovery of uranium from seawater with Mr. F. Pantanetti, Senior Advisor at CNEN. Mr. Pantanetti made the following points:

It is possible for Italy to recover enough uranium from seawater using the cooling water effluent from power plants and chemical plants to provide the uranium needed for the fast breeder reactors projected for Italy. This amounts to 40-60 tonnes per year.

Contrary to his 1976 IAEA report [37], their adsorbent of choice is hydrous titanium oxide, not galena ( $\mathrm{PbS}$ ).

His company has spent some time developing a sol gel process to produce hydrous titanium oxide spheres. The produced spheres have been in a size range of about $1 \mathrm{~mm}$. As yet no studies have been made on the mechanical properties of the spheres.

All his consideration has been focused on natural (passive) recovery methods. As an example they are considering using a strait between the island of Elba and a small adjacent island as a total engineered collection area. Filters would be placea across the strait $2-3 \mathrm{~m}$ below the low tide water level with some method of moving the filters to shore with a cycle frequency that would assure a complete loading. He anticipates a 25-30\% collection efficiency with this type of passive collection device. The pressure change across the fiiter must 
be low enough that the water does not simply bypass it. The current in this area apparently runs $50 \%$ of the time in each direction, "thus assuring" self-cleaning of debris from the filter.

Environmental concerns are an important consideration.

Industrial pollution of the Mediterranean Sea is of great concern too with respect to the effect on the adsorbent. Production of commercial fisheries is continually falling of $f$ due to continued industrial pollution. The Adriatic Sea has poor exchange and, considering the industrial pollution, is not worth pursuing.

He also said he did not think much of algae farming to recover uranium from the sea due to the problem of achieving the necessary contact with a large volume of water and due to the amount of energy expended to ash the algae preparatory to uranium recovery.

By Mr. Pantanetti's arrangement, several days later M. H. Campbell met with Mr. P. Gerontopoulos, AGIP Nuclear, TU-Institut, Karlsruhe. He discussed in generalities his broad background in preparing microspheres by the sol gel process. He specifically suggested he could prepare hydrous titanium oxide spheres of a $1 \mathrm{~mm}$ (or less) size with "meters of specific area". While he could not speak of the process in more depth for proprietary reasons, he did suggest the particles would have a good mechanical stability; he sinters at $1200+C$ which would not promote the performance of hydrous titanium oxide for adsorbing uranium.

\subsubsection{Uranerzbergbau, Bonn, West Germany}

On December 4, 1978, S. E. Binney met with Mr. Hans G. Bals and $\mathrm{Dr}$. Erwin Oser of Uranerzbergbau (UEB) who are working in conjunction with Professor Schwochau's group at Kernforschunganlage (KFA), Juelich, West Germany, Gesellschaft fur Kernenergieverwertung in Schiff'bau und Schiffahrt (GKSS), RWTH Aachen, Institut fur Luft- und Raumfahrt, and TU Berlin, Institut fur Meerestechnik. The following information was offered by $\mathrm{Mr}$. Bals and Dr. Oser:

UEB is working on hydrous titanium oxide and engineering designs. KFA is working on other adsorbents and GKSS is working on "natural" adsorbents, for example, peat. These projects are all funded by the federal government.

The hydrous titanium oxide produced by UEB has achieved capacities of 500-600 micrograms uranium per gram titanıum in fluidized beds at Helgoland, a German island of the North Sea 
coast. At Freetown, Sierra Leone, they only achieved about 300 micrograms uranium per gram of adsorbent but felt that this was due to the large copper concentrations in that region that were adsorbed onto the hydrous titanium oxide, which competed with the uranium adsorption. They want to improve their kinetics another factor of two or three and then hopefully build a pilot plant in four or five years.

Their hydrous titanium oxide is an amorphous gel with particles less than $1 \mathrm{~mm}$ in diameter. It was sensed that they could achieve high loadings or mechanical integrity, but not both simultaneously. They are also concerned about attrition (mechanical breakage) and solubility in seawater.

They have not definitely decided on an eluant yet, but have found both ammonium carbonate and sodium carbonate to be roughly equally effective.

They are concerned about the interference of other ions in the seawater (see Section 15.1.3).

They have observed no serious biological fouling problems yet, but realize this could be a problem.

They are unwilling to make any cost estimates at this time.

They have identified no co-product materials that they feel are both "precious" and concentrated enough by their adsorbent.

Their conceptual plant design utilizes a fluidized bed with a contact time of about 10 seconds. The hydrous titanium oxide residence time in the adsorbent section of the plant from input to exit is about a month. This plant woula be anchored in a strongly moving current such as the Gulf Stream. The Germans are not considering a pumped coastal site, since the North Sea is too cold and polluted, nor a tidal plant even though they have three or four meter tides in the North Sea on the Germany coast.

They talked to Dr. Ogata from Japan about a year ago. His 1500 micrograms uranium per gram titanium value came from a powdered titanium oxide stirred in a beaker for 24 hours. Dr. Ogata himself admitted that this would never work for uranium extraction from seawater. 
15.1.3 Kernforschunganlage (KFA), Juelich, West Germany

On December 5, 1978, M. H. Campbell and S. E. Binney met with $\mathrm{Mr}$. Bals and Dr. Oser of UEB, and Dr. Klaus Schwochau, Dr. Ludwig Astheimer, Dr. Hans J. Schenk, and Dr. E. G. Witte of KFA.

The meeting opened with an interesting discussion on adsorbents. While UEB has settled upon hydrous titanium oxide as being the best adsorbent available at this time, Dr. Schwochau inferred that a better adsorbent was in the works. Mr. Bals provided the following critique of the hydrous titanium oxide prepared at UEB:

The lifetime of the adsorbent is three months to one year and there is a 6-10\% adsorbent loss per cycle from a combination of physical abrasion (greatest effect) and solubility. The solubility is greatest during the elution cycle, being about 3-6\% with ammonium carbonate as the eluant.

UEB's hydrous titanium oxide has a capacity of 500-600 micrograms uranium per gram titanium. The uranium is adsorbed on the outer surface (about 100 molecular diameters). Even though preparation of the hydrous titanium oxide may vary slightly, the capacity remains roughly constant to within about $\pm 10 \%$. Uranium uptake does decrease with increasing crystalline structure, however. The surface is apparently fairly smooth. The density is about $1.1-1.2 \mathrm{~g} / \mathrm{cc}$.

The kinetics of the adsorption reaction is rapid with a $30-50 \%$ recovery of the uranium flowing though a fluidized bed of approximately $0.5 \mathrm{~m}$ height at a linear velocity of about 5 $\mathrm{cm} / \mathrm{s}$. This results in a roughly 10-15 second contact time of the seawater with the bed. Exposure to an additional bed thickness is not effective in collecting more uranium. The pressure drop across the bed is about 50-60 mm of water with a maximum of perhaps up to $100 \mathrm{~mm}$. They feel they need to process approximately $3000-4000$ cubic meters per second of seawater (this corresponds to about 10-13 grams of uranium per second flowing past the adsorbent and, at $50 \%$ recovery, about 160-210 tonnes of uranium adsorbed per year).

UEB hopes to attain uranium costs from seawater that are comparable to future terrestrial uranium prices. They feel it is a higher priority to establish the overall energy balance of this process than to determine a cost estimate, however.

The effect of temperature upon hydrous titanium oxide adsorption kinetics is a factor of about two increase between $20 \mathrm{C}$ and $30 \mathrm{C}$ and it is "very bad" at $15 \mathrm{C}$. Professor Schwochau commented that this was probably due to an increase of the uranyl ion diffusion coefficient. 
Professor Schwochau additionally commented that the presence of plankton in the cold water and the attendant hydrous titanium oxide fouling is yet another reason to stay away from cold water. Mr. Bals reported that they are planning to start work on biocides for their flotation bed.

The UEB preparation procedure for hydrous titanium oxide is precipitation in ammonium hydroxide with crushing taking place immediately after precipitation, followed immediately by sieving. The less heat involved in drying the precipitate, the better the titanium hydroxide sites are as adsorption sites. This treatment results in the very low density reported above. Since the hydrous titanium oxide is amorphous, no $x-r a y$ crystallography study can be done and the electron microscope or even Auger spectroscopy techniques are not useful because a vacuum must be drawn on the material before analysis and that removes the water.

UEB's hydrous titanium oxide is poorly selective for uranium compared to other metals which compete with the uranium. In actual tests at their Helgoland and Sierra Leone sites, the eluant has been analyzed for cations other than uranium. A typical result shows approximately $15,000 \mathrm{ppm}$ magnesium and slightly more calcium as well as vanadium, manganese, iron, copper, and zinc values higher than the uranium concentration. In their experiments Professor Schwochau reported only a partial elution of heavy metals in the ammonium carbonate and a cleanup elution with $1 \mathrm{M} \mathrm{HCl}$ as being needed to remove all metal ions. The hydrous titanium oxide has a solubility of one gram per liter in $1 \mathrm{M} \mathrm{HCl}$. About $3-5$ bed volumes of eluant were used in these studies. Mr. Bals admitted that to date it has been difficult to obtain replicate batches of hydrous titanium oxide although most properties are within a suitable specification range.

Spherical particles are easier to control in a fluidized bed.

Mr. Bals does not think attrition will be any greater in a fluidized bed than in a fixed bed.

Mr. Bals also made the following suggestions on the then current design basis for this study:

The depletion factor (for seawater) of $8-10$ is too high. An extraction efficiency of $30-50 \%$ should be optimum.

The bed thickness should be reduced to reduce the pumping head and accept a $50 \%$ recovery efficiency.

Establishing the beds below sea level would also reduce the cost of pumping. 
Professor Schwochau made several observatons with respect to hydrous titanium oxide as well as other adsorbent materials:

Uranium adsorption increases with an increase of the TiOH group in hydrous titanium oxide.

Professor Schwochau discussed his group's investigation for improved adsorbent materials. In comparison to hydrous titanium oxide, they are seeking a material that would be cheaper, available in large quantities, and capable of a concentration factor in excess of 100,000. Over 150 materials have been tested so far.

A predecessor group at KFA had studied uranium uptake in green and blue algae. That group has reported concentration factors for uranium of 10,000 to 100,000 with the algae. Subsequent experiments by $\mathrm{Dr}$. Schwochau's group found a concentration factor of only 600 for the blue algae. On review of the prior work, it was determined that artificial seawater had been used and they had failed to include the magnesium and calcium components. Thus the algae concentration concept was found unserviceable and no further work was done with it.

Brown coal was also evaluated as an adsorbent but failed to provide a suitable concentration factor, yielding less than 3 ppm uranium. Schwochau's group is currently working on an organic chelating ion exchange resin which proves to be fairiy promising. While the precise functional group is proprietary, they mention that this organic base material is capable of loading to more than $700 \mathrm{ppm}$ uranium from natural seawater in a flow through column. This capacity was apparently not a saturated value at that. The matrix is very nearly insoluble in seawater, being in the form of fairly rugged spheres. In Schwochau's opinion, stability should be good since a polymeric substrate (for example, styrene) would be more impervious to seawater than the condensation products used in earlier tests that showed disintegration of the substrate in seawater. The cost for this chelating resin is roughly the same as that for $\mathrm{TiO}_{2}$ (approximately $\$ 4 / \mathrm{kg}$ ). The uptake by the chelating resin decreases from cycle to cycle. Hydrochloric acid is needed to elute the uranium. They mentioned they need to stabilize the functional groups of their resin against seawater and their eluant. Their chelating resin has a stronger temperature dependence and faster kinetics (by a factor of about two) than the hydrous titanium oxide of the British. They also felt that this chelating resin could be produced in large quantities at the prices mentioned above. In side by side tests the capacity of the chelating resin was $700 \mathrm{ppm}$ uranium while that for hydrous titanium oxide was 400-500 ppm uranium using natural seawater. The process involved for the chelating resin is cation exchange as it is for hydrous titanium oxide. Only the 
uranyl ion is bound by either the chelating resin or hydrous titanium oxide since the carbonate concentration of the seawater has been observed to be the same before and after the exposure to the adsorbent. About $80-90 \%$ of the uranium can be eluted from the chelating resin with hydrochloric acid, although they are experimentally looking for a better eluant. They mentioned that the Japanese only get about 10-12 ppm uranium in their eluant stream.

Professor Schwochau had done some comparatıve studies on uranium uptake in chelating resins and hydrous titanium oxide as a function of temperature and uranium uptake per volume of seawater passed through. His study showed that uranium uptake improves as temperature increases and further that the chelating resin can have twice the hydrous titanium oxide uptake per unit volume of feed at $30 \mathrm{C}$. In comparing loading characteristics of commercially available ion exchange $r \in \operatorname{sins}$ with hydrous titanium oxide and their chelating resins, concentration factors for the commercial resins ranged from approximately 100 to 10,000 compared to approximately 200,000 for hydrous titanium oxide and their chelating resin. Further a comparison of uranium uptake per volume of seawater feed to the $\mathrm{pH}$ of the effluent showed that the commercial resins tend to depress the seawater $\mathrm{pH}$ initially with a loss of adsorption capability occurring as the $\mathrm{pH}$ increased past 7 so that rejuvenation of the resin would be required in order to recover uranium. This latter effect would be harmful to the environment and very costly in chemicals. This "pH effect" was not found for hydrous titanium oxide nor the chelating resin.

Dr. Schwochau's group at KFA uses silica gel as an analytical tool to pre-concentrate the uranium from seawater for fluorometric analysis. They haven't considered silica gel as an adsorbent because they feel it is too soluble in seawater (no value given) and has too low of a concentration factor. $\mathrm{Dr}$. Schwochau indicated the latter value was about 20,000, corresponding to 60-70 micrograms of uranium per gram of silica $g \in l$.

15.1.4 Atomic Energy Research Establishment (AERE), Harwell, Dideot, England

On December 6, 1978, M. H. Campbel1 and S. E. Binney met with Mr. Norman J. Keen, Mr. E. W. (Eddie) Hooper, and Dr. Richard Worswick. $\mathrm{Mr}$. Hooper was involved quite directly with much of the uranium extraction from seawater work as was Mr. Keen. This work was done before 1961 and again from 1965 to 1969. 
At the outset of this meeting Mr. Keen advised, probably from past experience, that early published results from Harwell were descriptions of studies at that time and that they should not be extrapolated. Later work, much of it not yet published, provided improved understanding and solved most of the problems described in those early articles.

With respect to the hydrous titanium oxide adsorbent, Mr. Keen made the following general statements:

A 16 month test was performed in which approximately 500 cubic meters of seawater per day were passed through a $10 \mathrm{~cm}$ bed on a 10 day cycle in an experiment at Portsmouth Harbor.

They stated that their hydrous titanium oxide loss, excluding an accidental mechanical loss, was not greater than $5 \%$ per year, but a $10 \%$ per year value was used in their estimates to assure conservatism. These losses include both solubility and mechanical attrition.

The British have done experiments in both packed and fluidized beds, although most of their work has been concentrated on the packed beds. This is the case for the data mentioned below.

A loading capacity of 300-400 micrograms uranium per gram titanium did not change over that time period (sampies were taken at the end to reconfirm this). The density of the titanium oxide is taken to be $0.5 \mathrm{~g} / \mathrm{cc}$.

Linear velocities of the seawater were varied from 0.15 to 0.56 $\mathrm{cm} / \mathrm{s}$, corresponding to contact times of about $20-70 \mathrm{~s}$. A $10 \mathrm{~cm}$ bed can recover $100 \%$ of the uranium at $0.5 \mathrm{~cm} / \mathrm{s}$.

They have observed that blinding of the bed by calcium carbonate precipitation can cause channeling of the flow through the bed. They lost about $30 \%$ of the carbonate from the eluant because of calcium carbonate, which could prove to be a major cost. Buildup of the calcium carbonate can be overcome, however, by a backwash after elution. If this is done, they felt there is no need for rejuvenation of the hydrous titanium oxide aside from simply adding "make-up" adsorbent. There should be no need to change out the adsorbent over a ten-year period.

Elution has been accomplished with sodium carbonate, ammonium carbonate, and sodium bicarbonate. Elution with the ammonium carbonate will give $90+\%$ elution efficiency.

A fluidized bed operation was carried out successfully with low attrition.

The cost of pigment grade titania is a reasonable cost for the hydrous titanium oxide adsorbent. 
Their hydrous titanium oxide has a specific surface area of about 400-500 square meters per gram after drying out (collapsed form). Presumably it is higher in its wetted form.

They feel they need to develop a tidy method of preparing the hydrous titanium oxide. However, reproducible loadings can be obtained if the process is carefully watched at several important steps.

Data presented by Mr. Hooper indicated that the initial uranium loading is controlled by film diffusion, at least for a temperature range of $3 \mathrm{C}$ to $35 \mathrm{C}$. After about 8 days some of the uranium begins to diffuse into the hydrous titanium oxide matrix.

Mr. Hooper had performed most of the experiments and had a wealth of information he had not yet published. In particular he had considerable data on the effects of seawater temperature upon uranium recovery. The series of curves he showed revealed a factor of about 10 difference between uptake at $10 \mathrm{C}$ as compared with $30 \mathrm{C}$. In addition the British also observed seasonal variations in their hydrous titanium oxide uptakes due to variation of seawater temperature at their weymouth laboratory.

A study of loading kinetics as a function of time and particle size showed that the adsorption mechanism is nearly instantaneous, and that uranium adsorption is preferential over most other cations (for example, iron, calcium, magnesium, etc.). The data would favor a thin bed with frequent elution. Actually, this study should be carried out specific to the design process to established the operating parameters.

A major effort needs to be mounted to improve the material characteristics of the hydrous titanium oxide adsorbent. Certainly a large surface area must be obtained per gram of hydrous titanium oxide, and furthermore, a more mechanically strong particle must be prepared. The two objectives might be achieved by coating an inert ceramic substrate with hydrous titanium oxide, although the bonding could represent a difficult problem.

A major problem yet to be addressed, according to Mr. Keen, is the dilution of the eluant by the rinse water in its initial transit through the bed. By Mr. Hooper's projections, this is a major cost item. He has suggested some sequential eiution by a "strong stream and a lean stream" to satisfy this probiem. The eluant could be reused from bed to bed up to a uranium loading of about $100 \mathrm{mg}$ uranium per $\mathrm{ml}$.

The paradox of the German viewpoint and the English viewpoint, 
namely, why the Germans assume a 30-50\% recovery, while the British assume a 90+\% recovery, was discussed. Mr. Keen agreed that the German viewpoint might be reasonable in the German approach to uranium recovery, but when using beds (downflowing or fluidized), they felt that the British figures applied. With respect to the lifetime of the hydrous titanium oxide (10 years versus 1 year), the British point to their experience.

The British feel that organic compounds will have problems in seawater due to solubility and biological attack and would therefore not recommend using any type of organic compound for uranium extraction from seawater.

An overall assessment of the impressions of these European contacts reveals the following points:

- A general view for recovery of uranium from seawater is not pessimistic, rather it is pragmatic. Technical information needs to be developed, but economic assessment might well be deferred until the technology is further advanced.

- Hydrous titanium oxide is the best adsorbent at present, but should be improved or replaced with a better material.

- A pilot plant operation is needed to truly assess the feasibility of uranium recovery from seawater. 


\subsection{JAPANESE TRIP REPORT}

\subsubsection{Summary and Conclusions}

Most of the current work in Japan on extracting uranium from seawater is part of an overall national effort which is coordinated by the Metal Mining Agency of Japan. Professor M. Kanno of Tokyo University has a key position as the overall technical coordinator or monitor.

The Japanese have made steady progress in improving the technology for the above effort. Much of their work has been published, usually first in Japanese. There is usually a lag of up to a year or more before the information appears in English.

Their current best recommended adsorbent for plant use is hydrous titanium oxide prepared without a binder. Its mechanical properties are improved by granulating and pressing the hydrous titanium oxide prior to drying [38]. The final drying temperature and degree of dehydration are important variables and are currently considered proprietary information by the Japanese.

The Japanese have made conceptual plant designs for recovering uranium from seawater $[38,22,39,40,41]$. Table $15.2-1$ gives some current recommendations.

The Japanese program is ready for construction of a Model Plant which would demonstrate both pumped and ocean current concepts and produce $10 \mathrm{~kg}$ of uranium per year. This would require about 0.2 cubic meters per second of seawater, 24 hours per day. This piiot plant is needed to help answer remaining technical questions, which cannot be resolved with existing small experimental facilities, and to provide further guidance for designing larger plants.

The Model Plant will be built and start operation in approximately four to six years, if funded by the Japanese government.

The Japanese might be willing to participate in a joint Japanese-U. S. cooperative program involving the Model Plant.

The People's Republic of China is reported to have 100 engineers working at eight test facilities on recovering uranium from seawater (see Section $15 \cdot 2 \cdot 3 \cdot 3)$. 
Table 15.2-1 Extraction of uranium from seawater:

Recommended plant conditions

Ad sorbent:

Hydrous titanium oxide prepared without a binder; $1 \mathrm{~mm}$ diameter particle size. Need 250 tonnes initial adsorbent inventory for a plant to recover 1000 tonnes of U/year.

Uranium loading:

$100 \mathrm{mg} \mathrm{U} / \mathrm{kg}$ of adsorbent. (This is equivalent to $>200 \mathrm{mg} \mathrm{U} / \mathrm{kg}$ of contained $\mathrm{Ti}$. )

Bed depth:

$10 \mathrm{~cm}$

Seawater velocity through bed:

20 to $40 \mathrm{~cm} / \mathrm{min}$. (contact time 30 to $15 \mathrm{~s}$ )

Plant cycle $(25 \mathrm{C})$ :

Load 10 days; 2 days elution.

$\mathrm{TiO}_{2}$ loss:

Believe $0.1 \%$ per loading/elution cycle with a fixed bed; somewhat higher for a fluidized bed.

Temperature effect:

Almost $40 \%$ increase in uranium uptake in 10 days at $25 \mathrm{C}$ compared with $15 \mathrm{C}$.

El uant :

Ammonium carbonate or sodium carbonate. Ammonium ion may be more objectionable as a nutrient in the ocean.

Repetitive cycles:

Adsorbent performance does not fall to anywhere near half original value after 10 cycles.

Fouling:

Once every 5 to 10 cycles elute with dilute (tentative $0.1 \mathrm{M}$ ) $\mathrm{HCl}$ to remove calcium, magnesium, strontium, vanadium, chromium; helps remove organic blockage. Titanium loss during acid wash may be 10 times a normal cycle loss. 
15.2.2 Meeting with Okayama College of Science Personnel, $12 / 4 / 78$, Toyo Hotel in Osaka City

Those present were: Dr. M. Shinagawa, Emeritus Professor of Csaka University; Dr. Y. Shigetomi, Professor of Chemistry, Okayama College of Science; Mr. Y. Kojima, Department of Chemistry, Okayama Colleg $\in$ of Science; Mr. Y. Murozono of Esso Standard Sekiyu; and F. W. Woodfield.

This work is now being carried on in the Chemistry Department of the Okayama College of Science by Mr. Kojima under Professor Shigetomi. Their uranium extraction studies employ hydrous titanium oxide in a porous polyacrylamide binder. The adsorbent is prepared by combining titanium (as $\mathrm{TiOH}$, or gel or powder form), sulfuric acid, and acrylonitrile to form acrylamide, which is neutralized and caused to polymerize by adding ammonium persulfate initiator. Further treatment with ammonium hydroxide forms the hydrous titanium oxide dispersed in the resin binder. The resin is crushed and seived to separate a 20-100 mesh size range of particles. Research is continuing on the best way of forming the above adsorbent, and on increasing the hydrous titanium oxide content relative to the resin binder; the higher this content the better it adsorbs uranium.

They described the following work using two sizes of glass columns:

$\begin{array}{llc} & \text { Small } & \text { Large } \\ \text { Column diameter, cm } & 5.6 & 60 \\ \text { Column overall length, m } & -- & 4 \\ \text { Fluidized bed height (upflow) } & 15 \mathrm{~cm} & 2 \mathrm{~m} \\ \text { Contact time, s } & -- & 10 \text { to } 30 \\ \text { o of U extracted from seawater feed } & >80 \% & v_{60 \%} \\ \text { Uranium loading } & 100 \mathrm{mg} \mathrm{U} / \mathrm{kg} \mathrm{Ti} & --\end{array}$

* Seawater pumped through for 10 days, $24 \mathrm{hr} /$ day.

Each column employed a 50 to 80 mesh saran screen both below and above the fluidized bed to retain the adsorbent. A 10 second contact time was the shortest tested. The optimum contact time had not yet been determined.

They had observed almost no temperature effect and hence felt that the natural variation in seawater temperature between $15 \mathrm{C}$ and $25 \mathrm{C}$ woula not be significant. (Note: This is at variance with information from the other Japanese groups visited.)

The presence of the resin binder apparently reduces the uranium loading capacity of the adsorbent. Dr. Shigetomi has attained a practical uranium loading of $100 \mathrm{mg} \mathrm{U/ \textrm {kg } ~ T i . ~ T h i s ~ i s ~ a b o u t ~} 2$ 1/2-fold lower than the comparable number from the Metal Mining Agency for hydrous titanium oxide which does not have a binder. 
Dr. Shigetomi and Mr. Kojima had measured the loading capacity of their adsorbent using strontium, had calculated the resulting grain surface area, and projected from this that the corresponding maximum uranium loading would be $2000 \mathrm{mg} \mathrm{U} / \mathrm{kg} \mathrm{Ti}$. This fact is reported for what it may be worth. It seems possible that differences in size, mobility, and penetrating power of the strontium ion, compared to the larger complex uranium-bearing ion, could make inner surfaces available for strontium adsorption which would not be available to uranium.

$\mathrm{Dr}$. Shigetomi and $\mathrm{Mr}$. Kojima had responded to a questionnaire from the Massachusetts Institute of Technology (MIT) and hence were aware of MIT's current study of the practicality of recovering uranium from seawater.

15.2.3 Visit to Sikoku Industrial Research Institute, 12/5/78; Visit to the Government Industrial Research Institute, Takamatsu City, on the Island of Sikoku

Both the Government Industrial Research Institute at Takamatsu and the Metal Mining Agency of Japan come under the Ministry of International Trade and Industry (MITI). However, the Institute at Takamatsu reports through the Agency of Industrial Science and Technology (AIST), while the Metal Mining Institute reports through the Agency of Natural Resources and Energy (ANRE).

An initial technical discussion was held in the Director's Office, after which experimental facilities used on the uranium from seawater program were toured. These experimental facilities were both at the Institute laboratory buildings in Takamatsu and at a salt-from-seawater plant located about 15 miles away in Sakaide City.

Present in the initial discussion were Dr. Y. Kimura, Director-General of the Institute; Dr. H. Miyazaki, Manager of the Chemistry Department; Mr. S. Katoh, Manager of the Inorganic Chemistry Division; Mr. K. Sugasaka, Manager of the Marine Resources Division; Mr. Y. Murozono of Esso Standard Sekiyu; and F. W. Woodfield.

Among other programs, the Chemistry Department of the Institute is conducting research on extracting mineral resources from seawater, and on processes for cleaning up certain industrial waste water streams. One class of adsorbents being studied is metal hydroxides dispersed in activated carbon and employing polyvinyl alcohol as a binder. Metal hydroxides tested have included those of magnesium, nickel, copper, zinc, aluminum, iron, chromium, titanium, and vanadium. The hydroxides are prepared by hydrolysis of the metal salt (usually the chloride) with sodium hydroxide solution, after first mixing the metal salt solution with activated carbon. Since they have found the commercially availabie activated carbons not always ideal, they prepare their own by carbonizing 
(pyrolyzing) shredded pine wood in a rotating glass tube furnace at $600 \mathrm{C}$ to $900 \mathrm{C}$. The glass tube was about $5 \mathrm{~cm}$ diameter by about $120 \mathrm{~cm}$ long. Low density carbon has been found more effective than dense carbon.

of all the metal hydroxides tested, hydrous titanium oxide is the most effective for removing uranium from seawater. Development work on improved adsorbents is continuing. Although not yet demonstrated, they hope within perhaps two to three years to demonstrate an adsorbent capable of loading to $200 \mathrm{mg} \mathrm{U} / \mathrm{kg} \mathrm{Ti}$ under plant conditions. (Note: It appears that the Metal Mining Agency work may already have demonstrated such loadings.)

Some of the Institute's work on uranium extraction is done with seawater which has been spiked to increase its uranium content. Figure 15.2-1 shows uranium concentrations on three adsorbents (hydrated copper, aluminum, and titanium in activated carbon) in equilibrium with spiked seawater containing 60 micrograms of U/liter.

\subsubsection{Experimental facilities at Takamatsu}

Figure 15.2-2 represents, schematically, equipment in one of the Institute laboratory buildings at Takamatsu. The top two Iines of equipment depict the process by which hydrous titanium oxide is formed on activated carbon, washed, filtered, dried, granulated, kneaded, extruded, broken up in a granulator, and screened into various particle size ranges. The bottom line of equipment shows three alternative small laboratory scale methods of contacting seawater with the adsorbent: column-type adsorbent beds, (2) a batch mixer/settler, and (3) a continuous unit composed of an area where fresh seawater is mechanicaliy mixed with adsorbent and a settling chamber between closely-spaced inclined conical baffles. The settled adsorbent particles are then recycled for repeated contact with fresh seawater, while the uranium-depleted seawater is drawn off by overflowing a circumferential weir at the top of the unit. The batch and continuous units at the Institute were about $60 \mathrm{~cm}$ in diameter.

One problem with the continuous unit has been incomplete separation of adsorbent particles from the seawater effluent.

\subsubsection{Experimental facilities at Sakaide City}

The Sanuki Engyo (salt manufacturing) Plant at Sakaide City on Sikoku Island processes 300,000 tonnes of seawater per day to produce salt. The Industrial Research Institute located pilot plant and bench-scale uranium recovery equipment at the salt plant beginning about 


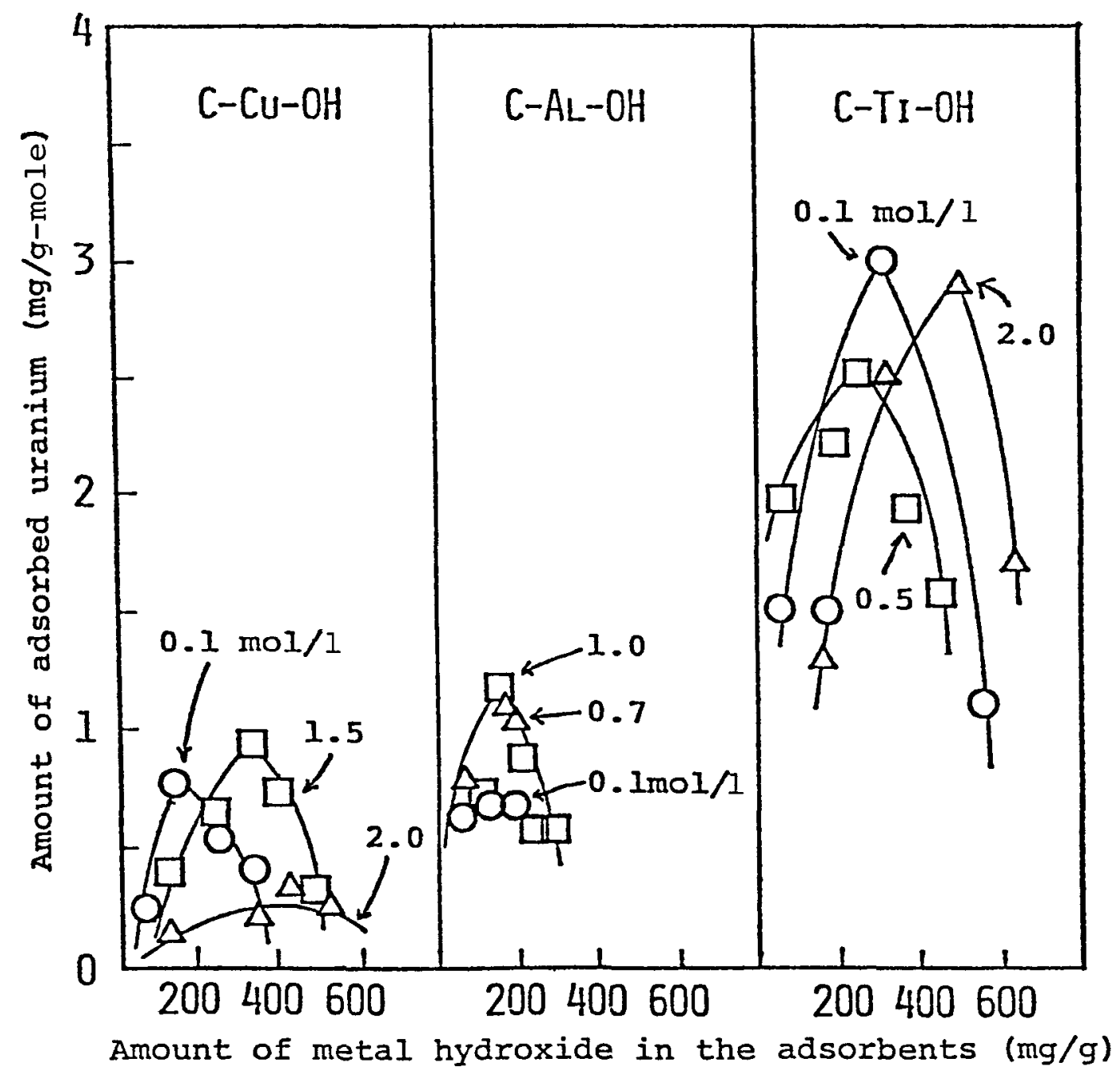

Figure 15.2-1 Uranium loading on metal hydroxides. 


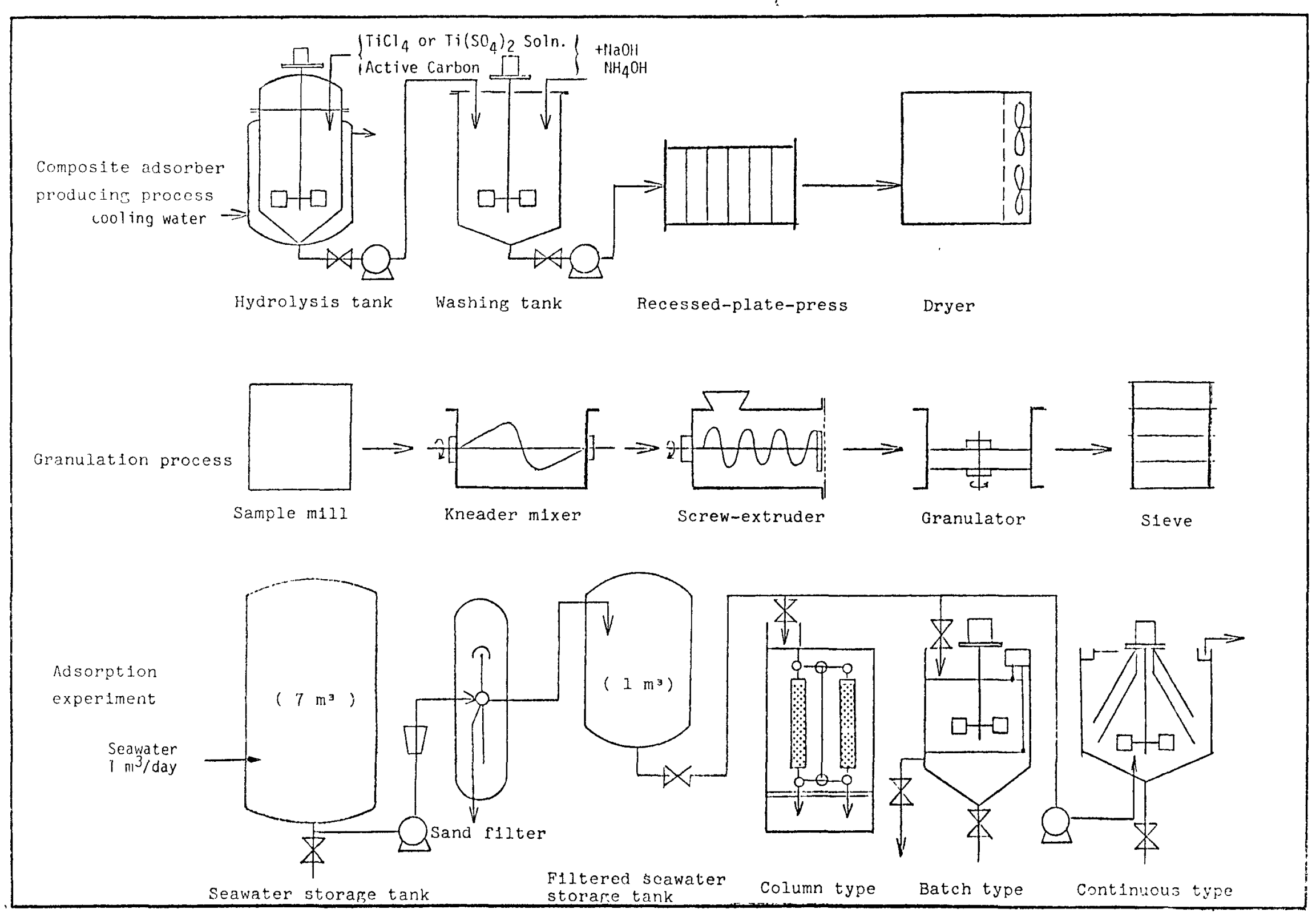

Figure 15.2-2 Uranium extraction schematic, Takamatsu, Japan 
four years ago to take advantage of the continuous supply of filtered seawater as feed for uranium extraction studies.

Three types of equipment for contacting the adsorbent with seawater are located at the salt plant, as follows:

(1) Packed columns of three diameters: $5 \mathrm{~cm}, 10 \mathrm{~cm}$, and $50 \mathrm{~cm}$.

(2) A tidal flow type apparatus for flowing 30 cubic meters per 24 hours through a 5 to $10 \mathrm{~cm}$ deep adsorbent bed with either up or down flow, simulating a one meter tidal head available to cause flow through the bed.

(3) A continuous flow unit, also for 30 cubic meters per 24 hours, composed of a stirring tank for contacting fresh seawater with the adsorbent, a settling tank where uranium-depleted seawater leaves via a top weir overflow, and equipped with a chain conveyer in the settling tank with scrapers to push the settled adsorbent to a bottom tank outlet where it is returned by a slurry pump to the stirred tank to be contacted with fresh seawater.

Mr. Y. Murozono and F. W. Woodfield were taken to the salt plant and shown the above equipment by Mr. K. Sugasaka, Manager of the Marine Resources Division, the component which has been doing the Institute's uranium from seawater work. Figure 15.2-3 shows schematically the three contactor concepts at the salt plant. Figure 15.2-4, reproduced from an Institute brochure, shows the continuous contactor (twin units) in the foreground, and the tidal flow unit at the righthand middle area of the picture. Figure 15.2-5 shows four views of the continuous unit, including the agitator in the stirring tank, the scraper blades on the chain conveyer, and the depleted seawater overflow weir. Figure 15.2-6 shows an outside view of the tidal flow unit. The other view on Figure 15.2- 6 was taken inside a small building. The $50 \mathrm{~cm}$ diameter glass packed column is slightly to the right of center; the smaller glass columns are to the right of the $50 \mathrm{~cm}$ column. The taller glass column on the left quarter of Figure 15.2-6 was originally used for the elution step, but more recently the $50 \mathrm{~cm}$ diameter column has been used for this purpose.

None of the above uranium from seawater experimental equipment at the salt plant was in operation during this visit. It was reported that one problem with the continuous unit was some carryover of adsorbent particles with the effluent seawater stream.

The seawater intake stream to the salt plant is routinely filtered through a sand filter. A portion of this filtered seawater stream is diverted and used for the uranium extraction studies, after first being filtered a second time through a small sand filter. Hence any problems which might be caused by plankton and other suspended material in the feed stream were avoided in most of the work conducted by the Institute 


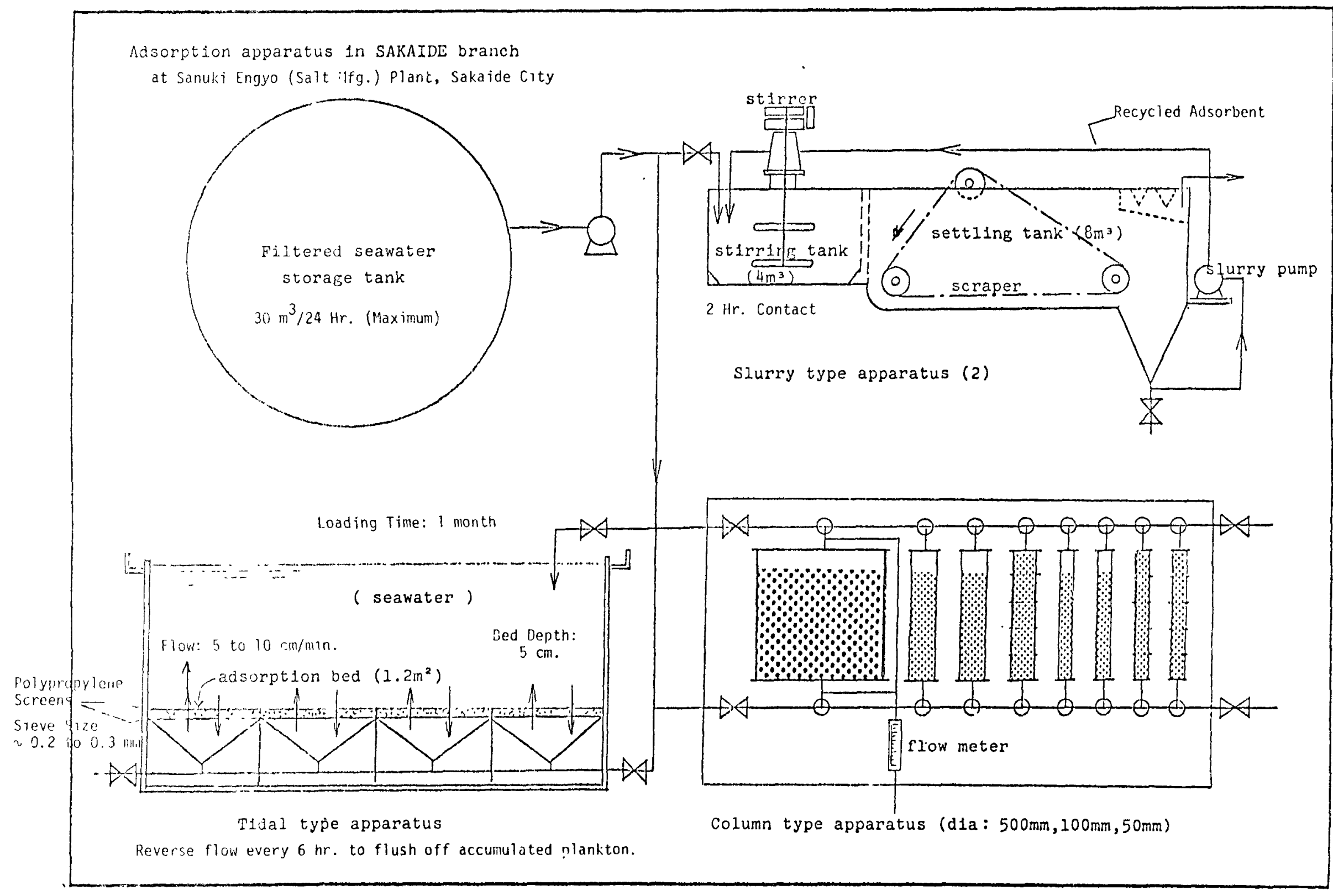

Figure 15.2-3 Uranium extraction schematic at Sakaide City, Japan. 


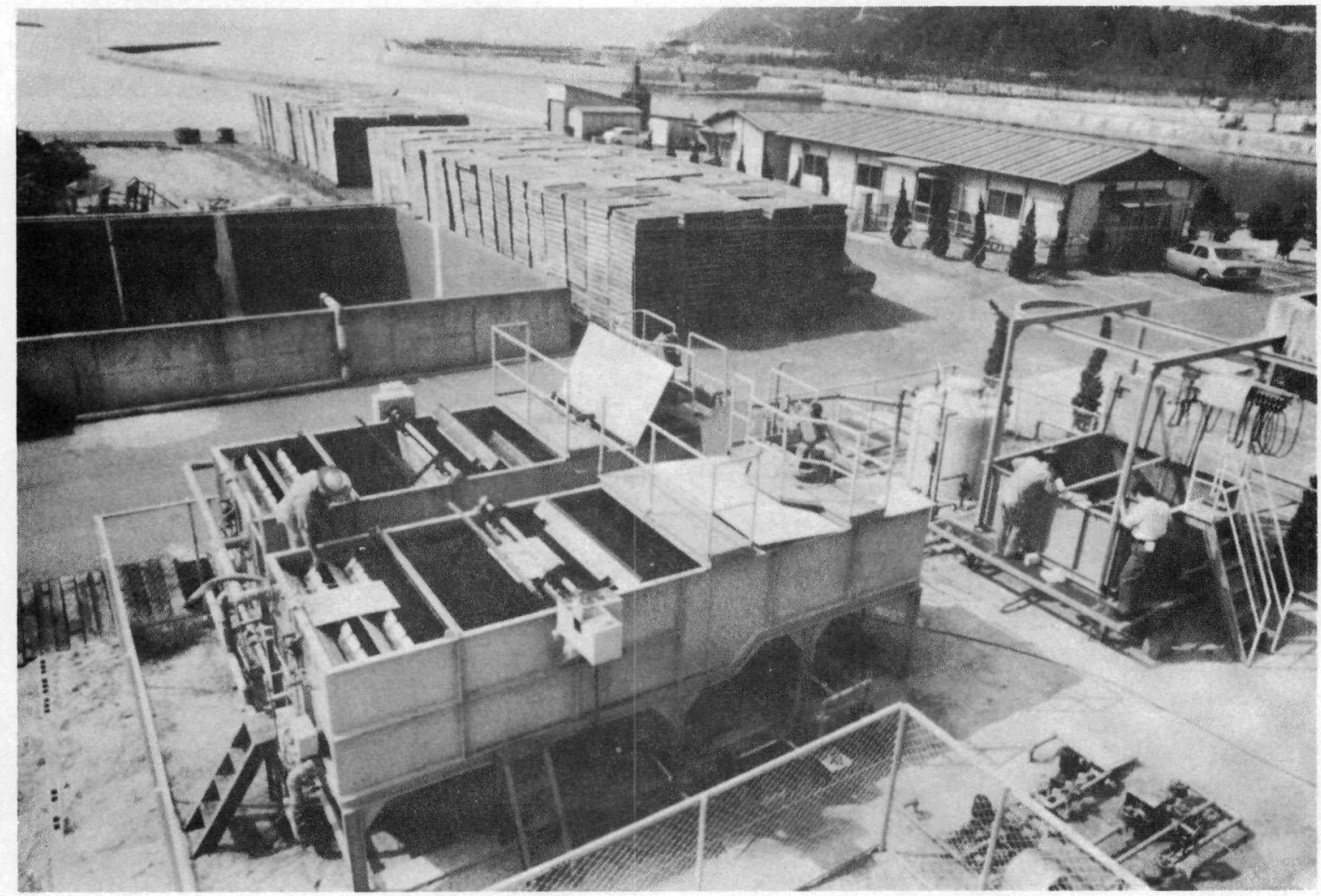

Figure 15.2-4 Continuous and tidal flow contactors at Sakaide, Japan. 

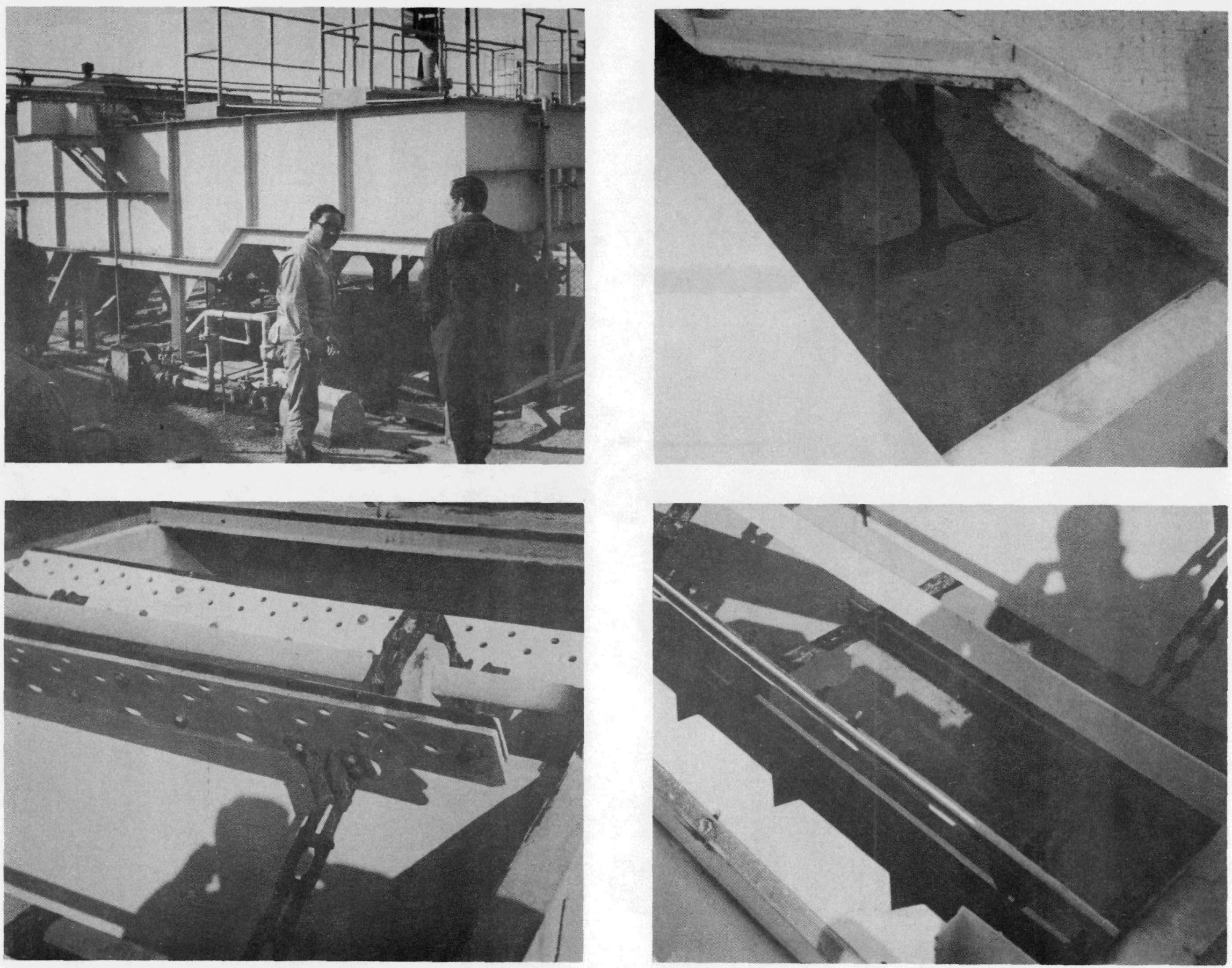

Figure 15.2-5 Continuous contactor at Sakaide City, Japan. 

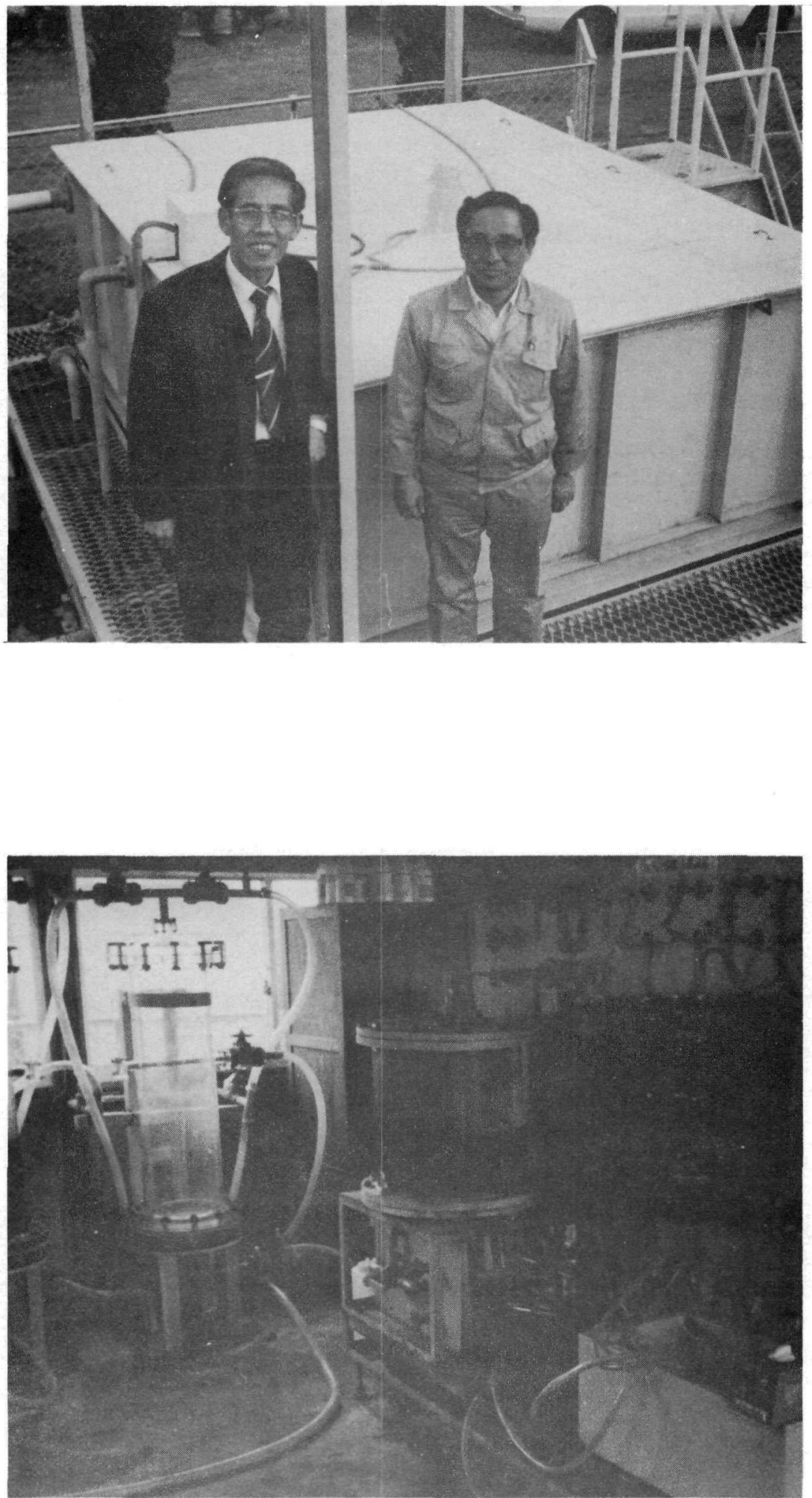

Figure 15.2-6 Tidal flow unit (upper) and packed contactors (lower) at Sakaide City, Japan. 
during the past four years. The Institute personnel recognize that plankton may be a serious problem and suggested the following three possible remedies:

(1) Filter the seawater.

(2) Operate with upflow to fluidize the bed.

(3) Alternate up and down flow through the bed every 6 to 24 hours, as needed, to backflush solids which have become impacted against the bed.

They also stated that the sodium carbonate and bicarbonate solution used for eluting uranium dissolves organic material (plankton) present, causing a brown colored eluate, and that this dissolved organic material adversely affects the second cycle uranium concentration step by impairing the uranium adsorption capacity.

They have used the same adsorbent bed for as many as 5 to 10 successive loading-elution cycles. After 10 cycles the uranium loading capacity can be as low as $10 \%$ to $20 \%$ of the initial performance due to calcium and magnesium carbonate blinding. However, a wash with $\mathrm{HCl}$ can regenerate the bed to $>90 \%$ of the original performance. (Note: Dr. M. Kanno stated that other work shows less deterioration in the adsorbent after 10 cycles.)

Figure 15.2-7 [23] shows the effect of temperature on adsorption of uranium from seawater. Between $17 \mathrm{C}$ and $45 \mathrm{C}$ the data show a two-fold higher adsorption at 100 minutes, and greater than a two-fold difference at about 10 minutes.

The Institute's primary mission with regard to uranium from seawater is the development of the primary adsorbent and demonstration of extracting uranium from seawater, rather than the subsequent purification and concentration steps.

\subsubsection{Studies by the People's Republic of China}

Mainland China has had an active uranium from seawater program since in the early 1970's. Although it was dormant for part of the period since then, the program is now active again. They are reported to have 100 engineers working at eight test facilities, including the following locations: Shanghai, Nanking, Peking, Tenshin, and Chitao.

They use a crushed hydrous titanium oxide (not mixed with activated carbon) and claim uranium loadings up to 300 to $500 \mathrm{mg} \mathrm{U} / \mathrm{kg} \mathrm{Ti}$ after exposure to seawater for 15 days. They use fluidized columns up to $10 \mathrm{~cm}$ in diameter with a fluidized bed almost one meter high. One reported problem has been carryover of the hydrous titanium oxide. 


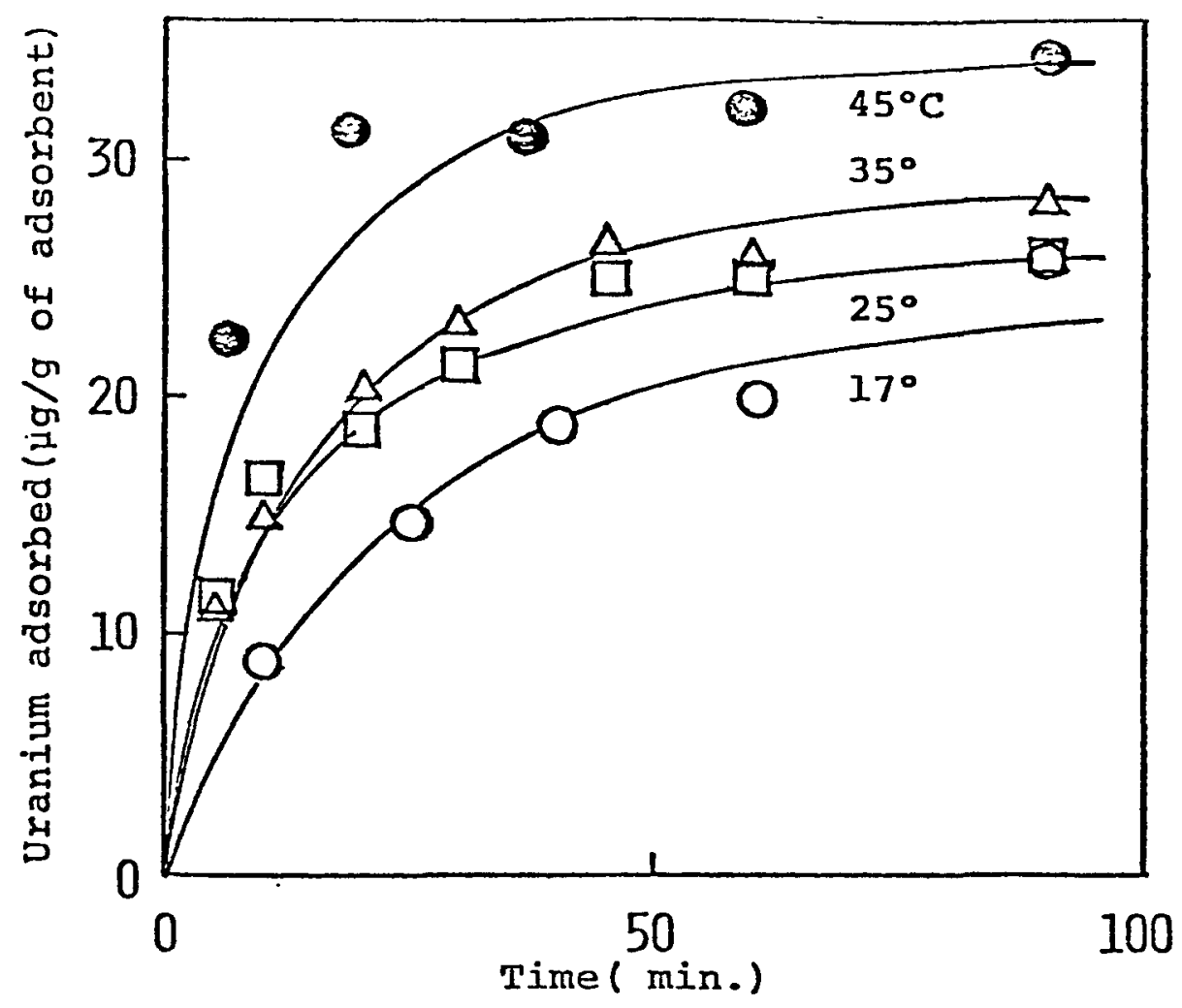

Figure 15.2-7 Temperature dependence of uranium adsorption on $\mathrm{C}-\mathrm{Ti}-\mathrm{OH}$. 
15.2.4 Japanese National Program on Uranium from Seawater, $12 / 6 / 78$, Tokyo; Discussions with the Metal Mining Agency of Japan

Those present were Mr. Kazuhiko Hida, Deputy Director, Nuclear Energy Industry Division, Agency of Natural Resources and Energy, Ministry of International Trade and Industry; Dr. Masayoshi Kanno, Chairman, Survey and Research Group (Prof. Dr. Eng., Professor of Nuciear Materials, Department of Nuclear Engineering, University of Tokyo); Dr. Noboru Ogata, Chief, Survey and Research Group, Japan Tobacco and Salt Corporation; Mr. Ken Saito, Director, Metal Mining Agency of Japan; Mr. Takashi Mayama, Manager, Geological Survey Department, Metal Mining Agency of Japan; Mr. Hiroshi Iwasaki, Technical Advisor, Technical Development Section, Geological Survey Department, Metal Mining Agency of Japan; Mr. Kyoichi Koyama, Assistant Chief, Technical Development Section, Geological Survey Department, Metal Mining Agency of Japan; Mr. Takahisa Yamamoto, Oceanographer, Member, Technical Development Section, Geological Survey Department, Metal Mining Agency of Japan; Ms. Tamaki Mizutani, Conference Interpreter; Mr. Y. Murozono, Esso Standard Sekiyu; and F. W. Woodfield.

Those present on December 7 for follow-up discussions at Tokyo University were Dr. M. Kanno, Mr. Y. Murozono, and F. W. Woodfield.

These two discussions are reported together, since the meeting at Tokyo University continued and extended the transfer of information begun the previous day.

\subsubsection{The national program for uranium from seawater}

The Japanese national program on recovering uranium from seawater has been active for over ten years. In 1974 the Metal Mining Agency of Japan was assigned an overall management coordinating role. A number of government groups and at least six industrial companies participate in parts of the overall program. Expenditures over the last four years have been 400 million yen (approximately $\$ 2$ million). Funds requested of the Japanese government for the next 6 to 7 years total 3 billion yen (approximately $\$ 15$ million).

The Japanese have produced gram quantities of yellowcake from seawater. Vials of such material were shown both at Takamatsu and in Tokyo. Their attitude is that the technology is known; the chalienge now is how to extract the uranium at an affordable price. This requires, however, solving a number of technical problems which they believe are solvable. It appears that Professor Kanno is the overall technical program monitor of the national program to recover uranium from seawater. The Japanese appear to have done much good work and to have made substantial progress. Their screening tests have evaluated more than 50 
adsorbents. Those based on hydrous titanium oxide are best. In spite of the work employing a resin binder or activated carbon binder (Sections 15.2.2 and 15.2.3), the current (but not necessarily final) majority opinion favors a new process they have developed to make relatively high capacity, and relatively mechanically stable, hydrous titanium oxide adsorbent particles without a supporting substrate. Not all of their latest work on adsorbents has been published; the latest published summaries appear in References [38,22,39,40,41]. Kanno L36] mentioned a high capacity hydrous titanium oxide adsorbent prepared by thermally decomposing a dilute titanium sulfate plus urea solution. The f'inal drying temperature and degree of dehydration are apparently important. The same reference indicated that the mechanical strength of hydrous titanium oxide adsorbents can be improved by granulating and pressing during certain stages in the preparation of the hydrous titanium oxide granules. These steps resulted in a stronger particle than the British produced in their studies.

Kanno [22] also quoted, for 0.7 to $1 \mathrm{~mm}$ diameter granules exposed 10 days in $25 \mathrm{C}$ seawater, a practical loading of about $100 \mathrm{mg} \mathrm{U} / \mathrm{kg}$ of adsorbent. This is equivalent to over $200 \mathrm{mg} \mathrm{U} / \mathrm{kg}$ of contained $\mathrm{Ti}$. It is also about one-fifth of the equilibrium saturation value of uranium on finely divided (about 40 micron) hydrous titanium oxide powder in contact with seawater.

They recommend a $10 \mathrm{~cm}$ bed depth and a 20 to $40 \mathrm{~cm} / \mathrm{min}$ seawater flow velocity through the bed to remove $60 \%$ to $80 \%$ of the uranium in the seawater.

The uptake of uranium from seawater in ten days is nearly $40 \%$ higher at $25 \mathrm{C}$ than at $15 \mathrm{C}$.

Much of the reported Japanese experimental work extracted relatively low percentages (e.g., 30\%) of the uranium present in the seawater. They feel that $90 \%$ is too high to be practical in a plant operation. The choice of a pumped plant concept provides an incentive to strive for a reasonably high percent recovery. The practical range of interest may be approximately $60 \%$ to $80 \%$.

Elution with ammonium carbonate or sodium carbonate solution proceeds quite rapidly at $60 \mathrm{C}$ or higher (esseritially $100 \%$ desorbed in one hour). At $25 \mathrm{C}$, greater than 24 hours is required to desorb $90 \%$. They propose a two-day plant desorption cycle. Uranium concentration in the desorbate has ranged from 10 to about $20 \mathrm{ppm}$. This is increased to approximately $3000 \mathrm{ppm}$ after a subsequent ion exchange cycle. The product stream contains more calcium and magnesium impurities than the product stream from a conventional uranium mill.

Battelle (presumably at Columbus) is studying elution with ammonium carbonate for the Japanese. While ammonium carbonate removes slightly more uranium than sodium carbonate, sodium may be an environmentally more acceptable pollutant than the ammonium ion because of the high nutrient property of the latter. 
Depending on seawater quality, about 5 to 10 loading-elution cycles should be attainable before the extraction capacity of the adsorbent bed drops sufficiently to require regeneration. This is accomplished by washing with approximately $0.1 \mathrm{M} \mathrm{HCl}$, which restores performance to nearly as good as new (presumably approximately 90\%). Complete dissolution of the adsorbent and re-precipitation is not considered necessary.

Hydrous titanium oxide bed losses are believed to be less than $0.1 \%$ in a normal loading-elution cycle, but could be higher with the bed fluidized. Hydrous titanium oxide lost in an acid wash cycle might be ten times as high. Titanium is a natural ingredient in seawater, and the above small additions to the ocean would probably not be environmentally objectionable.

Some of the important hydrous titanium oxide adsorbent development work in Japan has been conducted by the Kanebo Chemical Company (one patent al ready issued) and by Nippon Sekiyu (Oil) Company (patent pending).

Al though the United Kingdom recovered vanadium, the Japanese have not been able to (or have not assigned this a very high priority). Strontium is recoverable, if desired.

15.2.4.2 The Japanese Model Plant

The next major milestone in the Japanese national program is to build what they call a Model Plant. It would be sized to recover $10 \mathrm{~kg}$ of U/year. This requires about 0.2 cubic meters per second of seawater feed, 24 hours per day.

The Japanese have done some very good work in developing and demonstrating a better adsorbent, and in demonstrating the entire uranium extraction technique and subsequent concentration steps in small experimental equipment. The experimental work has been promising and has proceeded to a stage such that a larger facility is now needed to obtain information impossible to gather in the scattered smaller facilities. Some examples are: the effects on the process of plankton and other suspended solids in the seawater feed, assessing fouling problems caused by marine growths on the adsorbent particles and on equipment surfaces, long term tests of the adsorbent, beds, comparison of pumped versus ocean current flow concepts, long-term testing of construction materials and of the operation of flow-diversion gates in actual seawater and in process eluant and eluate streams, and in general a means of determining whether there are unexpected problems which develop in long term operation. The Model Plant should provide a meaningful demonstration of the extent to which uranium can be extracted from seawater in equipment large enough to permit projection to plant-scale performance. 
It is planned to start the Model Plant project in 1979, if it is funded by the Japanese government. It could be in operation in approximately four to six years, depending on program emphasis. Detailed evaluation studies are being made on two potential sites. Seawater will be supplied to test two concepts: (1) a seawater canal to simulate an ocean current contactor, and (2) pumps for pumped flow concepts.

In conjunction with a description of the Japanese plan for the Model Plant, Mr. K. Hida commented that it may be timely to consider a joint Japan-U. S. cooperative program on uranium from seawater.

\subsubsection{Plant scale concepts}

The Japanese have done some conceptual thinking about a full-scale plant to recover as much as 1000 tonnes of uranium per year from seawater $[38,22,39,40,41]$. Figure $15.2-8$ is an artist's drawing of an ocean current plant concept, and Figure 15.2-9 depicts a plant-scale pumped concept. They would plan to use $1 \mathrm{~mm}$ diameter hydrous titanium oxide particles to reduce flow resistance and minimize blockage of the bed. Such a plant would require an initial inventory of 250 tonnes of hydrous titanium oxide, at a projected cost somewhere in the range 400 to 1000 yen $/ \mathrm{kg}$ (approximately $\$ 2$ to $\$ 5 / \mathrm{kg}$ ).

For a $25 \mathrm{C}$ seawater temperature, they would plan to use a 5 to $10 \mathrm{~cm}$ adsorbent bed depth, with a 10 day uptake cycle and 2 day elution period. A pumped plant of this size would impose a 670 MWe power load. In one concept the plant would extend along $8 \mathrm{~km}$ of shoreline and be $130 \mathrm{~m}$ wide. It would use 467 pumps each with a capacity of 80 cubic meters per second. They are also considering a fewer number of larger pumps, if larger pumps can be obtained. 

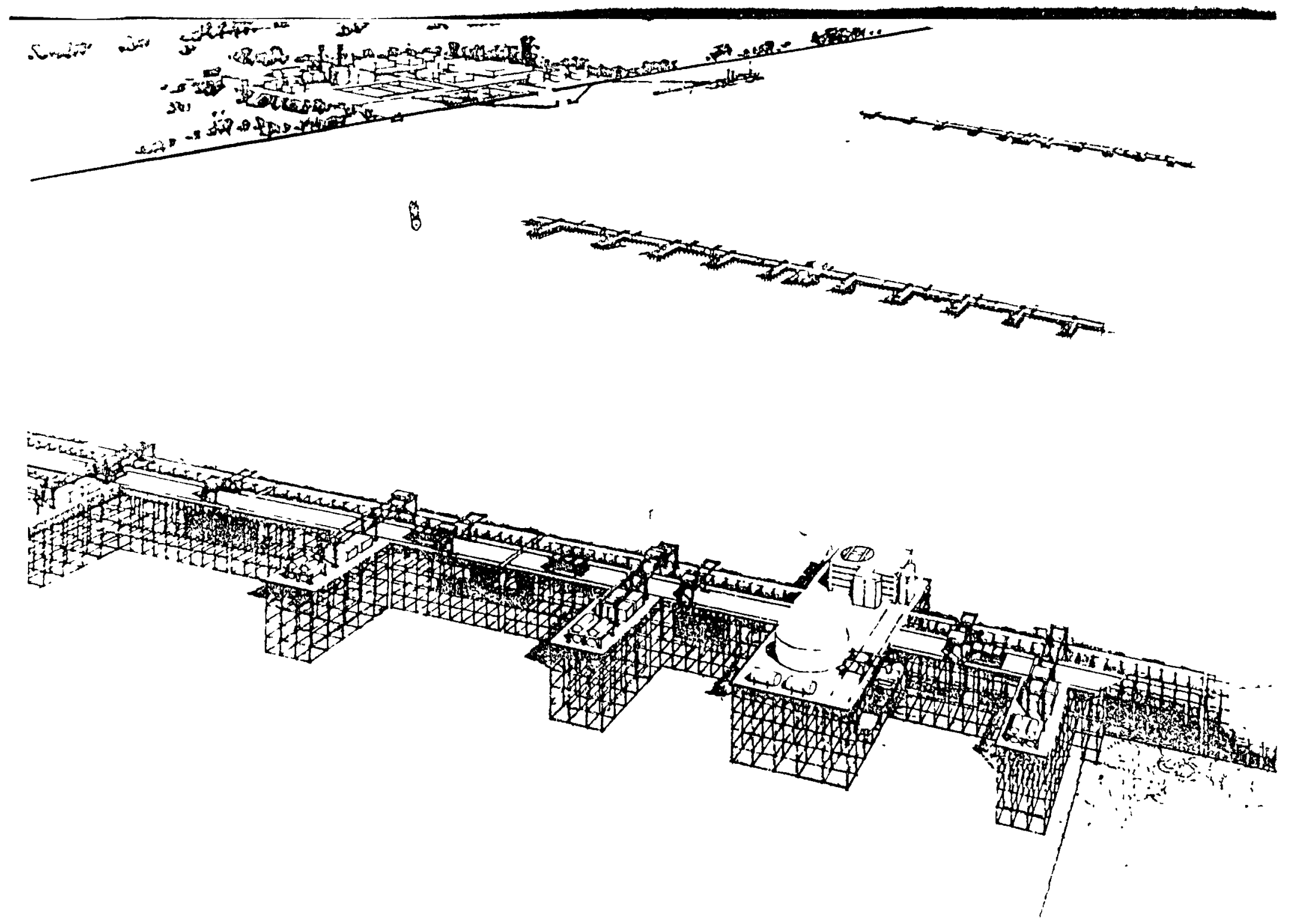

Figure 15.2-8 Artist's concept of an ocean current uranium extraction plant. 

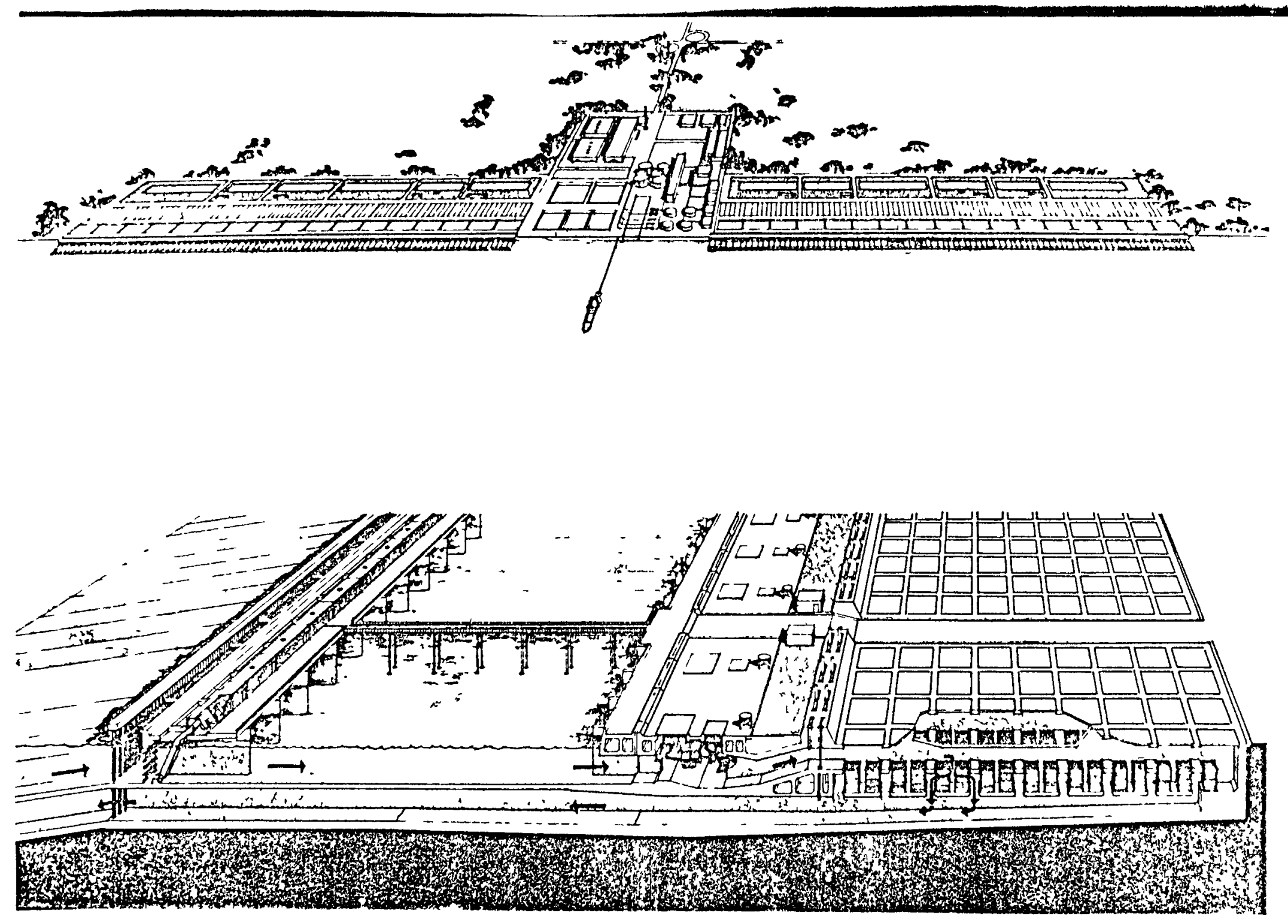

Figure 15.2-9 Artist's concept of a pumped seawater uranium extraction plant. 


\subsection{CHEMICAL PROCESS SELECTION CRITERIA}

Listed below are some of the questions that need to be answered about a chemical process and plant site in a positive manner in order to effectively extract uranium from seawater.

- Does the process have the capability of utilizing extremely large volume flow rates of seawater?

- Is the adsorbent material resistant to biological attack?

- Is the structural integrity of the adsorbent material sufficient to prevent mechanical breakage?

- Can the adsorbent material undergo a large number of adsorption/elution cycles?

- Is the adsorbent insoluble in seawater and the eluant?

- Is the adsorbent physically and chemically unchanged by the elution process?

- Can the uranium be efficiently extracted from the eluant?

- Can the eluant be efficiently recovered?

- Are losses in the elution process insignificant?

- Are desirable co-product trace metals also extracted?

- Are undesirable, competing trace metals of little significance?

- Is the seawater temperature high enough for good adsorption kinetics?

- Can the process handle silt or other particulate contamination?

- Is the process insensitive to pH?

- Is the process insensitive to alkalinity?

- Is the process insensitive to the nutrient level of the seawater?

- Is the process insensitive to the dissolved oxygen content of the seawater?

- Is the process insensitive to the salinity of the seawater?

- Will the process alter the local ecosystem? 
- Does the process add only non-toxic materials to the natural environment?

- Is thermal discharge insignificant?

- Are scale buildup and corrosion unimportant?

- Can workable adsorbent containment with realistic presslire drops be designed?

- Is the process applicable to more than a single plant design?

- Are the applicable plant designs reasonable on the basis of economics?

- Are the applicable plant designs reasonable on the basis of demonstrated technical and engineering techniques?

- Are the applicable plant designs reasonable on the basis of oceanographic considerations?

- Are the applicable plant designs reasonable on the basis of environmental impact?

- Are the applicable plant designs reasonable on the basis of plant site selection? 
Listed below in Table 15.4-1 are the various adsorbent materials and their uranium capacity, as reported in the literature. This list is provided primarily to acquaint the reader with the rather extensive work that has already been done in searching for an adsorbent that satisfies the criteria mentioned in Section 5.4.1.1. Only experiments performed in natural seawater at a natural uranium concentration are inciuded (see Section 5.4.2). The exposure time of the adsorbent in the seawater varies considerably for these results. The reader is referred to the original publication for further details.

Table 15.4-1 Adsorbents tested for extraction of uranium from seawater

\begin{tabular}{|c|c|c|}
\hline Ad sorbent & $\mathrm{mg} U / \mathrm{kg}$ metal* & Reference \\
\hline Activated carbon & $500 \mathrm{mg} \mathrm{U} / \mathrm{kg}$ ads. & {$[37]$} \\
\hline Aluminum hydroxide & $\begin{array}{l}56 \\
61\end{array}$ & {$[7]$} \\
\hline Basic aluminum carbonate & 73 & $\lfloor 7\rfloor$ \\
\hline Aluminum chromate & 123 & {$[7]$} \\
\hline Calcium phosphate & $\begin{array}{l}50-100 \mathrm{mg} \mathrm{U} / \mathrm{kg} \text { ads. } \\
30 \\
23\end{array}$ & $\begin{array}{r}{[37]} \\
{[7]}\end{array}$ \\
\hline Calcium hydrogen phosphate & 33 & {$[7]$} \\
\hline Cellulose & $300 \mathrm{mg} \mathrm{U} / \mathrm{kg}$ ads. & L37j \\
\hline Cobalt hydroxide & 12 & L'7 \\
\hline Chromium hydroxide & $\begin{array}{l}37 \\
68 \mathrm{mg} \mathrm{U} / \mathrm{kg} \text { ads. }\end{array}$ & $\begin{array}{l}\lfloor 7\rfloor \\
\lfloor 21\rfloor\end{array}$ \\
\hline Basic copper carbonate & $\begin{array}{l}16 \\
52\end{array}$ & $\lfloor 7 j$ \\
\hline Copper plumbate & 29 & $\lfloor 7\rfloor$ \\
\hline
\end{tabular}


Table 15.4-1 (continued)

\begin{tabular}{|c|c|c|}
\hline Adsorbent & $\mathrm{mg}$ U/kg metal* & Reference \\
\hline Copper hydroxide & 16 & ᄂ7」 \\
\hline $\begin{array}{l}\text { Composite adsorbent: } \\
\text { Active carbon }+ \\
\text { titanium hydroxide }(4: 1)\end{array}$ & $800 \mathrm{mg} \mathrm{U} / \mathrm{kg}$ ads. & [9] \\
\hline $\begin{array}{l}\text { Iron hydroxide }+ \\
\text { calcium carbonate }(1: 1)\end{array}$ & 21 & [7] \\
\hline $\begin{array}{l}\mathrm{Ti}(\mathrm{OH})_{4} / \text { basic zinc } \\
\text { carbonate }\end{array}$ & $\begin{array}{l}319 \mathrm{mg} \mathrm{U} / \mathrm{kg} \mathrm{Ti} \\
442 \mathrm{mg} \mathrm{U} / \mathrm{kg} \mathrm{Zn}\end{array}$ & {$[7]$} \\
\hline Iron(III) hydroxide & $\begin{array}{l}18 \\
15 \\
51 \\
36 \\
16\end{array}$ & [7] \\
\hline Iron(III) phosphate & 14 & {$[7]$} \\
\hline Iron(III) sulphide & 13 & {$[7]$} \\
\hline Lanthanum hydroxide & 33 & L7] \\
\hline Lanthanum carbonate & 14 & L7] \\
\hline Lead sulfide (galena) & $\begin{array}{r}134 \mathrm{mg} U / \mathrm{kg} \text { ads. } \\
3800 \mathrm{mg} U / \mathrm{kg} \text { ads. } \\
4 \mathrm{mg} \mathrm{U} / \mathrm{kg} \text { ads. } \\
338 \\
193 \\
200 \\
313 \\
338 \\
290 \\
315 \\
261 \\
244 \\
390 \\
304 \\
290\end{array}$ & $\begin{array}{l}\lfloor 21\rfloor \\
\lfloor 37\rfloor \\
{[42\rfloor} \\
L 19\rfloor \\
L 7\rfloor\end{array}$ \\
\hline
\end{tabular}

*unless otherwise noted 
Table 15.4-1 (continued)

\begin{tabular}{|c|c|c|}
\hline Ad sorbent & $\mathrm{mg}$ U/kg metal* & Reference \\
\hline Lead naphthalene & $\begin{array}{r}670 \\
882 \\
1074 \\
1893 \\
820 \\
972 \\
954 \\
895 \\
864 \\
700\end{array}$ & {$[7]$} \\
\hline Lead tartrate & $\begin{array}{r}69 \\
298 \\
313 \\
304 \\
263 \\
238 \\
299 \\
200 \\
334 \\
306\end{array}$ & {$[7\rfloor$} \\
\hline Lead oxalate & $\begin{array}{l}174 \\
109 \\
124 \\
141 \\
104\end{array}$ & {$[7\rfloor$} \\
\hline Lead borate & $\begin{array}{l}253 \\
183 \\
248 \\
213\end{array}$ & [7] \\
\hline Lead p-arsenate & $\begin{array}{l}332 \\
358 \\
422\end{array}$ & {$[7]$} \\
\hline Lead pyrophosphate & 479 & $\lfloor 7\rfloor$ \\
\hline Lead stannate & $\begin{array}{l}345 \\
363 \\
211 \\
316\end{array}$ & Ł7」 \\
\hline
\end{tabular}

* unless otherwise noted 
Table 15.4-1 (continued)

\begin{tabular}{|c|c|c|c|}
\hline & Ad sorbent & $\mathrm{mg} U / \mathrm{kg}$ metal* & Reference \\
\hline Lead & hydroxide & $\begin{array}{r}10 \mathrm{mg} \mathrm{U} / \mathrm{kg} \text { ads. } \\
132\end{array}$ & $\begin{aligned} \text { L21] } \\
{[7] }\end{aligned}$ \\
\hline Lead & chloride & 80 & $\lfloor 7\rfloor$ \\
\hline Basic & c lead chromate & 36 & $\lfloor 7\rfloor$ \\
\hline Lead & plumbate & 200 & $\lfloor 7\rfloor$ \\
\hline Lead & salicylate & 39 & [7] \\
\hline Lead & tannate & 36 & {$[7]$} \\
\hline Lead & m-hydroxybenzoate & 193 & {$[7]$} \\
\hline Lead & succinate & 50 & [7] \\
\hline Lead & malate & 199 & $\lfloor 7\rfloor$ \\
\hline Lead & malonate & 107 & [7] \\
\hline Lead & fumarate & 100 & ᄂ7 J \\
\hline Lead & glutarate & 51 & [7] \\
\hline Lead & teraphthalate & 36 & [7] \\
\hline Lead & polyacrylate & 169 & ᄂ7」 \\
\hline Lead & 2-hydroxy-3-naphthoate & 155 & $\lfloor 7\rfloor$ \\
\hline Lead & $\begin{array}{l}\text { naphthalene- } \\
2,7 \text {-disulphonate }\end{array}$ & 218 & $17 \mathrm{~J}$ \\
\hline Lead & $\begin{array}{l}\text { 2-naphthol- } \\
6,8 \text {-disul phonate }\end{array}$ & 190 & $17\rfloor$ \\
\hline Lead & $\begin{array}{l}\text { 1-amino-8-naphthol- } \\
\text { 3,6-disul phonate }\end{array}$ & 612 & เ7」 \\
\hline Lead & $\begin{array}{l}\text { 1-amino-2-naphthol- } \\
\text { 4-sul phonate }\end{array}$ & 370 & {$[7]$} \\
\hline
\end{tabular}


Table 15.4-1 (continued)

\begin{tabular}{|c|c|c|}
\hline Adsorbent & $\mathrm{mg} \mathrm{U} / \mathrm{kg}$ metal* & Reference \\
\hline Lead chromotropate & 328 & {$[7]$} \\
\hline Lead silicate & $\begin{array}{l}359 \\
235 \\
202\end{array}$ & [7] \\
\hline Lead titanium oxalate & $\begin{array}{l}178 \\
240 \\
305\end{array}$ & {$[7]$} \\
\hline Lead sulphate & 56 & {$[7]$} \\
\hline Basic lead sulphate & $\begin{array}{l}150 \\
143 \\
183\end{array}$ & โ7」 \\
\hline Lead vanadate & 24 & L7J \\
\hline Lead thiocarbonate & 240 & [7] \\
\hline Magnesium pyrophosphate & 9 & $\lfloor 7\rfloor$ \\
\hline Manganese dioxide & $18 \mathrm{mg} \mathrm{U} / \mathrm{kg}$ ads. & $\lfloor 21\rfloor$ \\
\hline Nickel hydroxide & 33 & $\lfloor 7\rfloor$ \\
\hline Silica gel & $8 \mathrm{mg} \mathrm{U} / \mathrm{kg}$ ads. & {$[7\rfloor$} \\
\hline Hydrous titanium oxide & $\begin{array}{l}1500 \mathrm{mg} / \mathrm{kg} \text { ads. } \\
268 \\
280 \\
320 \\
550 \\
350 \\
273\end{array}$ & $\begin{array}{l}\lfloor 37] \\
{[19\rfloor} \\
\lfloor 12\rfloor \\
{[15]} \\
\\
{[20]} \\
{[7]}\end{array}$ \\
\hline Titanic acid & $148 \mathrm{mg} \mathrm{U} / \mathrm{kg}$ ads. & $\lfloor 21\rfloor$ \\
\hline Titano gel & $24 \mathrm{mg} \mathrm{U} / \mathrm{kg}$ ads. & {$[18]$} \\
\hline Titanium ferrocyanide & 193 & $\lfloor 7\rfloor$ \\
\hline
\end{tabular}


Table 15.4-1 (continued)

Adsorbent

Titanium pyrophosphate

Titanium hydrosulphide

Basic zinc carbonate

Zinc hydroxide

Zine oxychloride

Zinc arsenate

Zinc vanadate

Zinc chromate

Zinc carbonate

Zinc aluminate

Zinc plumbate

Zeolites (ultramarine)

Anionites

AMF - 2-7P

$\mathrm{AMF}-21-8 \mathrm{P}$

AN $-2 \mathrm{~F}$

$A N-22-8 P$

$\mathrm{AP}-2-8 \mathrm{P}$

Polystyrene methylene phosphonic acid

8-hydroxyquinoline

*unless otherwise noted mg $U / k g$ metal*

220

[7]

293

[7]

512

445

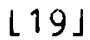

390

625

620

590

490

530

502

45

$[7]$

19

[7]

26

[7]

15

[7]

53

[7]

105

[7]

65

[7]

490

[7]

400-4000

mg $\mathrm{U} / \mathrm{kg}$ ads.

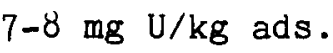

$\lfloor 43\rfloor$

$5 \mathrm{mg} \mathrm{U} / \mathrm{kg}$ ads.

$23 \mathrm{mg} \mathrm{U} / \mathrm{kg}$ ads.

$8 \mathrm{mg} \mathrm{U} / \mathrm{kg}$ ads.

$15 \mathrm{mg} \mathrm{U} / \mathrm{kg}$ ads.

$25 \mathrm{mg} \mathrm{U} / \mathrm{kg}$ ads.

$13 \mathrm{mg} \mathrm{U} / \mathrm{kg}$ ads. 
Table 15.4-1 (continued)

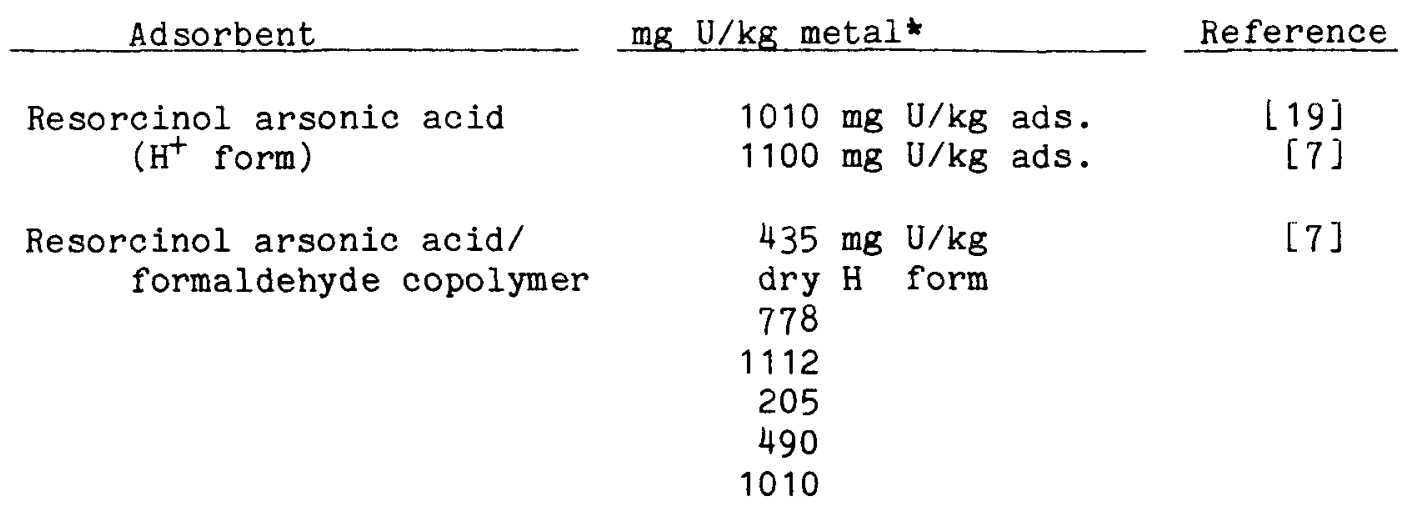

*unless otherwise noted 


\subsection{GLOSSARY OF CHEMICAL PROCESS TERMINOLOGY}

Adsorbent - A solid material having a special property for adhesion of certain molecules to its surface, e.g., hydrous titanium oxide

Adsorption - The adhesion of molecules to solid bodies to form a unimolecular surface layer, e.g., adhesion of uranyl ions to hydrous titanium oxide

Adsorbent bed - A layer of adsorbent of a defined thickness so installed that the flow of liquid feed material is unidirectional

Adsorbent capacity - As used in this document, adsorption capacity and operating capacity are synonymous, namely, a measure of the actual useful performance obtained with the adsorbent material operating in a bed under a prescribed set of conditions. Specifically this term refers to the total milligrams of uranium that can be effectively adsorbed per kilogram of hydrous titanium oxide

Adsorption rate - Adsorption is a surface phenomenon that occurs instantaneously as compared to some absorption (ion exchange) phenomena in which the ion active groups are accessible only through small pores and exhibit a low speed of exchange

Batch process - A chemical process that treats a finite lot (batch) for the complete unit operation, discharging one or more of the reactants before a new lot of feed material is added

Concentration factor - A ratio of the concentration of an element at a given point in the process as compared to the concentration of that same element in the feed material for the process. In the case of adsorption on hydrous titanium oxide, the concentration factor is the concentration of uranium in hydrous titanium oxide (mg $\mathrm{U} / \mathrm{kg} \mathrm{Ti}$ ) divided by the concentration of uranium in seawater (mg $U / 1$ seawater)

Continuous process - A process in which the feed material may be constantly added to a chemical process with the waste being constantly drawn off, e.g., fresh seawater input to the adsorbent beds, and uranium-depleted seawater discharge

Cycle - A completed round of events in which there is a final return to the original state; e.g., the adsorption cycle consists of loading, rinsing, eluting, rinsing

Dynamic bed - An adsorption bed that is continuously replenished with fresh adsorbent while uranium-loaded adsorbent is continuously moved out for elution at another location 
Eluant - A solution of complexant or electrolyte that removes selected elements on contact with a loaded adsorbent, e.g., passing ammonium carbonate eluant through a bed of hydrous titanium oxide to remove the adsorbed uranium; also called elutriant

Elution - The operation of passing an eluant through an adsorbent bed

Feed - The product-bearing material added to a chemical process that concentrates and/or purifies the desired product, e.g., seawater is the feed for the hydrous titanium oxide adsorbent

Fluidized adsorbent bed - An adsorbent bed that is floated in the feed stream without being carried out of the system

Flow rate - In the context of an adsorption bed, the rate at which the feed transits the bed, measured in $\mathrm{cm} / \mathrm{s}$

Fresh water - Water of suitable purity for process applications (as compared to seawater which is suitable only as feed)

Loading - Accumulation of an element upon the adsorbent

Prerinse - Fresh water rinse of the adsorbent to remove retained seawater prior to elution

Postrinse - Fresh water rinse of the adsorbent to remove retained eluant prior to returning the adsorbent to service in seawater

Secondary purification - Treatment of the uranium-loaded eluant to provide yellowcake of acceptable quality for uranium hexafluoride conversion plant feed material

Static bed - An adsorbent bed in a fixed position so that loading and elution are accomplished by piping and valves

Steam stripping - Steam used to heat the solution and serve as the sweeping gas to remove the volatile products. In this instance, ammonia and carbon dioxide are swept out of the eluant

Tonne - 1000 kilograms

Uranium recovery efficiency - The difference between unity and the ratio of the uranium concentration in the seawater waste stream and the uranium concentration in the seawater feed stream, expressed in percent:

Uranium recovery efficiency $=1-\frac{g U / I \text { in waste }}{g U / I \text { in feed }}$

Yellowcake - A crude uranium concentrate usually containing 75\% or more $\mathrm{U}_{3} \mathrm{O}_{8}$ 


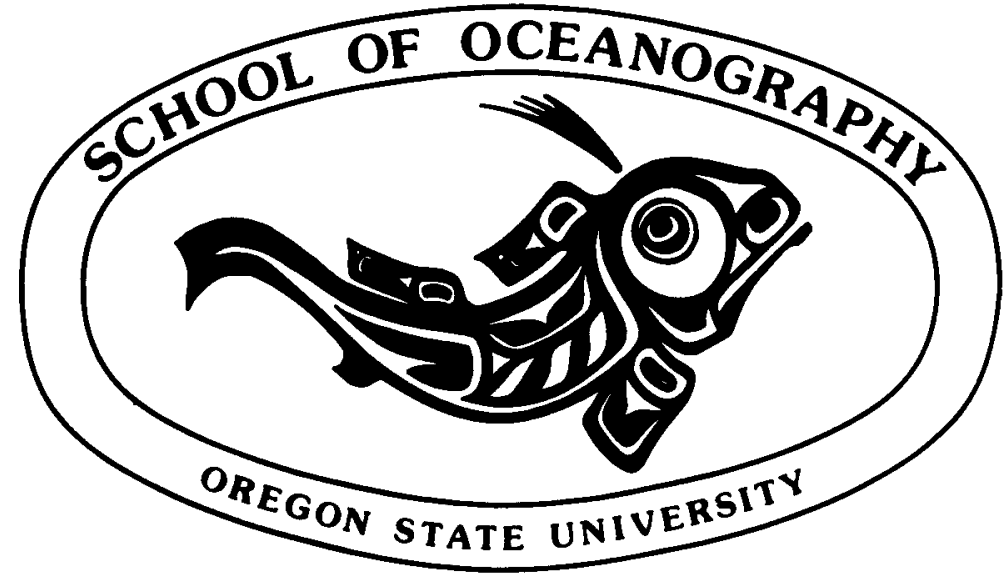

